Challenges in gastroenterological emergencies:

Outcome prediction in GI bleeding and acute pancreatitis

\author{
Ph.D. Thesis
}

Hágendorn Roland, M.D.

Szeged

2020 
Challenges in gastroenterological emergencies:

Outcome prediction in GI bleeding and acute pancreatitis

\author{
Ph.D. Thesis
}

Doctoral School of Clinical Medicine, Faculty of Medicine, University of Szeged, Szeged

Roland Hágendorn, M.D.

Doctoral School of Clinical Medicine, Faculty of Medicine, University of Szeged, Szeged First Department of Internal Medicine, Faculty of Medicine, University of Pécs, Pécs Institute for Translational Medicine, Medical School, University of Pécs, Pécs

Supervisor:

Alexandra Mikó, M.D., Ph.D.

Institute for Translational Medicine, Medical School, University of Pécs, Pécs

Program director:

Péter Hegyi, M.D., Ph.D., D.Sc., MAE

First Department of Medicine, Faculty of Medicine, University of Szeged, Szeged Institute for Translational Medicine, Medical School, University of Pécs, Pécs 


\section{PUBLICATIONS RELATED TO THE SUBJECT OF THE THESIS}

I. Roland Hágendorn, Áron Vincze, Ferenc Izbéki, László Gajdán, Szilárd Gódi, Anita Illés, Patrícia Sarlós, Nelli Farkas, Bálint Eröss, Veronika Lillik, Dóra Illés, Péter Varjú, Katalin Márta, Imola Török, Mária Papp, Zsuzsanna Vitális, Barnabás Bod, József Hamvas, Zoltán Szepes, Tamás Takács, László Czakó, Zsolt Márton, Andrea Szentesi, Andrea Párniczky, Péter Hegyi, Alexandra Mikó. Development of disturbance of consciousness is associated with increased severity in acute pancreatitis. PANCREATOLOGY $20: 5$ pp. $806-$ 812. , 7 p. (2020). IF: 3.629

II. Roland Hágendorn, Nelli Farkas, Áron Vincze, Zoltán Gyöngyi, Dezső Csupor, Judit Bajor, Bálint Erőss, Péter Csécsei, Andrea Vasas, Zsolt Szakács, László Szapáry, Péter Hegyi, Alexandra Mikó. Chronic kidney disease severely deteriorates the outcome of gastrointestinal bleeding: A meta-analysis. WORLD JOURNAL OF GASTROENTEROLOGY 23 : 47 pp. 8415-8425. , 11 p. (2017) IF: 3.34

\section{PUBLICATIONS NOT CLOSELY RELATED TO THE SUBJECT OF THE THESIS}

1. Dalma Dobszai, Péter Mátrai, Zoltán Gyöngyi, Dezső Csupor, Judit Bajor, Bálint Erőss, Alexandra Mikó, Lajos Szakó, Ágnes Meczker, Roland Hágendorn, Katalin Márta, Andrea Szentesi, Péter Hegyi: Body-mass index correlates with severity and mortality in acute pancreatitis: A meta-analysis. WORLD JOURNAL OF GASTROENTEROLOGY $25: 6$ pp. 729-743. , 15 p. (2019) IF: 3.3

2. Párniczky Andrea, Lantos Tamás, Tóth Eszter Margit, Szakács Zsolt, Gódi Szilárd, Hágendorn Roland, Illés Dóra, Koncz Balázs, Márta Katalin, Mikó Alexandra, Mosztbacher Dóra, Németh Balázs Csaba, Pécsi Dániel, Szabó Anikó, Szücs Ákos, Varjú Péter, Szentesi Andrea, Darvasi Erika, Erőss Bálint, Izbéki Ferenc, Gajdán László, Halász Adrienn, Vincze Áron, Szabó Imre, Pár Gabriella, Bajor Judit, Sarlós Patrícia, Czimmer József, Hamvas József, Takács Tamás, Szepes Zoltán, Czakó László Hegyi Péter. Antibiotic therapy in acute pancreatitis: From global overuse to evidence based recommendations PANCREATOLOGY $19: 4$ pp. 488-499. , 12 p. (2019) IF: 3.629

3. Szakács Zsolt, Gede Noémi, Gyöngyi Zoltán, Solymár Margit, Csupor Dezső, Erőss Bálint, Vincze Áron, Mikó Alexandra, Vasas Andrea, Szapáry László, Dobszai Dalma, Balikó Viktória, Hágendorn Roland, Hegyi Péter, Bajor Judit. Szakács Zsolt, Gede Noémi, Gyöngyi Zoltán, Solymár Margit, Csupor Dezső, Erőss Bálint, Vincze Áron, Mikó Alexandra, Vasas Andrea, Szapáry László, Dobszai Dalma, Balikó Viktória, Hágendorn Roland, Hegyi Péter, Bajor Judit. A call for research on the prognostic role of follow-up histology in celiac disease: a systematic review FRONTIERS IN PHYSIOLOGY 10 Paper: 1408 , 21 p. (2019) IF: 3.16

4. Gódi Szilárd, Erőss Bálint, Gyömbér Zsuzsanna, Szentesi Andrea, Farkas Nelli, Párniczky Andrea, Sarlós Patrícia, Bajor Judit, Czimmer József, Mikó Alexandra, Márta Katalin, Hágendorn Roland, Márton Zsolt, Verzár Zsófia, Czakó László, Szepes Zoltán, Vincze Áron, Hegyi Péter. Centralized Care 
For Acute Pancreatitis Significantly Improves Outcomes. JOURNAL OF GASTROINTESTINAL AND LIVER DISEASES 27 : 2 pp. 151-157. , 7 p. (2018) IF: 2.21

5. Szapáry László, Tinusz Benedek, Farkas Nelli, Márta Katalin, Szakó Lajos, Meczker Ágnes, Hágendorn Roland, Bajor Judit, Vincze Áron, Gyöngyi Zoltán, Mikó Alexandra, Csupor Dezső, Hegyi Péter, Erőss Bálint. Intralesional steroid is beneficial in benign refractory esophageal strictures: A metaanalysis

WORLD JOURNAL OF GASTROENTEROLOGY 24 : 21 pp. 2311-2319. , 9 p. (2018) IF: 3.34

6. Gódi Sz, Márta K, Pécsi D, Szabó A, Varjú P, Mikó A, Bajor J, Czimmer J, Hagendorn R, Pakodi F, Pár G, Sarlós P, Szabó I, Vincze Á, Kui B, Illés D, Szentesi A, Pavlovics A, Hegyi P. Acute pancreatitis should be treated in high volume specialist centres. PANCREATOLOGY 17 : 3S p. S108 (2017) IF: 3.629

7. Marta K, Szabo AN, Pecsi D, Varju P, Bajor J, Godi S, Sarlos P, Miko A, Szemes K, Papp M, Tornai T, Vincze A, Marton Z, Vincze PA, Lanko E, Szentesi A, Molnar T, Hagendorn R, Faluhelyi N, Battyani I, Kelemen D, Papp R, Miseta A, Verzar Z, Lerch MM, Neoptolemos JP, Sahin-Toth M, Petersen OH, Hegyi P. High versus low energy administration in the early phase of acute pancreatitis (GOULASH trial): protocol of a multicentre randomised double-blind clinical trial. BMJ OPEN 7 : 9 Paper: e015874, 10 p. (2017) IF: 2.42

8. Kenyeres P, Hagendorn R, Márton Zs, Halmosi R, Gaszner B, Toth K, Habon T. Tachycardia induced heart failure complicated with ventricular thrombus in a young patient with Friedreich's ataxia and cardiomyopathy. EUROPEAN HEART JOURNAL 35 : S1 pp. 1204-1204. , 1 p. (2014) IF: 12.33

9. Tarjányi Zita, Montskó Gergely, Kenyeres Péter, Márton Zsolt, Hágendorn Roland, Gulyás Erna, Nemes Orsolya, Bajnok László, L Kovács Gábor, Mezősi Emese. Tarjányi Zita, Montskó Gergely, Kenyeres Péter, Márton Zsolt, Hágendorn Roland, Gulyás Erna, Nemes Orsolya, Bajnok László, L Kovács Gábor, Mezősi Emese. Free and total cortisol levels are useful prognostic markers in critically ill patients: a prospective observational study. EUROPEAN JOURNAL OF ENDOCRINOLOGY $171: 6$ pp. 751-759. , 9 p. (2014) IF: 5.24

10. Godi Sz, Hágendorn R, Czimmer J, Szabó I, Pakodi F, Vincze A. Godi Sz, Hágendorn R, Czimmer J, Szabó I, Pakodi F, Vincze A. Prospective audit of colonoscopy quality. ZEITSCHRIFT FÜR GASTROENTEROLOGIE 47 : 5 Paper: A27 (2009)

11. Hagendorn R, Dömötör A, Godi Sz, Czimmer J, Hunyady B, Pakodi F, Vincze Á, Szabó I. Retrospective analysis of neddle-knife precut papillotomy in our practice. ZEITSCHRIFT FÜR GASTROENTEROLOGIE 47 : 5 Paper: A30 (2009) 
Number of publications related to the subject of the thesis:

2 (2 first author)

Cumulative impact factor of publications related to the thesis:

6.969

Q1: 2, Q2: -, Q3: -, Q4: - 3

Number of total accepted/published articles:

9 (2 first author)

Cumulative impact factor of the published articles:

29.546

Q1: 7, Q2: 2, Q3: -, Q4: -

9 (2 first author)

Number of total citation by MTM2:

47 independent

60 all

https://m2.mtmt.hu/gui2/?type=authors\&mode=browse \&sel=10045966

Hirsch Index: 


\section{TABLE OF CONTENTS}

List of abbreviations....................................................................................................................................................... 6 -

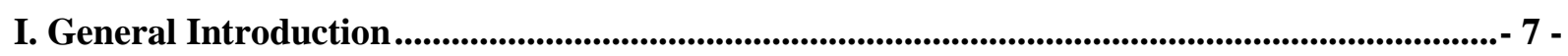

II. Pre-existing chronic kidney disease and GI bleeding........................................................... 8 -

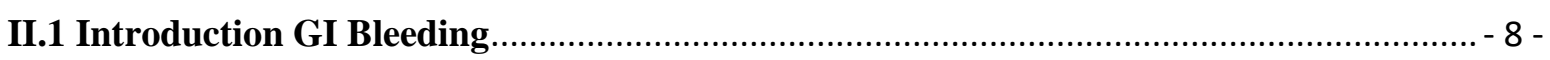

II.1.1. Clinical features and diagnosis of GI bleeding .................................................. - 8 -

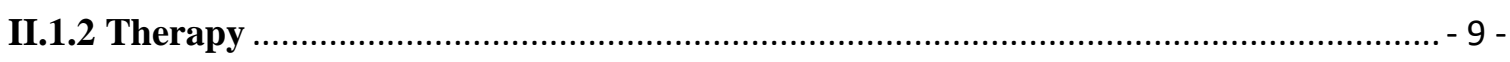

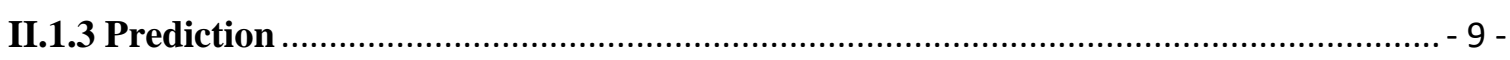

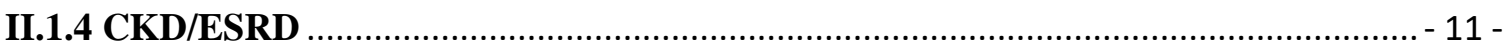

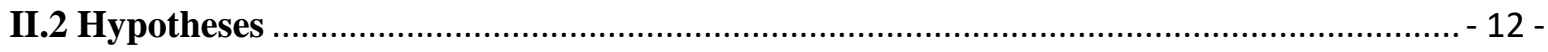

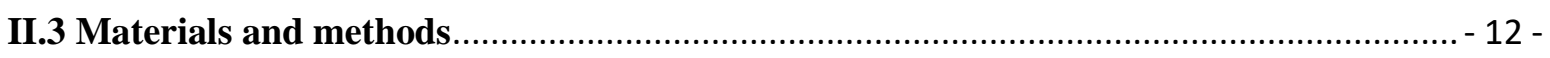

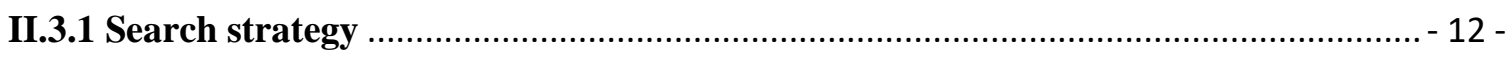

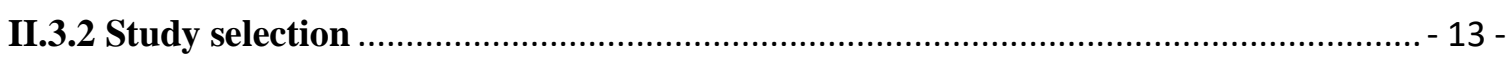

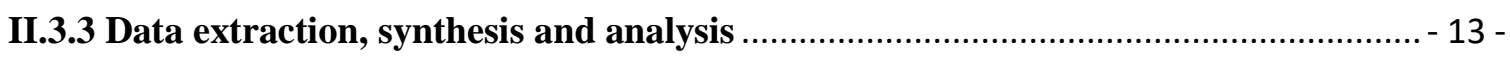

II.3.4 Quality of studies and risk of bias........................................................................ 14 -

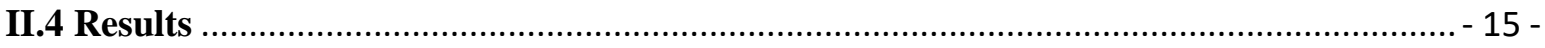

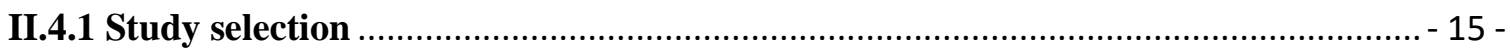

II.4.3 Required units for transfusion ........................................................................... 18 -

II.4.5 Length of hospitalization ....................................................................................... 19 -

II.4.6 Heterogeneity and quality assessment of data .................................................... - 19 -

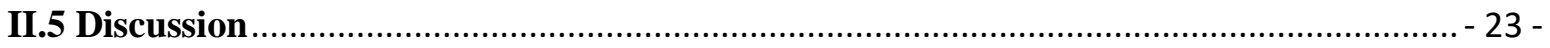

III. Disturbance of consciousness and acute pancreatitis .................................................................. 26 -

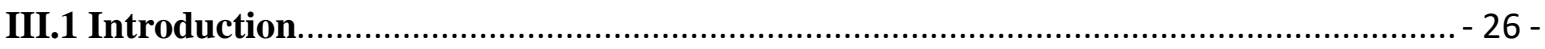

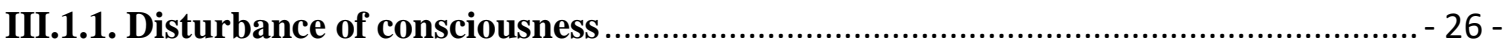

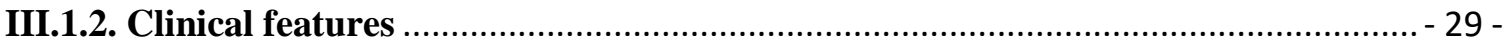

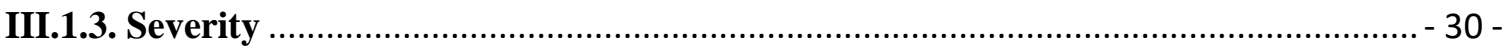

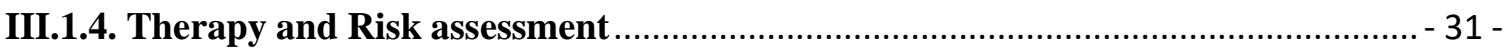

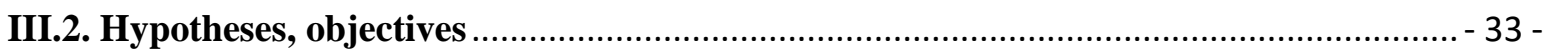

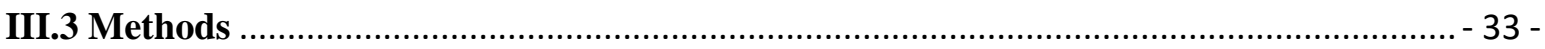

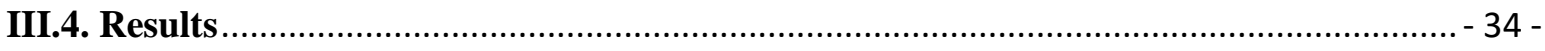


III.4.1 General characteristics of the entire cohort - 34 -

III.4.2 Demographic characteristics in DOC vs. Non-DOC groups. $-36-$

III.4.3. Demographic characteristics in ALC DOC vs. Non-ALC DOC groups . - 41 -

III.4.4. Severity and mortality of AP and LOH in DOC vs. Non-DOC groups $-41-$

III.4.5. Severity and mortality of AP and LOH in ALC DOC vs. Non-ALC DOC groups- 41

IV. Conclusions - 45 -

V. Acknowledgment $-46-$

VI. References - 47 - 


\section{List of abbreviations}

$\mathrm{ABP}$ - acute biliary pancreatitis

ALC-DOC - alcohol-associated disturbance of consciousness

$\mathrm{AP}$ - acute pancreatitis

APACHE - Acute Physiology and Chronic Health Evaluation

BISAP - Bedside Index for Severity in Acute Pancreatitis

$\mathrm{BMI}$ - body mass index

$\mathrm{CI}$ - confidence interval

CKD - chronic kidney disease

CRP - C-reactive Protein

CT - computed tomography

DOC - disturbance of consciousness

eGFR - estimated glomerular filtration rate

ERCP - endoscopic retrograde cholangiopancreatography

ESRD - end-stage renal disease

GAVE - gastric antral vascular ectasia

GFR - glomerular filtration rate

GCS - Glasgow Coma Scale

GI - gastrointestinal

HPSG - Hungarian Pancreatic Study Group

ICU - intensive care unit

LOH - length of hospitalization

$\mathrm{MD}$ - mean difference

MOF - multi-organ failure

MRI - magnetic resonance imaging

NOS - Newcastle-Ottawa Scale

OR - odd's ratio

PICO - Patient, Intervention, Comparison, Outcome

PRISMA-P - preferred reporting items for systematic review and meta-analysis protocols

SAP - severe AP

SD - standard deviation

UGIB - Upper GI bleeding 


\section{General Introduction}

In gastrointestinal emergency situations we have to face countless difficulties and challenges. Many of the situation require immediate surgical interventions or intensive care unit (ICU) admission, and for most of them, special scoring systems were defined, to detect the severity of the disease or the worsening condition of the patient.

Acute, severe gastrointestinal (GI) bleeding has previously required predominantly surgical care. Following the introduction and expansion of gastrointestinal endoscopy, the number of cases requiring surgery has dropped significantly. The incidence of upper nonvariceal bleeding and the need for operative intervention has been steadily declining since 1993. Although endoscopic modalities have undergone significant development, it can be said that we have not been able to achieve a significant improvement in the mortality of gastrointestinal bleeding in the last decades [1]. Possible reasons are the significant increase in the average age of the population and fatal outcomes due to the many comorbidities associated mostly with old age. It is often seen that GI bleeding can be stopped in a patient, yet the outcome is fatal. Accordingly, a reduction in mortality rates in the future will be possible if patient management, independent of endoscopic techniques can be improved. The key is to have a proper risk assessment and to pay more attention to the treatment of vulnerable patients (early, accurate risk assessment, closer observation, multi-parameter monitoring). There are several risk assessment and outcome predictor scoring systems, most of which rely on clinical parameters typical of the acute phase of bleeding. The Rockall scoring system calculates outcome based on comorbidities, however, e.g. in terms of renal failure, the stages are not properly defined [2].

Acute pancreatitis (AP) is a leading cause of hospital admissions worldwide [3,4]. The disease can be traced back to various causes, which can vary in severity [5,6]. According to the severity of the disease, we distinguish between mild, moderate and severe cases. Mortality in severe cases is much higher, approximately $30 \%$ [7]. As the mortality of severe cases is high, the disease has been in the focus of research in recent decades [8]. As a result, there is a significant improvement in mortality, but it is still high. Different scoring systems try to predict the outcome of cases with more or less success. Subsequent complications are not taken into account by these scoring systems. Accordingly, they do not clarify the effect of the case on the outcome. The modified Marshall scoring system takes multiple organ system dysfunctions into account, which are strongly correlated with mortality and ICU admission [9]. Three major organ systems are highlighted i.e., renal, cardiovascular, and respiratory 
failure formation are the most frequently researched and articles on topics, while neurological complications and regular use of the Glasgow Coma Scale (GCS) have been pushed into the background. In clinical practice, patients hospitalized for acute pancreatitis may have or may be formed neurological symptoms such as alcohol withdrawal syndrome, confusion and delirium. Disorder of consciousness means the development of spatial and temporal disorientation, it often occurs in hospitalized patients, especially the elderly. The currently used prognostic score systems do not take into account the disturbances of consciousness developed during hospital admission, so they cannot estimate their effect on the course of the disease. Treatment of AP is predominantly supportive, accordingly, if complications can be reduced with adequate patient care, it can also improve the outcome.

\section{Pre-existing chronic kidney disease and GI bleeding}

\section{II.1 Introduction GI Bleeding}

Acute GI bleeding is an abdominal emergency that remains a common cause of hospitalization [10]. An accurate diagnosis of GI bleeding relies on prompt resuscitation, initial risk evaluation, and provisional clinical diagnosis followed by an appropriate definitive investigation that enables specific therapeutic interventions. GI bleeding involves any bleeding in the GI tract from the esophagus, stomach, small intestines or large intestines to the anus.

\section{II.1.1. Clinical features and diagnosis of GI bleeding}

Upper GI bleeding (UGIB) has an annual incidence that ranges from 40 to 150 episodes per 100000 persons and a mortality rate of 6\%-10\% [11]. The main symptoms are haematemesis, melena and hematochezia. The most common causes of upper GI bleeding remains gastroduodenal ulcer disease, erosive esophagitis, gastritis/duodenitis, and esophagogastric varices. In addition to these, some other abnormalities can cause bleeding such as portal hypertensive gastropathy, angiodysplasia (vascular ectasia), Mallory-Weiss syndrome, Dieulafoy's lesion, gastric antral vascular ectasia (GAVE), hemobilia, haemosuccus pancreaticus, aortoenteric fistula, Cameron lesions, ectopic varices, iatrogenic bleeding after endoscopic interventions, gastrointestinal tumors. Endoscopy is highly useful for diagnosing 
the cause of UGIB, with $92 \%-98 \%$ sensitivity and 3\%-100\% specificity, and enables effective treatment of bleeding in the majority of cases [12]. Radiologic methods (computed tomography $[\mathrm{CT}]$ angiography) have a role in assessing UGIB only when upper endoscopy is not feasible or yields inconclusive results. Upper GI endoscopy may be contraindicated in the setting of shock, substantial comorbidity, or massive hemorrhage. Adequate endoscopic evaluation of the bleeding source may not be possible when extensive luminal blood obscures visualization or the bleeding originates from a difficult anatomic location such as the distal duodenum. Lower GI bleeding has an annual incidence ranging from 20 to 27 episodes per 100000 persons and a mortality rate of $4 \%-10 \%[13,14]$. The most frequent causes of lower GI bleeding in this population have been described; diverticulosis, hemorrhoids, ischaemic colitis, inflammatory bowel disease-associated bleeding, post polypectomy, colon cancer/polyps, rectal ulcer, vascular ectasia, radiation colitis/proctitis.

\section{II.1.2 Therapy}

The approach to medications and endoscopy are similar for patients with upper GI bleeding. It is particularly important to ensure that these patients are adequately resuscitated before undergoing upper endoscopy. Traditionally, three endoscopic treatment methods of upper GI bleeding have been used: injection therapy, thermal therapy, and mechanical therapy. If endoscopy fails surgery or interventional radiology are indicated. The accepted medications are acid suppression with proton pump inhibitors, prokinetics, vasoactive medications and antibiotics for patients with liver cirrhosis.

\section{II.1.3 Prediction}

Since GI bleeding is a potentially life-threatening acute disorder, understanding the risk factors that worsen the disease is of great importance. Scoring systems have therefore been developed to predict the outcome of therapy. The Rockall score is one of these scoring systems. It includes pre-endoscopic (age, shock and comorbidity) and post-endoscopic (diagnosis and presence or absence of endoscopic stigmata of recent hemorrhage) factors [2]. Several studies have demonstrated high mortality with higher Rockall scores [15]. However, Laeeq et al. [16] have not found significantly higher mortality in patients with high preendoscopic Rockall score (> 5). The Rockall score only assesses the risk of mortality in patients with upper GI bleeding. The Glasgow Blatchford score is another scoring system that uses clinical and laboratory parameters [17]. Neither scoring system makes a distinction between pre-existing renal failure and acute renal failure due to haemorrhage. The Rockall 
score takes into account renal failure for comorbidities but does not differentiate the degree of renal failure. The Glasgow Blatchford score system evaluates the incoming renal function value but does not differentiate between acute and chronic renal failure. Both of these scoring systems have been designed for the risk assessment of upper GI bleeding. The newer AIMS65 Score was designed to predict mortality in adults presenting with acute upper GI bleeding. It does not use renal function abnormalities in risk assessment [18].

\begin{tabular}{|c|c|c|c|}
\hline \multicolumn{3}{|c|}{ Glasgow-Blatchford Scoring System } & \multirow[b]{2}{*}{ BUN (mmol/L) } \\
\hline BUN (mg/dL) & $<18$ & 0 & \\
\hline & $18-22$ & 2 & $6.5-<8$ \\
\hline & $23-27$ & 3 & $8-<10$ \\
\hline & $28-70$ & 4 & $10-<25$ \\
\hline & $>70$ & 6 & $>25$ \\
\hline \multirow[t]{4}{*}{$\begin{array}{l}\text { Hemoglobin } \\
\text { (men, g/dL) }\end{array}$} & $>13$ & 0 & \\
\hline & $12-12.9$ & 1 & \\
\hline & $10-11.9$ & 3 & \\
\hline & $<10$ & 6 & \\
\hline \multirow{3}{*}{$\begin{array}{l}\text { Hemoglobin (wom- } \\
\text { en, g/dL) }\end{array}$} & $>12$ & 0 & \\
\hline & $10-11.9$ & 1 & \\
\hline & $<10$ & 6 & \\
\hline \multirow{4}{*}{$\begin{array}{l}\text { Systolic blood pres- } \\
\text { sure (mmHg) }\end{array}$} & $>110$ & 0 & \\
\hline & $100-110$ & 1 & \\
\hline & $90-99$ & 2 & \\
\hline & $<90$ & 3 & \\
\hline \multirow[t]{5}{*}{ Other markers } & Pulse $>100 \mathrm{bpm}$ & 1 & \\
\hline & $\begin{array}{c}\text { Presentation of } \\
\text { melena }\end{array}$ & 1 & \\
\hline & $\begin{array}{c}\text { Presentation of } \\
\text { syncope }\end{array}$ & 2 & \\
\hline & Hepatic disease & 2 & \\
\hline & Cardiac failure & 2 & \\
\hline
\end{tabular}




\begin{tabular}{|c|c|c|c|c|c|c|}
\hline \multicolumn{5}{|c|}{ Rockall Scoring System } & \multicolumn{2}{|c|}{ AIMS65 Score } \\
\hline Variable & Score $=0$ & Score $=1$ & Score $=2$ & Score $=3$ & Variable & Score \\
\hline Age (years) & $<60$ & $60-79$ & $>80$ & & Albumin $<3 \mathrm{~g} / \mathrm{dL}$ & 1 \\
\hline Comorbidity & & & $\begin{array}{c}\text { Congestive heart } \\
\text { failure, ischemic } \\
\text { heart disease }\end{array}$ & $\begin{array}{l}\text { Renal failure, liver } \\
\text { disease, metastatic } \\
\text { disease }\end{array}$ & $\begin{array}{l}\text { Systolic BP }<90 \mathrm{mmHg} \\
\text { Altered Mental Status } \\
\text { Age }>65 \mathrm{yr}\end{array}$ & $\begin{array}{l}1 \\
1 \\
1\end{array}$ \\
\hline Shock & No shock & Pullse $>100$ bpm & $\begin{array}{c}\text { Systolic BP }<100 \\
\text { mmHg }\end{array}$ & & & \\
\hline Source of bleeding & $\begin{array}{c}\text { Mallory-Weiss } \\
\text { Tear }\end{array}$ & $\begin{array}{l}\text { All other diagno- } \\
\text { ses. e.g., esophagi- } \\
\text { tis, gastritis, peptic } \\
\text { ulcer disease, } \\
\text { varices }\end{array}$ & Malignancy & & & \\
\hline $\begin{array}{c}\text { Stigmata of recent } \\
\text { bleeding }\end{array}$ & None & & $\begin{array}{l}\text { Adherent clot or } \\
\text { spurting vessel }\end{array}$ & & & \\
\hline
\end{tabular}

Table 1. The Glasgow-Blatchford, Rockall and AIMS65 scoring system. [19]

\section{II.1.4 CKD/ESRD}

CKD is defined by the presence of kidney damage or decreased kidney function for three or more months, irrespective of the cause. The persistence of the damage or decreased function for at least three months is necessary to distinguish CKD from acute kidney disease. Decreased kidney function refers to a decreased glomerular filtration rate (GFR), which is usually estimated (eGFR) using serum creatinine. [20] The most common causes of CKD are diabetes mellitus, drug toxicity, auto-immune diseases, urinary tract obstruction, kidney transplantation etc. CKD is classified based on the eGFR and the level of proteinuria. Patients are classified as G1-G5, based on the eGFR. Previous studies have shown evidence of increased risk of GI bleeding in CKD patients and with end-stage renal disease (ESRD) requiring renal replacement therapy in comparison with the general population, but also an association with higher mortality [21-23]. Further studies have demonstrated that bleeding in CKD patients from the upper GI tract is more common than from the lower GI tract [24]. The increased prevalence of small bowel erosions, ulcers and angioectasias is also well known in CKD patients and it may be as high as $33 \%$ and it often causes obscure gastrointestinal bleeding [25-27]. However, no meta-analyses or systematic reviews have been conducted to assess the difference between CKD/ESRD patients and the normal renal function population concerning GI bleeding. 


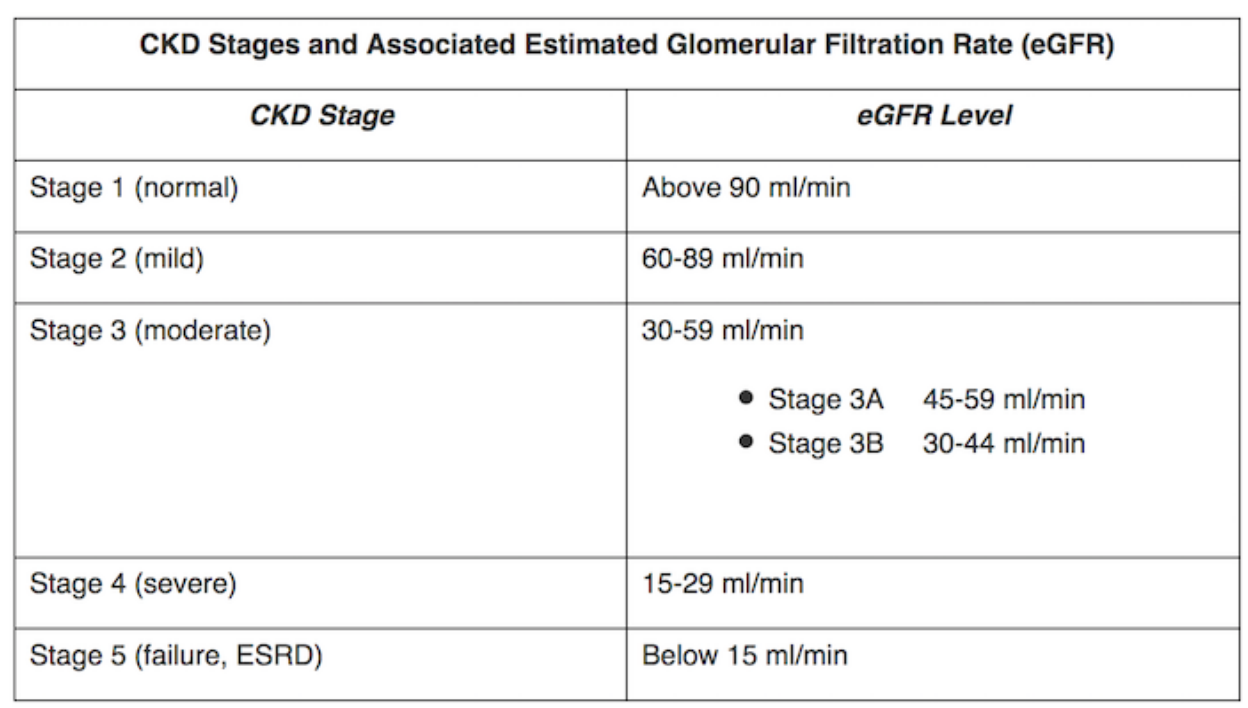

Table 2. CKD stages [28].

\section{II.2 Hypotheses}

Pre-existing CKD may worsen the prognosis in GI bleeding. We performed this meta-analysis to compare CKD patients and normal renal function patients based on GI bleeding. We investigated these two groups in terms of mortality, transfusion amount, rebleeding rate and length of hospitalization.

\section{II.3 Materials and methods}

\section{II.3.1 Search strategy}

This study was conducted using the preferred reporting items for systematic review and metaanalysis protocols (PRISMA-P) [29]. It was registered in the international prospective register of systematic reviews, PROSPERO (under registration number CRD42017077987). The meta-analysis was based on the PICO (Patient, Intervention, Comparison, Outcome) format (P: patients with GI bleeding; I: chronic renal failure; C: normal renal function; O: mortality, blood transfusion, rebleeding). A systematic search was performed in 3 databases, Pubmed, EMBASE and the Cochrane Library, with the following terms: "GI bleeding" OR "gastrointestinal bleeding" OR "gastrointestinal hemorrhage") AND ("chronic renal failure" OR "uremia" OR "chronic kidney failure"). The search was limited to human data and to fulltext English-language articles if appropriate. The exact search term in Pubmed was: [“GI bleeding”(All Fields) OR “gastrointestinal bleeding”(All Fields) OR “gastrointestinal 
hemorrhage"(All Fields)] AND [“chronic renal failure"(All Fields) OR "uraemia"(All Fields) OR “uremia"(MeSH Terms) OR "uremia"(All Fields) OR "chronic kidney failure"(All Fields)] AND ["humans"(MeSH Terms) AND English(lang)]. The database search was conducted up to 10 March 2017. Reference management software (EndNote X7) was used to remove duplicates by searching overlaps between titles, authors and publication years. The reference lists in the articles obtained were also checked, and one more eligible publication was found.

\section{II.3.2 Study selection}

The studies were selected separately by two investigators (RH and AM). Disagreements were resolved by consulting a third reviewer $(\mathrm{PH})$. Clinical studies were eligible provided they reported data on adult patients hospitalized with upper or lower GI bleeding grouped into normal renal function and CKD or ESRD groups. Articles were eligible containing data of CKD/ESRD patients and a control group in the same study. Information on mortality, transfusion, rebleeding and length of hospitalization (LOH) was manually searched. Case reports, conference abstracts, reviews and studies on pediatric patients up to age 18 alone were excluded. We found a high number of articles in which the risk of GI bleeding in CKD patients was studied, but they were not eligible for our meta-analysis, as there were no data available on outcomes of the GI bleeding in a control population without CKD/ESRD.

\section{II.3.3 Data extraction, synthesis and analysis}

Mortality data, number of transfused blood units, rebleeding and length of hospitalization data were extracted to analyse the influence of CKD and/or ESRD on the outcome of GI bleeding. In Sood et al [23], Tsai et al [30] and Boyle et al [31], the number of patients was calculated from percentages of mortality. Boyle et al[31] supplied information on transfusion in mean and standard error of mean, for which statistical calculation standard deviation (SD) was computed. Tsai et al [30] reported data from transfusions in the median and interquartile range, from which mean and SD were calculated with Hozo's method[32]. All meta-analytic calculations were performed with Comprehensive Meta-Analysis software (Version 3.0, Biostat Inc.) using the random-effects model (DerSimonian-Laird method[19]). Odds ratios (OR) and 95\% confidence intervals (CI) were calculated for binary outcomes. In the case of $\mathrm{LOH}$ and transfusion for comparing mean data, a mean difference (MD) with 95\% CI was calculated. All analyses were two-tailed, with an $\alpha$ of 0.05 . 
Heterogeneity was tested using Cochrane's $Q$ and the $I 2$ statistics. Based on the Cochrane Handbook, $I 2=100 \% \times(Q-\mathrm{df}) / \mathrm{Q}$, with $I 2$ representing the magnitude of the heterogeneity (moderate: 30\%-60\%; substantial: 50\%-90\%; considerable: 75\%-100\%) [33]. Only results that were available from at least 3 studies were displayed graphically with forest plots. We performed a sensitivity analysis to assess whether removing any study results in different interpretations and final conclusions [21]. To assess the effect of the year of publication on the outcome data we performed meta-regression analysis. We calculated the regression coefficient and interpreted the data with their 95\% CI and r-analog.

\section{II.3.4 Quality of studies and risk of bias}

Because of the low number of eligible articles, publication bias was obtained with a visual inspection of the funnel plots alone according to the Cochrane Handbook [33]. The Newcastle-Ottawa Scale (NOS) adjusted to our study design was used [34] to assess the quality of nonrandomized cohort studies. The selection, comparability and outcome data were assessed based on 6 items (Table 3) with the "star system": high-quality items with a low risk of bias received one star, while low-quality items with a high or unknown risk of bias were assigned no stars.

\begin{tabular}{|c|c|c|}
\hline Adapted Newcastle-Ottawa Scale Items & $\begin{array}{l}\text { High-quality items carrying a low risk of bias } \\
\text { (green) }\end{array}$ & $\begin{array}{c}\text { Low-quality items carrying a high (red) or an } \\
\text { unknown (yellow) risk of bias }\end{array}$ \\
\hline $\begin{array}{l}\text { Item 1: Representativeness of the initial study } \\
\text { population - patients with GI bleeding and CKD/ } \\
\text { ESRD }\end{array}$ & $\begin{array}{l}\text { All patients with upper or lower GI bleeding and } \\
\text { CKD/ESRD were included. }\end{array}$ & $\begin{array}{l}\text { Low: any selection criteria were applied to the } \\
\text { study population (e.g., only transplanted patients). } \\
\text { Unknown: no data on selection process. }\end{array}$ \\
\hline $\begin{array}{l}\text { Item 2: Representativeness of the initial study } \\
\text { population - patients with GI bleeding without } \\
\text { CKD/ESRD }\end{array}$ & $\begin{array}{l}\text { All patients with upper or lower GI bleeding } \\
\text { without CKD/ESRD included. }\end{array}$ & $\begin{array}{l}\text { Low: any selection criteria were applied to the } \\
\text { study population. } \\
\text { Unknown: no data on selection process. }\end{array}$ \\
\hline Item 3: Ascertainment of exposure & $\begin{array}{l}\text { We defined chronic renal failure as present when } \\
\text { EGFR was }<60 \mathrm{~mL} / \mathrm{min} \text { at least } 3 \mathrm{mo} \text {. We defined } \\
\text { end-stage renal disease as a condition where } \\
\text { hemodialysis or chronic peritoneal dialysis is } \\
\text { performed at least for } 3 \text { mo. }\end{array}$ & $\begin{array}{l}\text { Low: CKD or ESRD is not present in all of the } \\
\text { patients. } \\
\text { Unknown: no definitions of the conditions } \\
\text { mentioned are provided. }\end{array}$ \\
\hline Item 4: Comparability of cohorts A & $\begin{array}{l}\text { Study controls for age: no significant difference } \\
\text { was detected. }\end{array}$ & $\begin{array}{l}\text { Low: significant difference was detected. } \\
\text { Unknown: no statement. }\end{array}$ \\
\hline Item 5: Comparability of cohorts B & $\begin{array}{l}\text { Study controls for taking ulcerogenic drugs: no } \\
\text { significant difference was detected }\end{array}$ & $\begin{array}{l}\text { Low: significant difference was detected between } \\
\text { taking ulcerogenic drugs. } \\
\text { Unknown: no comparison made by taking } \\
\text { ulcerogenic drugs. }\end{array}$ \\
\hline Item 6: Follow-up time for rebleeding & The follow-up time is clearly defined. & $\begin{array}{l}\text { Low: incomplete follow-up } \\
\text { Unknown: no follow-up time is mentioned. }\end{array}$ \\
\hline
\end{tabular}

Table 3. Modified Newcastle-Ottawa Scale criteria. 
3 items were included during the selection process. In the case of representativeness in the study population, we assigned a star if all of the GI bleeding patients with normal or impaired renal function were included. If any selection criteria were applied, we assigned no points. We used the classical definition of CKD [35], which characterizes the disease with a glomerular filtration rate $(\mathrm{GFR})<60 \mathrm{ml} / \mathrm{min}$ lasting longer than 3 mo. ESRD was defined as a condition where hemodialysis or chronic peritoneal dialysis is performed for at least 3 mo. Concerning outcome, only the follow-up time for rebleeding was rated in articles that provided this information. Assessment of outcome and length of follow-up were not rated because most of the articles were retrospective.

\section{II.4 Results}

\section{II.4.1 Study selection}

1063 articles (EMBASE: 589; PubMed: 459; Cochrane: 15) were found altogether through database searches. The flowchart (Figure 2) shows the study selection strategy.

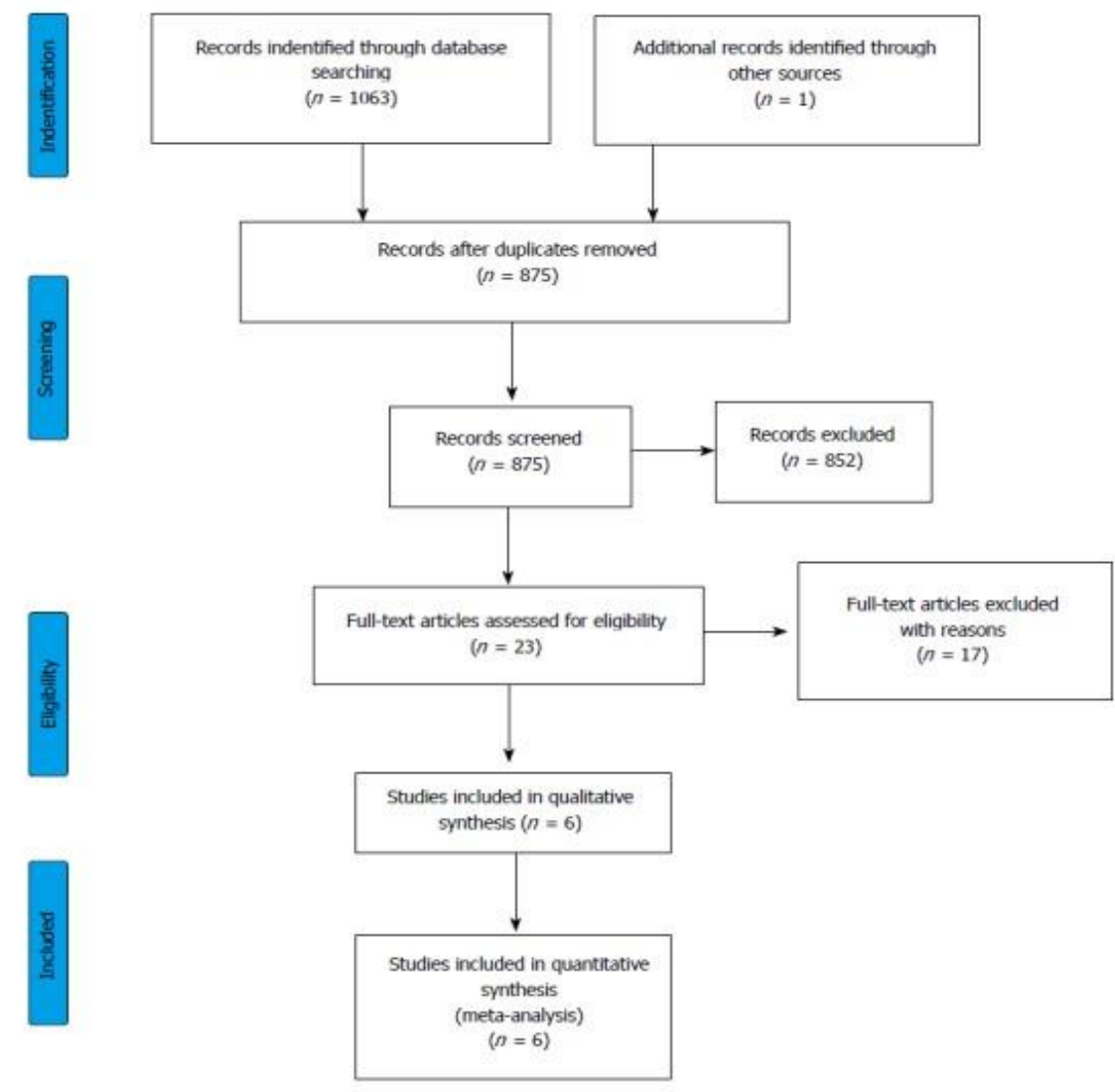

Figure 2. The flowchart of the study selection procedure. 
Studies in our meta-analysis were dated from 1946 to 2017. After removing duplicates, 875 publications remained. Following initial screening based on titles and abstracts, 23 articles were retrieved and screened. A further 18 were excluded because of missing outcome data or a missing control group. Patients with acute renal failure were also included in the analysis reported in Alvarez et al [36], so we did not use the data in that publication. The remaining 5 $[23,30,31,37,38]$ and one other [21] eligible record which was found in reference lists were included in the meta-analysis. The basic characteristics of the 6 eligible articles in the metaanalysis are shown in Table 4.

\begin{tabular}{|c|c|c|c|c|c|c|c|c|c|c|}
\hline Ref. & Country & Study type & Years of study & Group & Sample size & Age & Mortality & Transfusion & Rebleeding & $\begin{array}{c}\text { Length of } \\
\text { hospitalization }\end{array}$ \\
\hline \multirow[t]{2}{*}{ Boyle ef $a f^{[1]}, 1983$} & United & Retrospective & $1977-1981$ & Control & 40 & $54 \pm 2^{1}$ & $\overline{\sqrt{ }}$ & $\overline{\sqrt{ }}$ & - & $\bar{v}$ \\
\hline & States & & & CKD (mix) & 20 & $59 \pm 4^{1}$ & & & & \\
\hline \multirow[t]{3}{*}{ Cheung et al $\left.\right|^{(2)}, 2010$} & Canada & Retrospective & $2000-2006$ & Control & 50 & $67 \pm 13$ & $\sqrt{ }$ & $\sqrt{ }$ & $\sqrt{ }$ & $\checkmark$ \\
\hline & & & & CKD & 50 & $71 \pm 13$ & & & & \\
\hline & & & & ESRD & 50 & $68 \pm 12$ & & & & \\
\hline \multirow[t]{2}{*}{ Hung ef af ${ }^{[29}, 2014$} & Taiwan & Retrospective & 2007 & Control & 6322 & $54.6 \pm 13.3$ & $\sqrt{ }$ & - & - & . \\
\hline & & & & ESRD & 110 & NR & & & & \\
\hline \multirow[t]{3}{*}{ Sood et al ${ }^{1 \eta}, 2012$} & United & Retrospective & 2007 & Control & 347245 & NR & $\sqrt{ }$ & - & - & . \\
\hline & States & & & CKD & 35985 & NR & & & & \\
\hline & & & & ESRD & 14983 & NR & & & & \\
\hline \multirow[t]{2}{*}{ Tsai et al ${ }^{[1]}, 1996$} & Taiwan & Prospective & $1991-1994$ & Control & 640 & $55.7 \pm 16.2^{2}$ & $\sqrt{ }$ & $\sqrt{ }$ & $\sqrt{ }$ & . \\
\hline & & & & ESRD & 58 & $64.1 \pm 11.4^{2}$ & & & & \\
\hline \multirow[t]{2}{*}{ Zuckerman ef $a^{p 9}, 1985$} & United & Retrospective & $1980-1983$ & Control & 423 & $63(16-96)^{3}$ & . & . & $\sqrt{ }$ & - \\
\hline & States & & & CKD (mix) & 59 & $57(24-84)^{3}$ & & & & \\
\hline
\end{tabular}

Table 4. Basic characteristics of the studies included in the meta-analysis.

These 6 publications contained data on 406,035 patients, of whom 51315 had impaired renal function parameters and 354720 had normal renal functions. 2 articles contained data on patients with CKD and 4 on ESRD patients. There were 2 studies involving CKD and ESRD patients, with their group identified as the CKD mixed group. The number of ESRD patients analysed was 15201, the CKD group had 36035 members, and 79 patients could be classified in the CKD mixed group. 


\section{II.4.2 Mortality}

Data on mortality was available in all of the articles included, but Zuckerman et al [38] reported no mortality data for the control group; we, therefore, removed it from the statistical analysis. Hung et al [37] reported mortality data from a 6-wk follow-up period, while the other articles contained data on an unknown follow-up period. In the subgroup analysis for CKD and ESRD, a higher mortality rate was detected compared to the control population $(\mathrm{CKD}: \mathrm{OR}=1.786,95 \% \mathrm{CI}: 1.689-1.888, P<0.001 ;$ ESRD: $\mathrm{OR}=2.530,95 \% \mathrm{CI}: 1.386-$ 4.616, $P=0.002$, Figure 3).

\begin{tabular}{|c|c|c|c|c|c|c|c|c|c|}
\hline \multirow[t]{2}{*}{ Study name } & \multirow[t]{2}{*}{ Subgroup within study } & \multicolumn{4}{|c|}{ Statistics for each study } & \multicolumn{2}{|c|}{ Dead/Total } & \multirow[t]{2}{*}{ Odds ratio and 95\%CI } & \multirow{2}{*}{ Risk of bias } \\
\hline & & $\begin{array}{l}\text { Odds } \\
\text { ratio }\end{array}$ & $\begin{array}{l}\text { Lower } \\
\text { limit }\end{array}$ & $\begin{array}{l}\text { Upper } \\
\text { limit }\end{array}$ & $\rho$ value & Renal failure & Control & & \\
\hline Soodet d/ 2012 & CKD & 1.782 & 1.685 & 1.885 & 0.000 & $1511 / 35985$ & $8334 / 347245$ & & (6) (1) (2) \\
\hline Boyle et a/ 1983 & CKD $(m b)$ & 3.083 & 0.618 & 15.390 & 0.170 & $4 / 20$ & $3 / 40$ & & 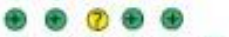 \\
\hline \multirow[t]{2}{*}{ Cheung et al 2010} & CKD & 4.571 & 0.919 & 22.730 & 0.063 & $8 / 50$ & $2 / 50$ & & $\oplus \oplus \oplus \oplus \oplus \oplus$ \\
\hline & CKD & 1.786 & 1.689 & 1.888 & 0.000 & $1523 / 36055$ & $8339 / 347335$ & i & \\
\hline Hung et al 2014 & ESRD & 1.190 & 0.793 & 1.786 & 0.401 & & & 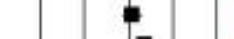 & $4 \oplus 000$ \\
\hline Sood et al 2012 & ESRD & 2.276 & 2.112 & 2.452 & 0.000 & $794 / 14983$ & $8334 / 347245$ & E & (1) $(9)$ \\
\hline Cheung et a/ 2010 & ESRD & 4.571 & 0.919 & 22.730 & 0.063 & $8 / 50$ & $2 / 50$ & & 두 $\oplus \oplus \oplus \oplus \oplus$ \\
\hline \multirow[t]{2}{*}{ Tsai et a/ 1996} & ESRD & 7.717 & 3.055 & 19.493 & 0.000 & $8 / 58$ & $13 / 640$ & & (4) $\oplus \oplus \odot \oplus$ \\
\hline & ESRD & 2.530 & 1.386 & 4.616 & 0.002 & $810 / 15091$ & $8349 / 347935$ & & \\
\hline
\end{tabular}

Figure 3. Forest plot representing the differences in mortality in gastrointestinal bleeding patients with normal and impaired renal function. Size of squares for risk ratio reflects weight of trial in pooled analysis. Horizontal bars represent 95\%CI. CKD: Chronic kidney disease; ESRD: End-stage renal disease. 


\section{II.4.3 Required units for transfusion}

4 studies reported data on the transfused units of red blood cells. The required transfusion was 1.8 times higher in the patients with abnormal renal function $(\mathrm{MD}=1.863,95 \% \mathrm{CI}$ : 0.812 $2.915, P<0.001$, Figure4).

\begin{tabular}{lcccccc} 
Study name & Subgroup within study & \multicolumn{3}{c}{ Statistics for each study } & Difference in means \\
and $95 \%$ C
\end{tabular}

Figure 4. Forest plot representing the required units of transfusion in gastrointestinal bleeding patients with normal and impaired renal function. Size of squares for the difference in standardized mean values reflects weight of trial in pooled analysis. Horizontal bars represent 95\%CI. CKD: Chronic kidney disease; ESRD: End-stage renal disease.

\section{II.4.4 Rebleeding rate}

It was possible to retrieve data on the rebleeding rate from 3 articles, but Cheung et al [21] contained simultaneous data from the CKD and ESDR groups, which could be analysed. Boyle et al [31]. also presented data on rebleeding. However, this included cases of uncontrolled bleeding, so we excluded these data from our analysis. We found that patients with impaired renal function tend to bleed again 2.5 more times than patients with normal renal function $(\mathrm{OR}=2.510,95 \% \mathrm{CI}: 1.521-4.144, P<0.001$, Figure5).

\begin{tabular}{|c|c|c|c|c|c|c|c|c|c|c|}
\hline \multirow[t]{2}{*}{ Study name } & \multirow[t]{2}{*}{ Subgroup within study } & \multirow[t]{2}{*}{ Outcome } & \multicolumn{4}{|c|}{ Statistics for each study } & \multicolumn{2}{|c|}{ Exposed/Total } & \multirow[t]{2}{*}{ Odds ratio and $95 \% \mathrm{Cl}$} & \multirow[t]{2}{*}{ Risk of bias } \\
\hline & & & $\begin{array}{l}\text { Odds } \\
\text { ratio }\end{array}$ & $\begin{array}{l}\text { Lower } \\
\text { limit }\end{array}$ & $\begin{array}{l}\text { Upper } \\
\text { limit }\end{array}$ & $P$ value & Cases & Controts & & \\
\hline Cheung et a/ 2010 & CKD & Rebleeding & 1.194 & 0.371 & 3.841 & 0.766 & $7 / 50$ & $6 / 50$ & $\oplus$ & $\oplus \oplus \oplus \oplus \oplus$ \\
\hline Tsal et al 1996 & ESRD & Rebleeding & 1.691 & 0.487 & 5.869 & 0,408 & $3 / 58$ & $20 / 640$ & (4) & (4) \\
\hline Zuckerman et al 1985 & $C K D(m i x)$ & Rebleeding & 2.864 & 1.476 & 5.555 & 0.002 & $15 / 59$ & $45 / 423$ & $\oplus$ & $\oplus 000$ \\
\hline Cheung et a/ 2010 & ESRD & Rebleeding & 4.495 & 1.610 & 12.545 & 0,004 & $19 / 50$ & $6 / 50$ & $\oplus$ & $\oplus \oplus \oplus \oplus \oplus$ \\
\hline & & & 2.510 & 1.521 & 4.144 & 0.000 & $44 / 217$ & $77 / 1163$ & & \\
\hline
\end{tabular}

Figure 5. Forest plot representing the rebleeding rate in gastrointestinal bleeding patients with normal and impaired renal function. Size of squares for risk ratio reflects weight of trial in pooled analysis. Horizontal bars represent 95\% CI. CKD: Chronic kidney disease; ESRD: End-stage renal disease. 


\section{II.4.5 Length of hospitalization}

Two of the six articles included reported hospital stay outcomes. Patients with impaired renal function spent significantly more time in hospital after GI bleeding (MD = 13.245, 95\%CI: 6.886-19.623, $P<0.001$, Figure 6).

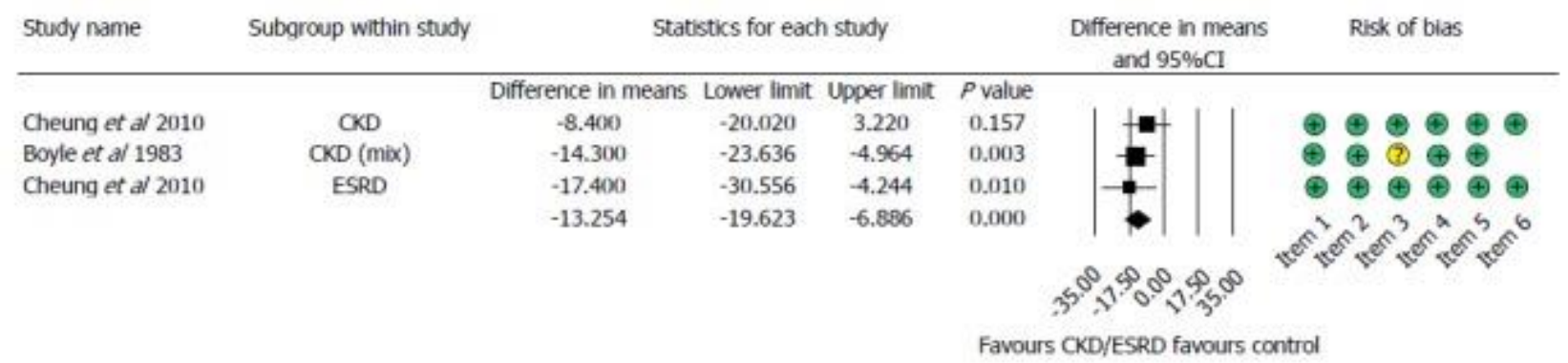

Figure 6. Forest plot representing the differences in length of hospitalization in gastrointestinal bleeding patients with normal and impaired renal function. Size of squares for the difference in standardized mean values reflects weight of trial in pooled analysis. Horizontal bars represent 95\% CI. CKD: Chronic kidney disease; ESRD: End-stage renal disease

\section{II.4.6 Heterogeneity and quality assessment of data}

High heterogeneity was detected for mortality in the ESRD group $(\mathrm{Q}=17.082 ; \mathrm{DF}=3 ; I 2=$ $82.438 \% ; P<0.001)$, while the heterogeneity for $\mathrm{CKD}$ was low $(\mathrm{Q}=1.767 ; \mathrm{DF}=2 ; I 2=$ $0 \% ; P=0.413)$. However, a low heterogeneity was detected for the transfusion requirements $(\mathrm{Q}=3.448 ; \mathrm{DF}=3 ; I 2=13.003 \% ; P=0.328)$, the rebleeding rate $(\mathrm{Q}=3.328 ; \mathrm{DF}=3 ; I 2=$ $9.845 \% ; P=0.344)$ and $\mathrm{LOH}(\mathrm{Q}=1.100 ; \mathrm{DF}=2 ; I 2=0 \% ; P=0.577)$. To ascertain publication bias, we only made a visual assessment of the funnel plot (Figure 7) because we were only able to include 6 studies in our meta-analysis. 

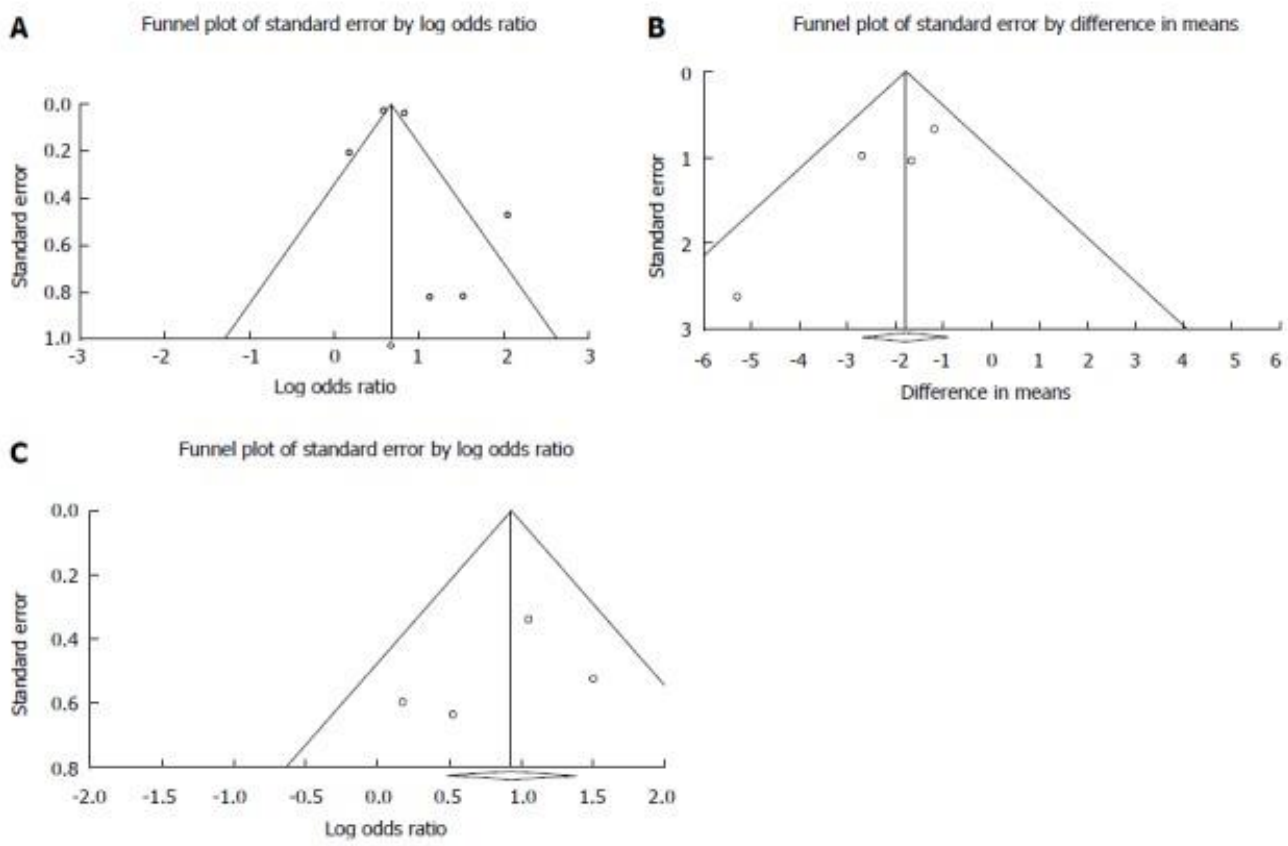

Figure 7. Funnel plot. A: Funnel plot of mortality; B: Funnel plot of required transfusion; and $C$ : Funnel plot of rebleeding

Sensitivity analysis showed no significant difference in the OR of mortality, by removing any of the articles (Figure 8).

\begin{tabular}{|c|c|c|c|c|c|c|c|}
\hline$\underline{\text { Study name }}$ & $\underline{\text { Subgroup within study }}$ & & & with stu & noved & & Odds ratio $(95 \% \mathrm{CI})$ \\
\hline & & Point & $\begin{array}{c}\text { Lower } \\
\text { llmitt }\end{array}$ & $\begin{array}{c}\text { Upper } \\
\text { llmitt }\end{array}$ & Z-Value & p-Value & with study removed \\
\hline IIung et al. 2014 & ESRD & 2.429 & 1.853 & 3.185 & 6.421 & 0.000 & \\
\hline Sood et al. 2012 & $\mathrm{CKD}$ & 3.207 & 1.787 & 5.754 & 3.907 & 0.000 & \\
\hline Sood et al. 2012 & ESRD & 2.967 & 1.668 & 5.277 & 3.701 & 0.000 & \\
\hline Boyle et al. 1983 & CKD(mix) & 2.135 & 1.650 & 2.761 & 5.779 & 0.000 & \\
\hline Cheung et al. 2010 & CKD & 2.112 & 1.636 & 2.726 & 5.735 & 0.000 & \\
\hline Cheung et al. 2010 & ESRD & 2.112 & 1.636 & 2.726 & 5.735 & 0.000 & \\
\hline Tsai et al. 1996 & ESRD & 1.967 & 1.544 & 2.507 & 5.472 & 0.000 & \\
\hline Zuckerman et al. 1985 & CKID(mix) & 2.061 & 1.628 & 2.609 & 6.014 & 0.000 & \\
\hline & & 2.150 & 1.670 & 2.767 & 5.942 & 0.000 & \\
\hline
\end{tabular}

Figure 8: Sensitivity analysis of mortality data

Meta-regression showed slight significance, in the most recent articles the OR is decreasing with the time (regression coefficient: $b=-0.0548$; 95\%CI: -0.0968 to $-0.0128 ; P=0.0105$; r- 
analog: 0.2, Figure 9/A. The number of required units for transfusion has not changed since the $1980 \mathrm{~s}$ ( $b=-0.0028 ; 95 \% \mathrm{CI}:-0.0242$ to $-0.0186 ; P=0.7972 ; \mathrm{r}$-analog: 0.00 , Figure $9 / \mathrm{B})$. Based on data from 4 articles, no difference in rebleeding rate could be observed in the last 30 years $(b=0.0027 ; 95 \% \mathrm{CI}:-0.0353$ to $0.03 ; P=0.8726$; r-analog: 0.00 , Figure $9 / \mathrm{C})$.

A

Regression of Log odds ratio on Publication year

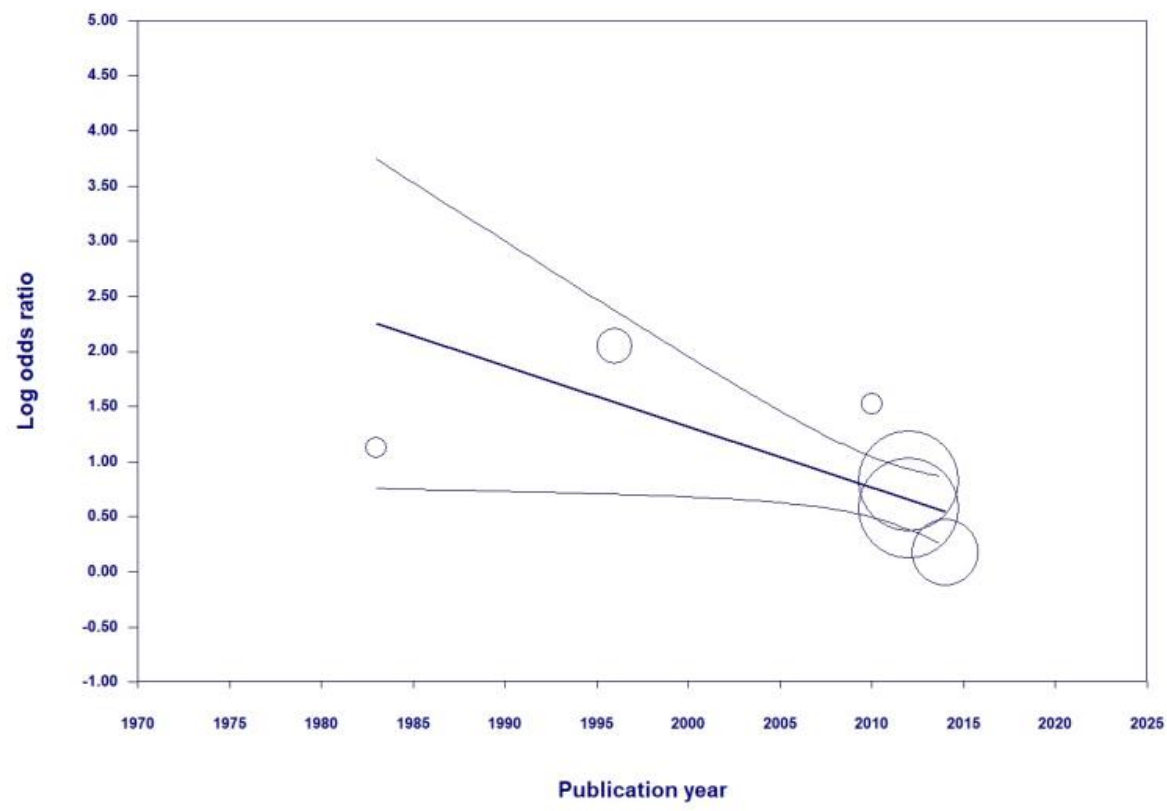

B

Regression of Std diff in means on Publication year

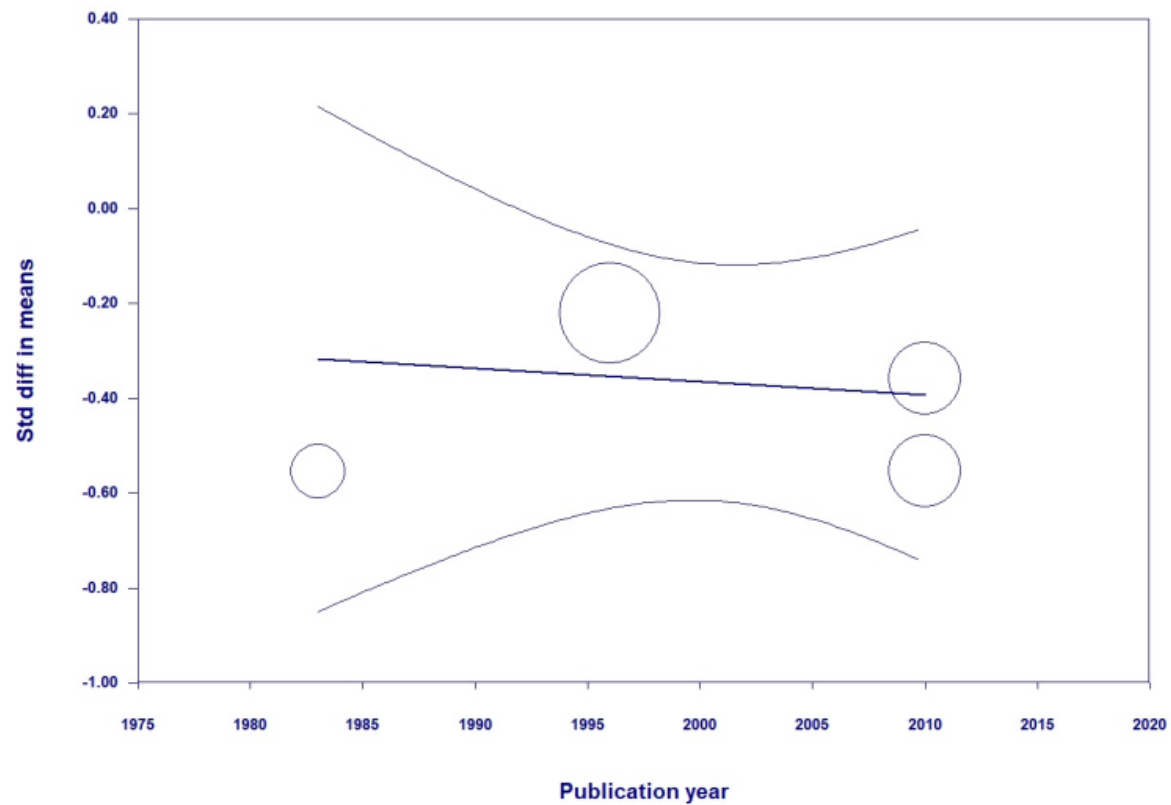


C Regression of Log odds ratio on Publication year

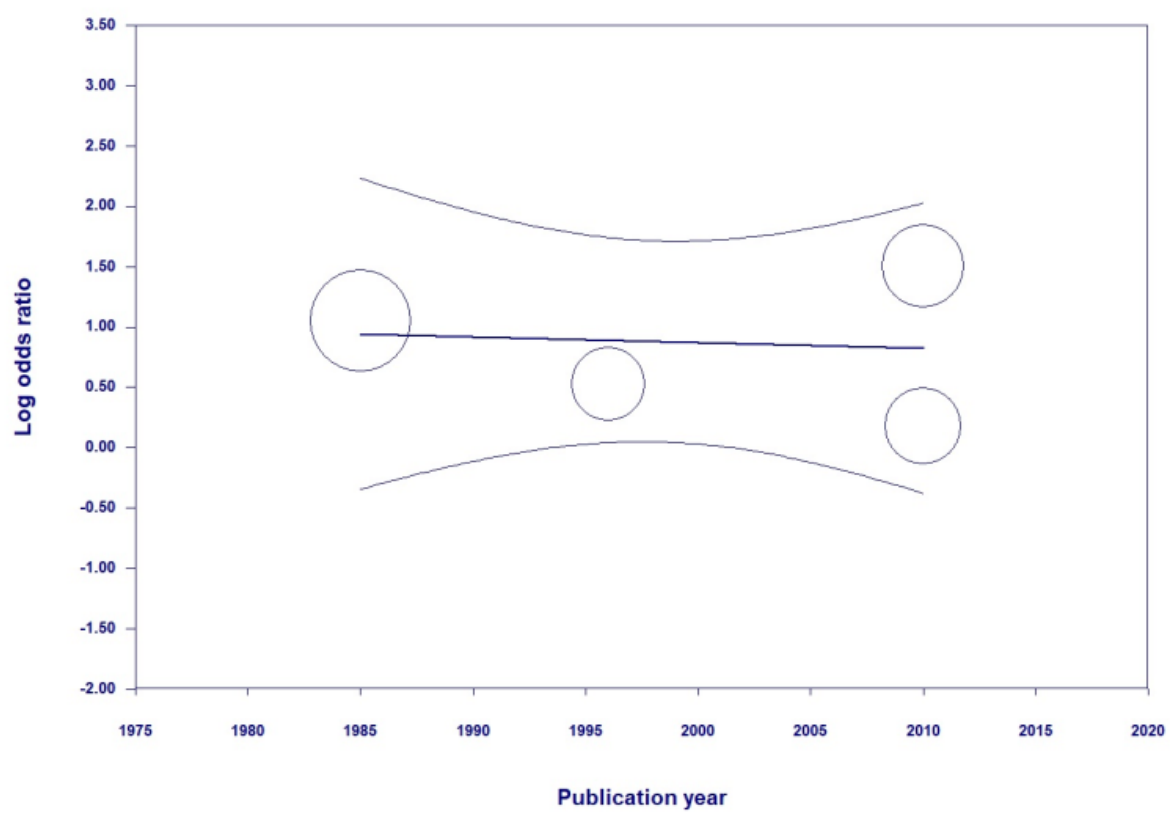

Figure 9. A: Meta-regression of mortality data. B: Meta-regression for rebleeding data. C:

Meta-regression for number of required units for transfusion

On the score based on the Newcastle-Ottawa Scale, articles were assigned between 2 and 6 stars out of a maximum of 6 stars (Table 5).

\begin{tabular}{|c|c|c|c|c|c|c|c|}
\hline ARTICLE & 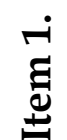 & $\stackrel{\dot{\sim}}{\Xi}$ & $\stackrel{\dot{\theta}}{\ddot{D}}$ & $\underset{\stackrel{+}{ \pm}}{\stackrel{ \pm}{ \pm}}$ & نْ & $\begin{array}{l}\stackrel{\bullet}{\Xi} \\
\stackrel{\Xi}{ \pm}\end{array}$ & 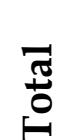 \\
\hline Boyle et al. 1983 & * & * & - & * & * & & $4 *$ \\
\hline Cheung et al. 2010 & * & * & * & * & * & * & $6^{*}$ \\
\hline Hung et al. 2014 & * & * & - & - & - & & $2 *$ \\
\hline Sood et al. 2012 & * & * & - & - & - & & $2 *$ \\
\hline Tsai et al. 1996 & * & * & * & - & * & - & $4^{*}$ \\
\hline Zuckerman et al. 1985 & * & * & - & - & - & * & $3 *$ \\
\hline
\end{tabular}

Table 5. Stars based on the Modified Newcastle-Ottawa Scale 
There was a low risk of bias in representativeness in the study and the control population; it received $100 \%$ (Figure 10 ).

A

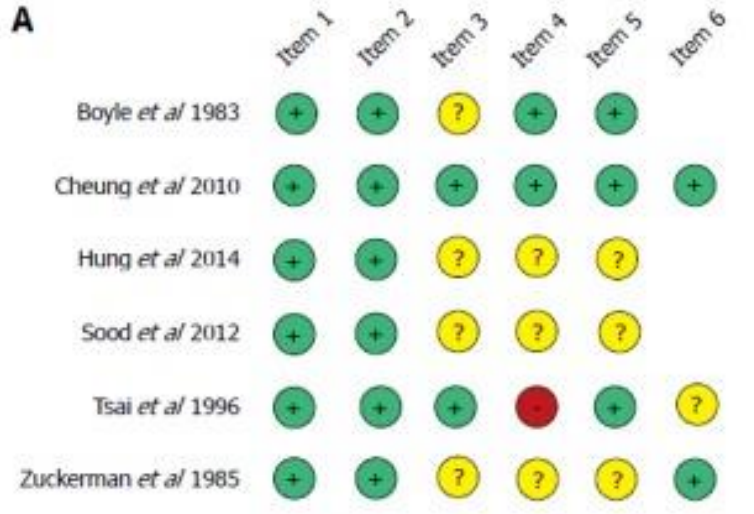

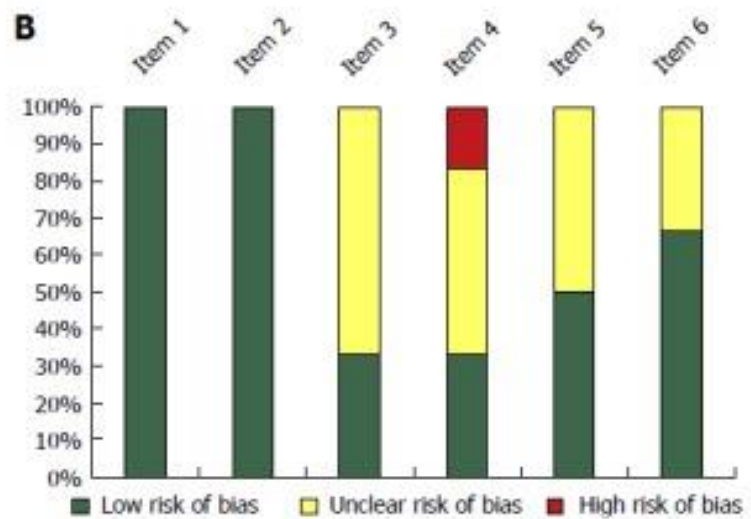

(Figure 10). Risk assessment of articles included in the meta-analysis based on the modified Newcastle-Ottawa Scale (A); Risk of bias assessment graph (B).

With regard to ascertaining exposure, 33\% of the articles represented a low risk of bias, while $66 \%$ had an unclear risk of bias. In these articles CKD and ESRD were not clearly defined, or patients were sorted based on a code system. With regard to a comparison of age, half of the articles contained no clear data on the groups and there was a significant difference in the ages of the ESRD and control groups in Tsai et al [30]. 50\% of the articles reported data on taking ulcerogenic drugs; the other half represented an unclear risk of bias. The follow-up time for rebleeding was analysed in 3 articles; only one did not report this clearly.

\section{II.5 Discussion}

$\mathrm{CKD}$ is a term that covers all degrees of decreased renal function (mild, moderate, and severe chronic kidney disease), where the GFR is lower than $60 \mathrm{~mL} / \mathrm{min}$ for longer than $3 \mathrm{mo}[[35]]$. CKD is a worldwide public health problem, with both incidence and prevalence rising and the main causes being diabetes mellitus and high blood pressure. ESRD patients requiring hemodialysis or peritoneal dialysis 3 times a week represent a high burden and cost for the health care system. As the prevalence of hypertension and diabetes mellitus, the most important etiological factors for CKD and ESRD is increasing worldwide, we predict that GI 
bleeding with CKD will be a growing problem. According to Ohmori et al [27] the number of patients on hemodialysis has tripled between 1990 and 2010. This is the first meta-analysis to report on the severity of complications after GI bleeding in patients with CKD or ESRD and normal renal function groups. Based on a systematic search in 3 databases, we were able to include 6 articles, which contained data on 406035 patients, of whom 51315 had impaired renal function. A higher prevalence of peptic ulcers was reported among ESRD patients undergoing long-term dialysis[39, 40]. The elevated risk for GI bleeding in CKD and ESRD patients is also well known [41]. The most frequent causes of lower GI bleeding in this population have been described; diverticulosis, hemorrhoids, and ischaemic colitis have been identified in addition to angioectasias [42], but no cohort study has been conducted on this topic yet. Although we did not intend to narrow our search to upper GI bleeding, the articles eligible for our inclusion criteria contained data only on patients with upper GI bleeding, and no studies with lower GI bleeding met our inclusion criteria. Only a few of the studies detailed the endoscopic findings and cause of bleeding. Cheung et al [21] included only peptic ulcer bleeding patients, while the study of Hung et al [37] examined only esophageal variceal bleeding. Tsai et al [30] found that erosive gastritis was significantly higher in ESRD group, while Boyle et al [31] saw gastric ulcer as the most common cause of bleeding in the impaired renal function group, but it was not significant compared to controls. Zuckerman et al [38] found significantly more angiodysplasia and erosive esophagitis in the impaired renal function group.

Based on the pooled data, we found that ESRD increases mortality 2.5 times while CKD increases it 1.8 times in GI bleeding compared to the controls with normal renal function, but these ORs are not significantly different. Weng et al [43] reported that ESRD patients admitted with primary upper GI bleeding have a profoundly increased risk of in-hospital mortality. Using a large multi-center database, Sood et al [23] reported that the in-hospital mortality risk is 50\% higher in CKD patients and 3 times greater in ESRD patients. Holden et al [44] reported that the incidence rate of major bleeding episodes in hemodialyzed patients was $2.5 \%$ per person-year and that use of aspirin and/or warfarin increased this risk. Based on the result of the meta-regression the mortality-rate of GI bleeding has improved since the 1980s. It is likely one of the reasons for the heterogeneity of the data. Inhomogen patient groups also result in a significant bias. However, the sensitivity analysis showed that none of the articles influences significantly the pooled OR. 
Cardiovascular disease, current smoking [45] and even hemostasis disorders [46] may play a role in the background of higher risk for GI bleeding in ESRD patients. Unfortunately only a few of the analysed articles detailed the other comorbidities of the GI bleeding patients. In the article of Cheung et al [21], there was no significant difference in the comorbidities between ESRD, CKD and normal renal function group. More people in CKD and ESRD groups suffered from hypertension, diabetes mellitus and platelet abnormalities in the study of Sood et al [23], while the cirrhosis was less common than in controls. Volume replacement and blood transfusion are important parts of the therapy of GI bleeding. This meta-analysis demonstrated that patients with chronic impaired renal function develop 2.5 times more rebleeding episodes and require almost 2 more red blood cell units for transfusion than the control group. Patients with impaired renal function spent more time in the hospital than the control group.

There are several limitations to this study; therefore, the results of this meta-analysis should be regarded with caution. Unfortunately, only a low number of articles was found on this topic, with half of them written in the 1980s and 1990s. In the recent articles, CKD and ESRD groups were separated, but in the earlier publications these groups were mixed, leading to a bias in our analysis, and the definition of GFR was also not mentioned. The diagnosis was based on elevated creatinine level. Hung et al [37] only involved patients with cirrhosis and the mortality rate was monitored up to $6 \mathrm{wk}$, while hospital mortalities were presumably included in the other articles. Publications with rebleeding data did not follow patients for the same time interval, and 1 paper did not report on the follow-up time. The strength of this meta-analysis is the high number of patients.

Our results have demonstrated that patients with ESRD show higher mortality during GI bleeding. CKD patients require more transfusion, and the rebleeding rate is also more elevated than that in patients with normal renal function. Because of these severe conditions, the $\mathrm{LOH}$ is also longer. Patients with ESRD or CKD should be observed more carefully due to the elevated complication rate. In this meta-analysis, we wanted to highlight the importance of this clinical problem and we believe that it needs further scientific research. In order to understand the effect of CKD/ESRD and other comorbidities on the outcomes of GI bleeding in more details, observational trials, and registries on GI bleeding should be developed. 


\section{Disturbance of consciousness and acute pancreatitis}

\section{III.1 Introduction}

\section{III.1.1. Disturbance of consciousness}

Patients hospitalized for AP may have a variety of neurological symptoms, such as confusion, alcohol withdrawal syndrome, and delirium. Disorder of consciousness (DOC) means the development of spatial and/or temporal disorientation, often occurring among hospitalized patients, especially the elderly. The (GCS) is a widespread point system for determining the state of consciousness. (Table 6).

Glasgow Coma Scale

\begin{tabular}{|c|c|c|}
\hline Behavior & Response & Score \\
\hline $\begin{array}{l}\text { Eye opening } \\
\text { response }\end{array}$ & $\begin{array}{l}\text { Spontaneously } \\
\text { To speech } \\
\text { To pain } \\
\text { No response }\end{array}$ & $\begin{array}{l}4 \\
3 \\
2 \\
1\end{array}$ \\
\hline $\begin{array}{l}\text { Best verbal } \\
\text { response }\end{array}$ & $\begin{array}{l}\text { Oriented to time, place, and person } \\
\text { Confused } \\
\text { Inappropriate words } \\
\text { Incomprehensible sounds } \\
\text { No response }\end{array}$ & $\begin{array}{l}5 \\
4 \\
3 \\
2 \\
1\end{array}$ \\
\hline $\begin{array}{l}\text { Best motor } \\
\text { response }\end{array}$ & $\begin{array}{l}\text { Obeys commands } \\
\text { Moves to localized pain } \\
\text { Flexion withdrawal from pain } \\
\text { Abnormal flexion (decorticate) } \\
\text { Abnormal extension (decerebrate) } \\
\text { No response }\end{array}$ & $\begin{array}{l}6 \\
5 \\
4 \\
3 \\
2 \\
1\end{array}$ \\
\hline
\end{tabular}

Table 6. The Glasgow Coma Scale Scoring System. 
Adding the scores of each answer gives the following evaluation results:

- GCS 8 or below

- GCS 9-12

- GCS 13 or higher
- coma (unconscious)

- moderate confusion

- slight confusion

Based on their depth and severity, we can distinguish between confusion, i.e., inability to think clearly, delirium, lethargy, and stupor. The disoriented patient is unable to assess his or her own relationship to the objects and locations around him or her and is not informed in time. Delirium means confused and illogical thinking, the delirious patient is often hallucinatory and disoriented. A patient with lethargy does not respond to external stimuli, even if it is a danger. Stupor is a deeper form of disturbance of consciousness, it can still respond to pain stimuli, but in its more severe form, the patient no longer responds to any external stimuli. Delirium is a nebulous, deeply overwhelmed state of consciousness characterized by severe visual, acoustic, and haptic sensory impairments, memory impairment, incoherent thinking, incoherent speech, intermittent aggression, agitation, dullness, behavioral abnormalities, sleep apnea, and wakefulness [47]. Delirium affects a third of hospitalized patients over 70 years of age. It can be triggered by relatively mild deterioration (constipation, sleep deprivation, exsiccosis, sensory depression, social isolation [48]. Other etiological factors may also induce delirium, such as organic, brain dysfunction, systemic disease (infection, hypoxia), metabolic abnormality or ionic disorder, toxic effect (alcohol, drug, or drug effect). An important subgroup of delirium is delirium tremens, which occurs in chronic ethyl consumers after acute alcohol withdrawal. It is characterized by sudden and severe mental or nervous system changes. Leading signs are altered mental status (global confusion) and sympathetic overdrive (autonomic hyperactivity), which can progress to cardiovascular collapse. It is a medical emergency with a high mortality rate, making early recognition and treatment essential. Alcoholism is a common condition that many clinicians have to contend with. Symptoms of alcohol withdrawal syndrome are caused by the depressant effects of alcohol on the central nervous system. Alcohol simultaneously increases inhibitory tone (by regulating GABA activity) and inhibits excitatory tone (by regulating excitatory amino acids). In the case of chronic alcohol consumption, homeostasis can be maintained only in the presence of alcohol for a longer time. As a result of abandoning chronic alcohol intake, we can see signs of central nervous system overactivity. Depending on 
how much time elapsed after alcohol consumption, different phases of withdrawal can be observed [49] Table 7.

\begin{tabular}{|l|l|l|}
\hline SYNDROME & CLINICAL SYMPTOMS & $\begin{array}{l}\text { STARTING AFTER } \\
\text { ALCOHOL WITHDRAWAL }\end{array}$ \\
\hline SLIGHT WITHDRAWAL & $\begin{array}{l}\text { Tremor, mild restlessness, } \\
\text { headache, sweating, } \\
\text { palpitations, anorexia, } \\
\text { gastrointestinal symptoms, } \\
\text { normal mental status. }\end{array}$ & 6 -36 hours \\
\hline SPASM & $\begin{array}{l}\text { Single or brief tonic-clonic } \\
\text { seizures, short postictal } \\
\text { period, status epilepticus rare. }\end{array}$ & $6-48$ hours \\
\hline ALCOHOLIC & $\begin{array}{l}\text { Visual, auditory and / or } \\
\text { tactile hallucinations with } \\
\text { intact orientation and normal } \\
\text { vital parameters. }\end{array}$ & $12-48$ hours \\
\hline DELIRIUM TREMENS & $\begin{array}{l}\text { Delirium, achycardia, hypertension, } \\
\text { fever, sweating. }\end{array}$ & \\
\hline
\end{tabular}

(Table 7). Phases of alcohol withdrawal.

Risk factors for severe alcohol withdrawal syndrome include previous alcohol withdrawal events, delirium tremens, older age, concomitant surgical or internal medicine disease (trauma, infection, sepsis, liver failure, etc.), elevated blood alcohol levels, time of last drink consumption, previous benzodiazepine use, and male gender itself [50]. Mortality in delirium tremens is $5 \%$ but may be higher in the absence of treatment. Alcohol withdrawal syndrome and delirium tremens are often seen in patients with acute pancreatitis because alcohol is one of the leading etiologists of pancreatitis. Patients, who do not respond adequately to initial sedative doses, require close monitoring, and aggressive or even ICU therapy. 
The few available reports about pancreatic encephalopathy reported different hypotheses about the underlying mechanisms, one even concluded that it is difficult to differentiate it from Wernicke encephalopathy [51].

\section{III.1.2. Clinical features}

The pancreas is an abdominal, retroperitoneal organ that, plays various important and combined physiological roles. The insufficient exocrine or endocrine function can lead to numerous diseases, such as various types of diabetes mellitus, acute or chronic pancreatitis.

Acute pancreatitis (AP) is an inflammatory disease of the pancreas. The main symptoms are abdominal pain and elevated levels of pancreatic enzymes. Acute pancreatitis is one of the most common gastrointestinal diseases requiring urgent hospitalization worldwide, characterized by significant morbidity and mortality. The annual incidence of acute pancreatitis varies from country to country, averaging between 13 and 80 cases per 100,000 population. [52] The incidence is rising worldwide due to increased rates of obesity, alcohol consumption and gallstones. Depending on the severity of the disease mortality is still expected to be $2-5 \%$. Mortality in AP is usually due to multi-organ failure in the first twoweek period. After two weeks it is usually due to sepsis and its complications. The main etiological factors are biliary stones (40-70 \%), alcohol (25-35\%) and hypertriglyceridemia (1-14 \%). Also, several other minor factors may be included for example hypercalcemia, postendoscopic retrograde cholangiopancreatography (ERCP), Genetic risk (PRSS1, CFTR, SPINK1 gene mutation), medications, biliary obstruction, autoimmune pancreatitis, infections and toxins. Besides, the cases are approximately $15-25 \%$ idiopathic. The definition of AP is based on the $2 / 3$ rules. At least two of the following criteria must be present to diagnose AP [53, 54]: (1) clinical feature (upper abdominal pain), (2) laboratory measurement (serum amylase or lipase $>3 x$ upper limit of normal) (3) imaging (CT, MRI, ultrasonography) alterations such as edema or intraabdominal fluid. 


\section{III.1.3. Severity}

The Revised Atlanta Classification (2012) divides acute pancreatitis into two main categories

-Interstitial edematous acute pancreatitis, which is characterized by acute inflammation of the pancreatic parenchyma and peripancreatic tissues, but without recognizable tissue necrosis

-Necrotizing acute pancreatitis, which is characterized by inflammation associated with pancreatic parenchymal necrosis and/or peripancreatic necrosis

Based on the severity, acute pancreatitis is divided into three groups:

-Mild acute pancreatitis which is characterized by the absence of organ failure and local or systemic complications

-Moderately severe acute pancreatitis which is characterized by transient organ failure (resolves within 48 hours) and/or local or systemic complications without persistent organ failure ( $>48$ hours)

-Severe acute pancreatitis which is characterized by persistent organ failure that may involve one or multiple organs

The prognosis of the severe form is poor; it evolves in $8.8 \%$ in AP, and the mortality may reach $28 \%$ in the severe cases [55]. In the case of moderate AP, organ failure develops and resolves within $48 \mathrm{~h}$, while in severe forms, it persists longer [56] Local complications of acute pancreatitis include acute peripancreatic fluid collection, pancreatic pseudocyst, acute necrotic collection, and walled-off necrosis. Organ failure is defined if two or more for any of three organ systems (respiratory, cardiovascular, or renal) is affected using the modified Marshall scoring system. A score of 2 or more over a period of more than 48 hours for any one of the three organ systems is defined as persistent organ failure while if it is present for less than 48 hours, is known as transient organ failure. Level of severity should be assessed during the disease process and hospital stay using this scoring system. Early and persistent organ failure is a strong indicator of increased mortality, and length of hospitalization. Persistent organ failure is widely accepted as a reliable criterion for severe AP [57]. Blood urea nitrogen is a predictive factor of persistent organ failure after $48 \mathrm{~h}$. There is no predictor 
of persistent organ failure that can be justifiably used in clinical practice within $48 \mathrm{~h}$ of admission [58].

\section{III.1.4. Therapy and Risk assessment}

Acute pancreatitis has no special therapy. We do not have special drugs that stop the inflammation. Therapy is mainly symptomatic and supportive. As a result of an adequate fluid treatment started in time, the formation of severe pancreatitis is less likely. In addition, supportive therapy includes adequate nutrition, analgesia, and, if necessary, antibiotic or interventional (endoscopic, radiological, surgical) therapy.

The ability to predict AP severity can help identify patients at increased risk for morbidity and mortality, thereby assisting in appropriate early triage to intensive care units and selection of patients for specific interventions. Multiple predictive models have been developed to predict the severity of AP based upon clinical, laboratory, and radiologic risk factors, various severity grading systems, and serum markers. Some of these can be performed on admission in the emergency room, while others can only be obtained after the first 48 to 72 hours. However, these predictive models have low specificity (ie, high false-positive rates), which, when coupled with the low prevalence of severe AP (15 to 25 percent), results in low positive predictive values. The most commonly used risk estimation point systems in the clinic are the APACHE II- and BISAP score. Both of these scoring systems include impaired mental status, the APACHE II score contains the GCS, while in the BISAP score the impaired mental status is present, but these systems evaluates it only on admission. 


\begin{tabular}{|c|c|c|c|c|c|c|c|c|c|}
\hline & +4 & +3 & +2 & +1 & 0 & +1 & +2 & +3 & +4 \\
\hline $\begin{array}{l}\text { Rectal temperature } \\
\text { ( } \mathrm{C})\end{array}$ & $\geq 41$ & $39-40.9$ & & $38-38.9$ & $36-38.4$ & $34-35.9$ & $32-33.9$ & $30-31.9$ & $\leq 29.9$ \\
\hline MAP $(\mathrm{mmHg})$ & $\geq 160$ & $130-159$ & $110-129$ & & $70-109$ & & $50-69$ & & $\leq 49$ \\
\hline Heart rate (/min) & $\geq 180$ & $140-179$ & $110-139$ & & $70-109$ & & $55-69$ & $40-54$ & $\leq 40$ \\
\hline $\begin{array}{l}\text { Respiratory rate } \\
\text { (/min) }\end{array}$ & $\geq 50$ & $35-49$ & & $25-34$ & $12-24$ & $10-11$ & $6-9$ & & $\leq 5$ \\
\hline \multicolumn{10}{|c|}{ If $\mathrm{FiO}_{2} \geq 50 \%$, check A-a gradient; if $\mathrm{FiO}_{2}<50 \%, \mathrm{PaO}_{2}$} \\
\hline A-a gradient & $\geq 500$ & $350-499$ & $200-349$ & & $<200$ & & & & \\
\hline $\mathrm{PaO}_{2}(\mathrm{mmHg})$ & & & & & $>70$ & $61-70$ & & $55-60$ & $<55$ \\
\hline Arterial pH & $\geq 7.7$ & $7.6-7.69$ & & $7.5-7.59$ & $7.3-7.49$ & & $7.25-7.3$ & $7.15-7.2$ & $<7.15$ \\
\hline $\mathrm{Na}(\mathrm{mM})$ & $\geq 180$ & $160-179$ & $155-159$ & $150-154$ & $130-149$ & & $120-129$ & $111-19$ & $\leq 110$ \\
\hline $\mathrm{K}(\mathrm{mM})$ & $\geq 7$ & $6-6.9$ & & $5-5.9$ & $3.5-4.9$ & $3-3.4$ & $2.5-2.9$ & & $<2.5$ \\
\hline Creatinine(mg/L) & $\geq 35$ & $20-34$ & $15-19$ & & $6.0-14$ & & $<6.0$ & & \\
\hline Hematocrit (\%) & $\geq 60$ & & $50-59.9$ & $46-49.9$ & $30-45.9$ & & $20-29.9$ & & $<20$ \\
\hline WBC count $\left(10^{9} / \mathrm{L}\right)$ & $\geq 40$ & & $20-39.9$ & $15-19.9$ & $3-14.9$ & & $1-2.9$ & & $<1$ \\
\hline \multicolumn{10}{|c|}{ Glasgow coma score (GCS): $0-12$ points $=15-$ GCS } \\
\hline Age (y) & \multicolumn{9}{|l|}{ Points } \\
\hline$<44$ & \multicolumn{2}{|l|}{0} & \multicolumn{5}{|c|}{ Chronic health (history of chronic conditions) ${ }^{a}$} & \multicolumn{2}{|l|}{ Points } \\
\hline $45-54$ & \multicolumn{2}{|l|}{2} & \multicolumn{5}{|l|}{ None } & \multicolumn{2}{|l|}{0} \\
\hline $55-64$ & \multicolumn{2}{|l|}{3} & \multicolumn{5}{|c|}{ If patient is admitted after elective surgery } & \multicolumn{2}{|l|}{2} \\
\hline $65-74$ & \multicolumn{2}{|l|}{5} & \multicolumn{5}{|c|}{$\begin{array}{l}\text { If patient is admitted after emergency surgery or for } \\
\text { reason other than after elective surgery }\end{array}$} & \multicolumn{2}{|l|}{5} \\
\hline$>75$ & \multicolumn{2}{|l|}{6} & & & & & & & \\
\hline
\end{tabular}

Table 8. APACHE II scooring system[59]

\begin{tabular}{|lll|}
\hline Parameters & Score 0 & Score 1 \\
\hline Blood urea nitrogen & $<25 \mathrm{mg} / \mathrm{dl}$ & $>25 \mathrm{mg} / \mathrm{dl}$ \\
\hline Impaired mental status & Absent & Present \\
\hline SIRS & Absent & Present \\
\hline Age & $<60$ years & $>60$ years \\
\hline Pleural effusion & Absent & Present \\
\hline
\end{tabular}

Table 9. The BISAP scooring system [60]

There are several risk factors worsening severity and mortality, but there is little knowledge of the factors that affect the outcome of the disease [5-9]. Until now, no study focused on the influencing role of DOC on the outcome of AP. We aimed to determine its effect by a cohort analysis. 


\section{III.2. Hypotheses, objectives}

Based on literature data, AP has several aggravating factors that worsen survival parameters. Of these factors predisposing to a negative outcome, we targeted disturbances of consciousness in our research because the literature in this area is incomplete.

Hypothesis 1.)

In case of development of disturbance of consciousness during hospitalization, the course of pancreatitis will be more severe, and LOH longer.

Hypothesis 2.)

The development of disturbance of consciousness is associated with more severe AP, thereby increasing the mortality of the underlying disease.

To verify our assumptions, we performed an analysis of HPSG prospective register data.

\section{III.3 Methods}

The Hungarian Pancreatic Study Group (HPSG) established a prospective international registry containing AP patients' data. All participants signed the written consent form. The study was approved by the Scientific and Research Ethics Committee of the Medical Research Council (22254-1/2012/EKU). For this HPSG cohort study data of 1220 patients were used, since they contained data about the level of consciousness during hospitalization. This cohort overlaps with the cohorts discussed in our previous articles [53, 55, 61], but data and results of the analysis on DOC are only published in this report. Data were collected between January 2013 and January 2017. Based on the presence of DOC, patients were sorted into DOC and Non-DOC groups. The DOC group was further divided into alcohol-related DOC (ALC DOC) and non-alcohol-related DOC (Non-ALC DOC). Definition and data collection DOC was diagnosed if the patient had confusion, disorientation, memory deficit, hyper- or hypoactivity, or symptoms of alcohol withdrawal such as anxiety, shaky hands, headache, insomnia or sweating, or epileptic seizure; or signs of delirium. The information of DOC was collected from the prospectively collected database of the HPSG registry and the patients' documentation, answering a post hoc defined research question. In severe cases, the documentation also included psychiatric consultation. Table 12. contains the data of DOC of the 47 analyzed patients: time of onset, number of episodes, duration of DOC, description of 
symptoms, and applied therapy. Descriptive statistical tools were used to characterize our cohort. To examine differences between the groups, in case of age, we used an independent sample t-test, whereas the length of hospitalization ( $\mathrm{LOH}$ ) with the Mann-Whitney test were analyzed. To analyze the connection between severity, mortality, and DOC, and between the time of onset of DOC and severity, the Chi-squared test or Fisher exact test was performed. All statistical analyses were done using SPSS Ver. 24 Software (IBM Corporation Armonk, New York). The significance level was set at 0.05 .

\section{III.4. Results}

\section{III.4.1 General characteristics of the entire cohort}

A total of 1220 cases from 20 centers were analyzed. The list of centers is shown in Table 10.

\begin{tabular}{|c|c|c|c|}
\hline COUNTRY & TOWN & INSTITUTION & NO \\
\hline \multirow[t]{19}{*}{ Hungary } & Pécs & First Department of internal Medicine, University of Pécs & 362 \\
\hline & Szeged & First Department of Medicine, University of Szeged & 200 \\
\hline & & II. Hospital Szeged & 47 \\
\hline & & Second Department of Medicine, University of Szeged & 36 \\
\hline & & Emergency Unit, University of Szeged & 10 \\
\hline & & Department of Surgery, University of Szeged & 4 \\
\hline & Székesfehérvár & Szent György University Teaching Hospital of County Fejör & 199 \\
\hline & Budapest & Bajcsy-Zsilinszky Hospital & 137 \\
\hline & & Buda Hospital of the Hospitaller Order of Saint John of God & 4 \\
\hline & & Heim Pall Children's Hospital, Budapest, Hungary & 1 \\
\hline & Debrecen & Department of Internal Medicine & 76 \\
\hline & & Institute of Surgery, University of Debrecen & 7 \\
\hline & Békéscsaba & Dr. Réthy Pál Hospital & 54 \\
\hline & Gyula & Pándy Kálmán Hospital of County Békés & 26 \\
\hline & Miskolc & $\begin{array}{l}\text { Borsod-Abać-Zemplén County Hospital and University Teaching } \\
\text { Hospital }\end{array}$ & 14 \\
\hline & Kecskemét & Bács-Kiskun County University Teaching Hospital & 11 \\
\hline & Makó & Healtcare Center of County Csongrad & 10 \\
\hline & Szentes & Dr. Bugyi István Hospital & 10 \\
\hline & Szombathely & Markusovszky University Teaching Hospital & 8 \\
\hline Romania & Targu Mures & $\begin{array}{l}\text { Mures County Emergency Hospital } \\
\text { Total number of patients }\end{array}$ & 1220 \\
\hline
\end{tabular}

Table 10. Distribution of patients by centers

Data were complete for age, gender, etiology of pancreatitis, $\mathrm{LOH}$, the severity of acute pancreatitis, and mortality. Our registry included data about alcohol consumption in $99.6 \%$ (Table 11). 
Epidemiology, etiology, outcome

Age

Gender

Etiology

Alcohol consumption

Length of hospitalization

Severity of AP

Mortality

Average uploaded data
OVERALL UPLOADED DATA

1220

1220

1220

1216

1220

1220

1220
$\%$

100

100

100

99.6

100

100

100

99.9

Table 11. Data upload rate and accuracy

Quality characteristics of the Hungarian Pancreatic Study Group registry for the 1220 patients with acute pancreatitis.

The basic characteristics of the analyzed population are shown in Fig. 11. More than half of our patients were male (n: 683), and 46\% were female (n: 537). The most common etiological factor was biliary pancreatitis (38.4\%, n: 469), followed by idiopathic (19.2\%, n: 234), and alcohol-induced pancreatitis (15.2\%, n: 186). In the case of acute alcoholic pancreatitis, male dominance can be seen (male 87\%, n: 162; female 13\%, n: 24). In some cases, we found combined etiology (11.9\%). In our study, $67.5 \%$ of the cases were mild. Moderate pancreatitis was observed in $26.7 \%$ of cases and severe inflammation in $5.8 \%$ of the cases. The LOH was almost three times more (23.5 days \pm 2.5$)$ in case of severe acute pancreatitis than in mild ones (8.6 days \pm 0.17 ). In moderate cases, the average $\mathrm{LOH}$ was $18 \pm 0.7$ days. The total mortality rate was $2.4 \%$. In severe cases, the mortality reached $29.9 \%$, in mild cases, $0.2 \%$ only, and in moderate cases, $2.2 \%$. (Fig. 11A-F). 


\section{A Gender distribution}

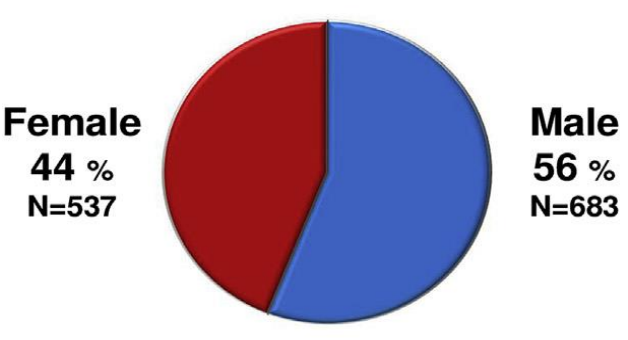

C LOH (days)

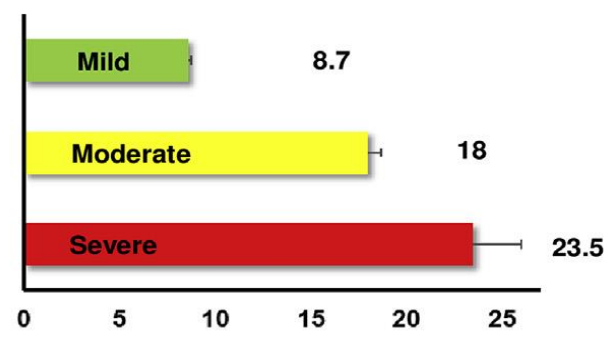

\section{$\mathbf{E}$}

\section{Etiology}

\begin{tabular}{|c|c|}
\hline biliary & 469 \\
\hline alcoholic & 186 \\
\hline hyperlipidaemia & 44 \\
\hline drug induced & 4 \\
\hline anatomic malformation & 1 \\
\hline postERCP & 34 \\
\hline idiopathic & 234 \\
\hline infection & 2 \\
\hline combined & 145 \\
\hline others & 96 \\
\hline
\end{tabular}
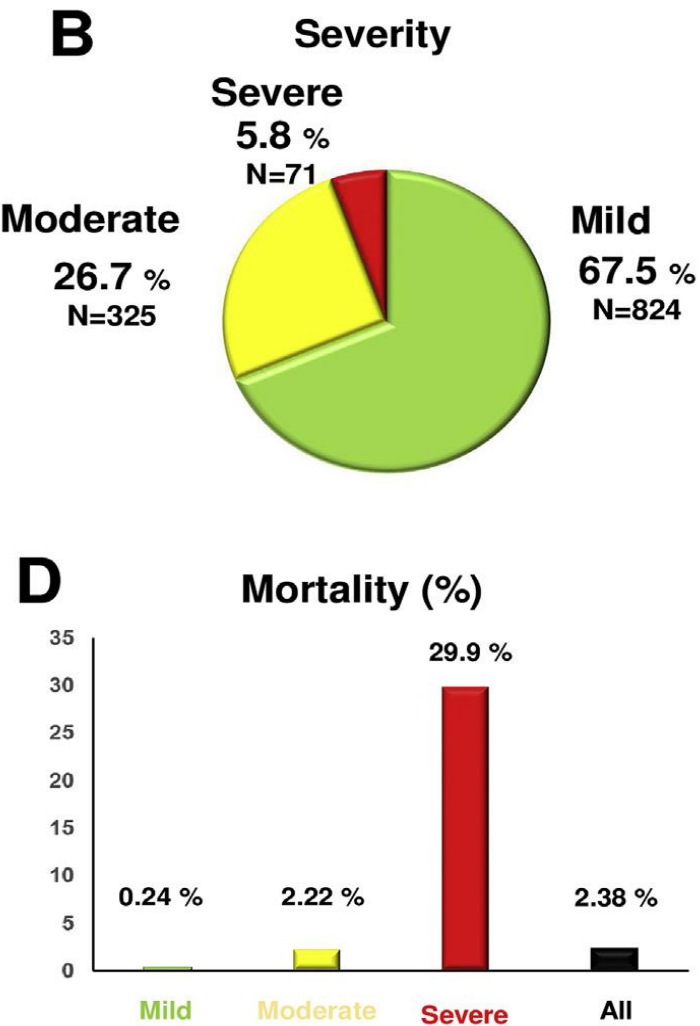

\section{F Age distribution}

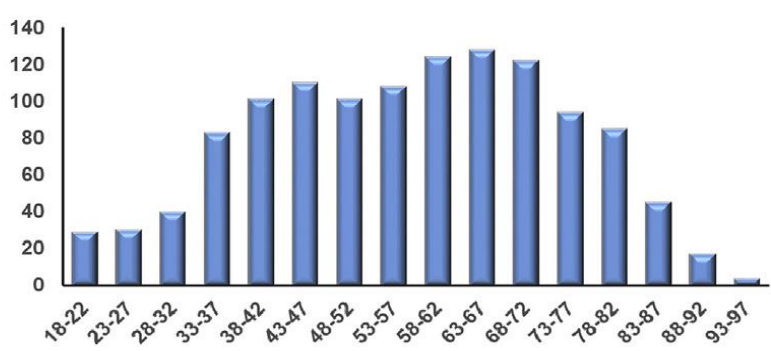

Fig. 11. A. Overall gender distribution. 11.B. Distribution based on severity. 11.C. The average length of hospitalization in days. 11.D. Overall mortality and mortality based on severity classes. 11.E. Distribution based on the etiology of acute pancreatitis. 11.F. Age distribution of the population.

\section{III.4.2 Demographic characteristics in DOC vs. Non-DOC groups}

From the 1220 patients of the HPSG registry, 47 patients (3.9\%) developed DOC (Fig. 12A). Based on the type of DOC, delirium (n: 18), confusion (n: 16), alcohol withdrawal syndrome (n: 9), and convulsion (n: 3) groups were identified. According to the etiology of DOC, in our cohort, alcohol (n: 23), older age (n: 9), and sepsis (n: 6) caused the most cases of DOC. 
However, ischemia (n: 3) hypoglycemia (n: 1) and electrolyte imbalance (n: 1) also caused DOC. In addition, 4 cases were idiopathic (Fig. 12C).

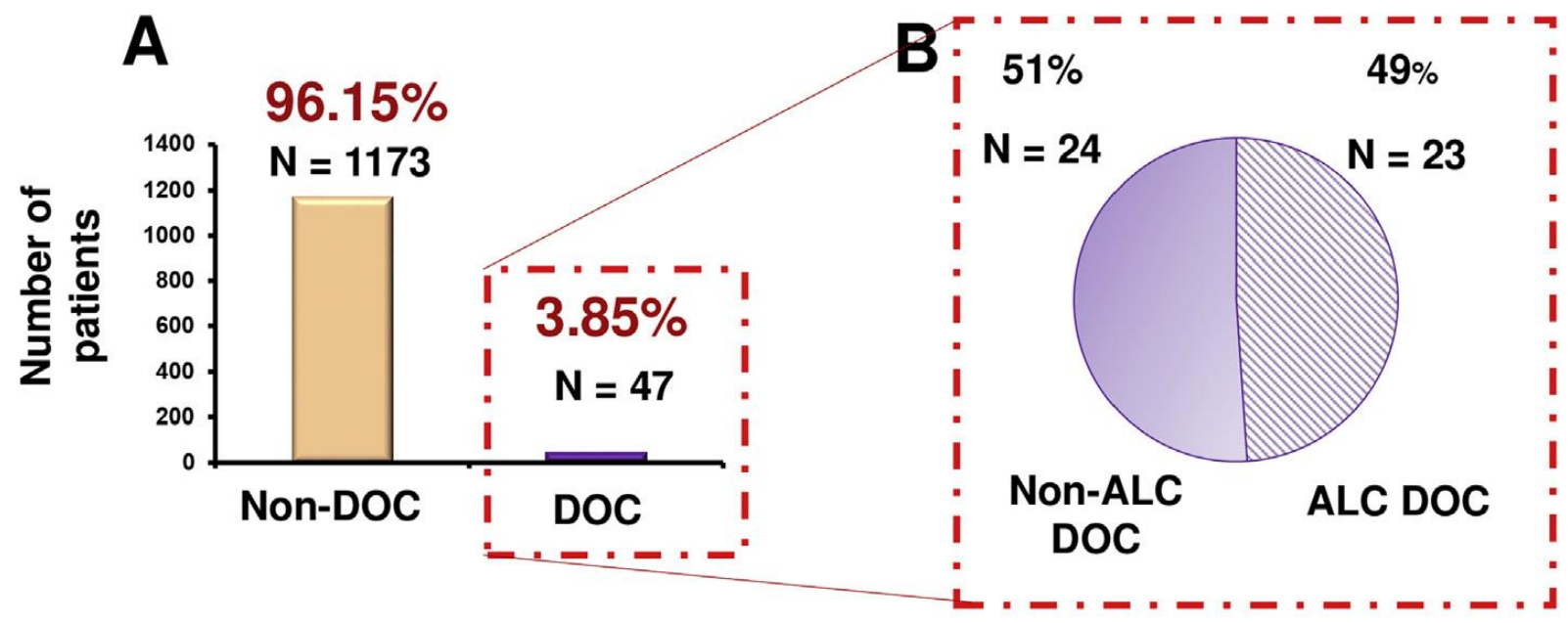

C

Type of DOC

\begin{tabular}{|l|r|}
\hline confusion & 16 \\
\hline delirium & 19 \\
\hline alcohol withdrawal & 9 \\
\hline convulsion & 3 \\
\hline
\end{tabular}

\section{Etiology}

\begin{tabular}{l|r|}
\hline alcohol & 23 \\
\hline sepsis & 6 \\
\hline dementia & 9 \\
\hline ischemia & 3 \\
\hline idiopathic & 4 \\
\hline hypoglycaemia & 1 \\
\hline Impairment of salt and water balance & 1 \\
\hline
\end{tabular}

Alcohol-related: 23

\begin{tabular}{l|r|}
\hline confusion & 1 \\
\hline delirium & 12 \\
\hline alcohol withdrawal & 9 \\
\hline convulsion & 1 \\
\hline
\end{tabular}

Non-alcohol related: 24

\begin{tabular}{|l|r|}
\hline confusion & 15 \\
\hline delirium & 7 \\
\hline alcohol withdrawal & 0 \\
\hline convulsion & 2 \\
\hline
\end{tabular}

Fig. 12. A Distribution of disturbance of consciousness (DOC) of patients with acute pancreatitis (n). 12.B Distribution of alcohol-related DOC (ALC DOC) and non-alcoholrelated DOC (Non-ALC DOC) (n). 12.C Distribution of DOC based on type and etiology (n).

The male ratio was $55.4 \%$ (n: 650) in the Non-DOC group, while $70.2 \%$ (n: 33 ) in the DOC group. The presence of DOC showed a higher incidence in men than in women $(70.2 \%$ vs. $29.8 \%$, n: 33 vs. n: 14 , p: 0.045) (Fig. 13A). The age differed significantly between the groups; in the DOC group, the subjects were older (62.2 \pm 18.7 vs. $56.5 \pm 17$ years, p: 0.025$)$ (Fig. 13C). 

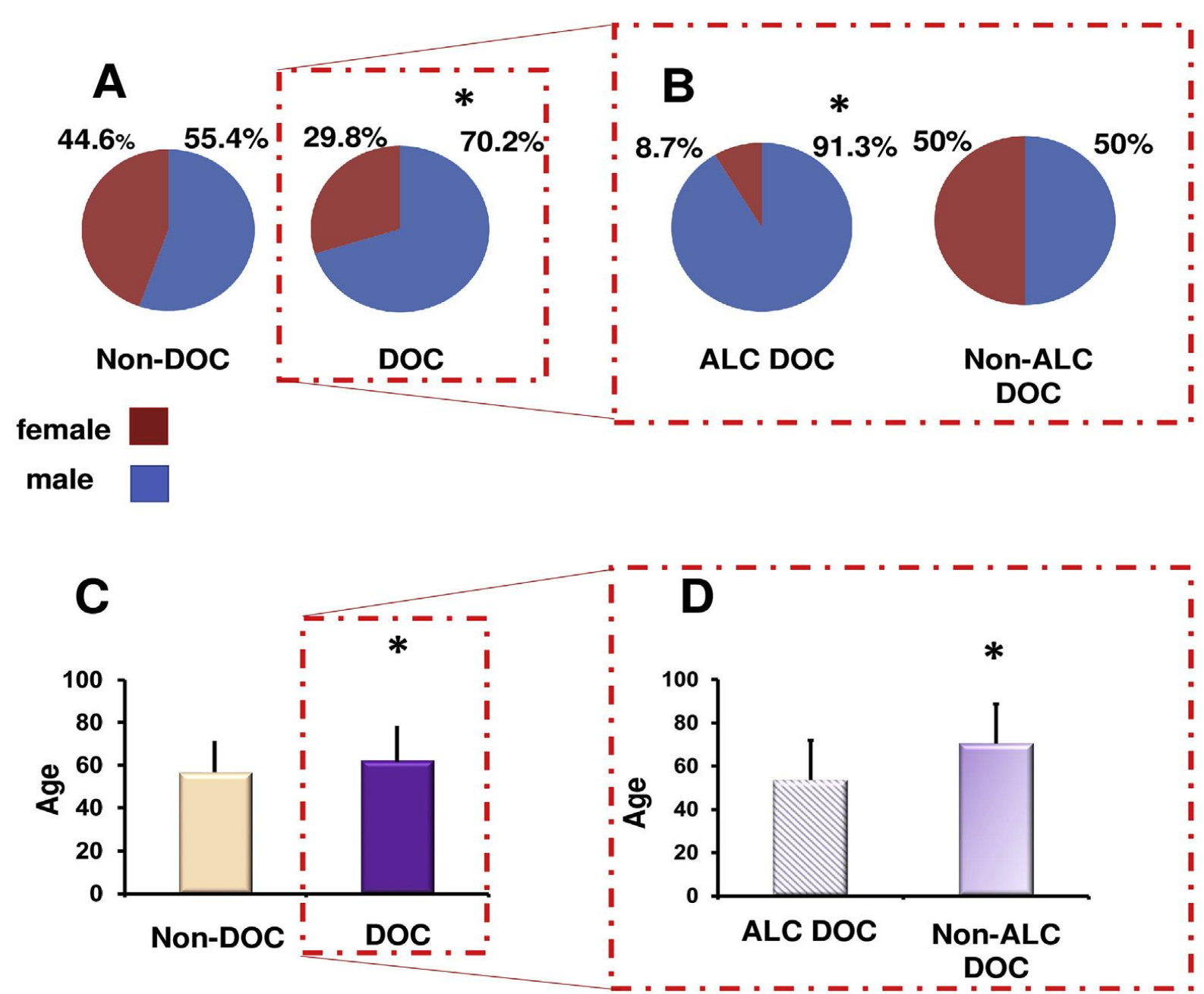

Fig. 13.A. Sex distribution of disturbance of consciousness (DOC) and Non-DOC groups (Compared with Chi-squared test). Fig. 13.B Sex distribution of alcohol-related DOC (ALC DOC) and non-alcohol-related (Non-ALC DOC) groups (Compared with Fisher-test). 13.C Age distribution of DOC and Non-DOC groups (Compared with independent sample t-test). 13.D. Age distribution of ALC DOC and Non-ALC DOC groups (Compared with independent sample t-test).

Table 12. shows the data of the 47 cases with DOC. From the nine severe AP, in 3 cases were two episodes seen, from the 13 moderate in 1 case could be two episodes detected, while in the 25 mild cases, no one had two episodes. Regarding the time of onset, an analysis with the Fisher test was performed, which showed no significant difference (p: 0.321 ) as to whether DOC started on the first day or other days of hospital stay. 


\begin{tabular}{|c|c|c|c|c|c|c|c|c|c|}
\hline $\begin{array}{c}\text { Number } \\
\text { of } \\
\text { patients }\end{array}$ & Age & Gender & Type of DOC & $\begin{array}{c}\text { Etiology of } \\
\text { DOC }\end{array}$ & $\begin{array}{c}\text { Time of } \\
\text { onset }\end{array}$ & $\begin{array}{c}\text { Number } \\
\text { of } \\
\text { episodes }\end{array}$ & Duration & $\begin{array}{l}\text { Description of } \\
\text { symptoms }\end{array}$ & Applied therapy \\
\hline 1 & 45 & male & delirium & alcohol & N.A. & 1 & N.A. & delirium tremens & $\begin{array}{c}\text { chlorpromazine, } \\
\text { clonazepam }\end{array}$ \\
\hline 2 & 63 & male & $\begin{array}{c}\text { alcohol } \\
\text { withdrawal }\end{array}$ & alcohol & 1st day & 1 & 2 days & $\begin{array}{c}\text { agression, } \\
\text { hyperactivity }\end{array}$ & clonazepam \\
\hline 3 & 67 & male & $\begin{array}{c}\text { alcohol } \\
\text { withdrawal }\end{array}$ & alcohol & N.A. & 1 & N.A. & delirium tremens & N.A. \\
\hline 4 & 80 & male & confusion & ischemia & 1 st day & 1 & 2 weeks & confusion & N.A. \\
\hline 5 & 59 & male & $\begin{array}{c}\text { alcohol } \\
\text { withdrawal }\end{array}$ & alcohol & 1 st day & 1 & N.A. & delirium tremens & $\begin{array}{l}\text { clonazepam, } \\
\text { tiapride }\end{array}$ \\
\hline 6 & 36 & male & delirium & alcohol & N.A. & 1 & N.A. & delirium tremens & N.A. \\
\hline 7 & 84 & male & delirium & alcohol & N.A. & 1 & N.A. & delirium tremens & N.A. \\
\hline 8 & 66 & male & delirium & idiopathic & 1 st day & 2 & N.A. & delirium tremens & $\begin{array}{l}\text { propofol, } \\
\text { clonazepam }\end{array}$ \\
\hline 9 & 79 & female & confusion & dementia & 1 st day & 1 & 4 days & confusion & $\begin{array}{l}\text { clonazepam, } \\
\text { tiapride }\end{array}$ \\
\hline 10 & 65 & male & delirium & alcohol & N.A. & 2 & N.A. & delirium tremens & $\begin{array}{c}\text { clonazepam, } \\
\text { haloperidol, } \\
\text { dexmedetomidin, } \\
\text { clonazepam, } \\
\text { tiapride }\end{array}$ \\
\hline 11 & 87 & female & confusion & idiopathic & 7th day & 1 & N.A. & confusion & quetiapine \\
\hline 12 & 50 & male & delirium & alcohol & 1 st day & 1 & 1 days & delirium tremens & clonazepam \\
\hline 13 & 47 & male & delirium & alcohol & 1st day & 1 & N.A. & delirium tremens & N.A. \\
\hline 14 & 89 & male & delirium & dementia & 4th day & 1 & 1 days & confusion & quetiapine \\
\hline 15 & 57 & male & $\begin{array}{c}\text { alcohol } \\
\text { withdrawal }\end{array}$ & alcohol & 1st day & 1 & N.A. & $\begin{array}{c}\text { alcohol } \\
\text { withdrawal }\end{array}$ & clonazepam \\
\hline 16 & 86 & male & confusion & dementia & 1 st day & 1 & N.A. & confusion & tiapride \\
\hline 17 & 40 & male & delirium & sepsis & 1 st day & 1 & N.A. & delirium & none \\
\hline 18 & 43 & male & delirium & alcohol & 1 st day & 1 & 3 days & delirium tremens & chlordiazepoxide \\
\hline 19 & 24 & male & convulsion & idiopathic & N.A. & 1 & N.A. & convulsion & none \\
\hline 20 & 74 & male & confusion & alcohol & 1st day & 1 & 4 days & confusion & risperdal \\
\hline 21 & 74 & male & delirium & alcohol & 8th day & 1 & 3 days & delirium tremens & $\begin{array}{l}\text { clonazepam, } \\
\text { haloperidol }\end{array}$ \\
\hline 22 & 58 & female & confusion & $\begin{array}{l}\text { electrolyte } \\
\text { imbalance }\end{array}$ & 2 months & 1 & N.A. & hallucination & $\begin{array}{l}\text { tiapride, } \\
\text { alprazolam }\end{array}$ \\
\hline 23 & 70 & male & $\begin{array}{c}\text { alcohol } \\
\text { withdrawal }\end{array}$ & alcohol & 4th day & 1 & 3 day & $\begin{array}{c}\text { alcohol } \\
\text { withdrawal }\end{array}$ & $\begin{array}{l}\text { tiapride, } \\
\text { clonazepam }\end{array}$ \\
\hline 24 & 83 & female & confusion & dementia & N.A. & 1 & 2 weeks & $\begin{array}{l}\text { hyperactivity, } \\
\text { confusion }\end{array}$ & $\begin{array}{l}\text { tiapride, } \\
\text { haloperidol }\end{array}$ \\
\hline 25 & 43 & female & convulsion & alcohol & 3rd day & 1 & minutes & convulsion & carbamazepine \\
\hline 26 & 92 & male & confusion & ischemia & N.A. & 1 & N.A. & confusion & vinpocetine \\
\hline 27 & 90 & female & confusion & hypoglycemia & 1 st day & 1 & N.A. & somnolence & glucose \\
\hline 28 & 74 & female & confusion & idiopathic & 5th day & 1 & N.A. & confusion & N.A. \\
\hline 29 & 68 & male & delirium & sepsis & 1 st day & 1 & 3 weeks & delirium tremens & venlafaxine \\
\hline
\end{tabular}




\begin{tabular}{|c|c|c|c|c|c|c|c|c|c|}
\hline $\begin{array}{c}\text { Number } \\
\text { of } \\
\text { patient }\end{array}$ & Age & Gender & Type of DOC & $\begin{array}{c}\text { Etilogy of } \\
\text { DOC }\end{array}$ & $\begin{array}{c}\text { Time of } \\
\text { onset }\end{array}$ & \begin{tabular}{|c|} 
Number \\
of \\
episodes
\end{tabular} & Duration & $\begin{array}{l}\text { Description of } \\
\text { symptoms }\end{array}$ & Applied therapy \\
\hline 30 & 60 & male & delirium & alcohol & 1st day & 1 & N.A. & $\begin{array}{c}\text { alcohol } \\
\text { withdrawal } \\
\end{array}$ & tiapride \\
\hline 31 & 44 & male & delirium & alcohol & N.A. & 1 & N.A. & $\begin{array}{c}\text { alcohol } \\
\text { withdrawal }\end{array}$ & $\begin{array}{l}\text { clonazepam, } \\
\text { tiapride }\end{array}$ \\
\hline 32 & 54 & male & $\begin{array}{c}\text { alcohol } \\
\text { withdrawal }\end{array}$ & alcohol & N.A. & 1 & N.A. & $\begin{array}{c}\text { alcohol } \\
\text { withdrawal }\end{array}$ & N.A. \\
\hline 33 & 61 & male & $\begin{array}{c}\text { alcohol } \\
\text { withdrawal }\end{array}$ & alcohol & N.A. & 1 & N.A. & $\begin{array}{c}\text { alcohol } \\
\text { withdrawal }\end{array}$ & clonazepam \\
\hline 34 & 83 & male & confusion & dementia & N.A. & 1 & N.A. & confusion & tiapride \\
\hline 35 & 43 & male & delirium & sepsis & 1st day & 2 & N.A. & $\begin{array}{c}\text { delirium } \\
\text { tremens, } \\
\text { hallucination }\end{array}$ & $\begin{array}{c}\text { dexmedetomidine, } \\
\text { propofol, } \\
\text { midazolam, } \\
\text { risperidone }\end{array}$ \\
\hline 36 & 37 & male & $\begin{array}{c}\text { alcohol } \\
\text { withdrawal }\end{array}$ & alcohol & 1st day & 1 & N.A. & $\begin{array}{c}\text { alcohol } \\
\text { withdrawal } \\
\text { syndrome }\end{array}$ & $\begin{array}{c}\text { clonazepam, } \\
\text { sertraline, tiapride }\end{array}$ \\
\hline 37 & 83 & female & confusion & dementia & 6th day & 1 & 2 days & confusion & tiapride \\
\hline 38 & 72 & male & confusion & dementia & 10th day & 1 & N.A. & confusion & N.A. \\
\hline 39 & 35 & male & delirium & alcohol & N.A. & 1 & N.A. & delirium tremens & $\begin{array}{c}\text { propofol, } \\
\text { midazolam, } \\
\text { clonazepam, } \\
\text { risperidone, } \\
\text { haloperidol }\end{array}$ \\
\hline 40 & 48 & female & delirium & sepsis & $\begin{array}{c}\text { N.A.; } \\
\text { 25th day }\end{array}$ & 2 & N.A. & agitatio, delirium & aplrazolam \\
\hline 41 & 47 & male & delirium & sepsis & 1st day & 1 & N.A. & delirium tremens & N.A. \\
\hline 42 & 33 & male & delirium & alcohol & 3rd day & 1 & 10 days & $\begin{array}{c}\text { delirium } \\
\text { tremens, } \\
\text { hyperactivity, } \\
\text { agitation }\end{array}$ & $\begin{array}{c}\text { tiapride } \\
\text { chlordiazepoxide }\end{array}$ \\
\hline 43 & 30 & female & $\begin{array}{c}\text { alcohol } \\
\text { withdrawal }\end{array}$ & alcohol & 1st day & 1 & N.A. & $\begin{array}{c}\text { alcohol } \\
\text { withdrawal } \\
\text { syndrome }\end{array}$ & $\begin{array}{c}\text { chlordiazepoxide, } \\
\text { clomethiazole }\end{array}$ \\
\hline 44 & 81 & female & confusion & dementia & 2nd day & 1 & N.A. & confusion & none \\
\hline 45 & 75 & female & confusion & dementia & 3rd day & 1 & N.A. & confusion & $\begin{array}{c}\text { tiapride } \\
\text { clonazepam }\end{array}$ \\
\hline 46 & 62 & female & confusion & sepsis & N.A. & 1 & N.A. & confusion & N.A. \\
\hline 47 & 82 & female & convulsion & ischemia & $\begin{array}{c}\text { on } \\
\text { admission }\end{array}$ & 1 & N.A. & convulsion & $\begin{array}{l}\text { vinpocetine } \\
\text { piracetam }\end{array}$ \\
\hline
\end{tabular}

Table 12. Data of disturbance of consciousness (DOC) of the 47 analyzed patients: time of onset, number of episodes, duration of DOC, description of symptoms, and applied therapy 


\section{III.4.3. Demographic characteristics in ALC DOC vs. Non-ALC DOC groups}

From the registered 47 patients with DOC, 23 (48.9\%) cases were ALC DOC, whereas 24 $(51.1 \%)$ cases were Non-ALC DOC (Fig. 12B). In the ALC DOC group, the delirium was present more often than in the Non-ALC DOC group (n: 12 vs. n: 7), while in the Non-ALC group, the confusion with milder clinical features was more often present (n: 15) (Fig. 12C).

ALC DOC showed a significant correlation with gender. It developed more frequently in men than women (91.3\% vs. 8.7\%; n: 21 vs. n: 2; p: 0.002), while in Non-ALC DOC, no difference was seen between the genders (Fig. 3B). Patients with Non-ALC DOC were older than patients with ALC DOC (70.5 \pm 18.4 vs. $53.5 \pm 15$ years, p: 0.002) (Fig. 13D).

\section{III.4.4. Severity and mortality of AP and LOH in DOC vs. Non-DOC groups}

Analysis between the DOC and Non-DOC groups showed higher incidence of severe AP (19.2\% vs. $5.3 \%$,. n: 9/47 vs. n: 62/1173, p < 0.001) (Fig. 14A), 8.8 times higher mortality (14.9\% vs.1.7\%, n: $7 / 47$ vs. n: 20/1173, p < 0.001) (Fig. 14C), and a longer LOH in the DOC group (Me: 11; IQR: 8-17 days vs. Me: 9; IQR: 6-13 days, p: 0.049) (Fig. 14E) respectively.

\section{III.4.5. Severity and mortality of AP and LOH in ALC DOC vs. Non-ALC DOC groups}

Severity and mortality of AP and LOH in ALC DOC vs. Non-ALC DOC groups. Moderate AP developed more frequent in patients with ALC DOC vs. Non-ALC DOC group $(43.5 \%$ vs. 12.5\% n: 10 vs. n: 3) while the incidence of severe AP was 7 times higher in Non-ALC vs. ALC DOC group (33.3\% vs. 4.4\%, n: 8 vs. n: 1), p < 0.001 (Fig. 4B). Mortality showed no difference between the analyzed groups (n: 3 vs. n: 4) (Fig. 14D). Concerning the LOH, patients with Non-ALC DOC showed a tendency for longer hospitalization (Me: 13; IQR: 720 days vs. Me: 9.5; IQR: 8-15.5 days, p: 0.119) (Fig. 14F). 

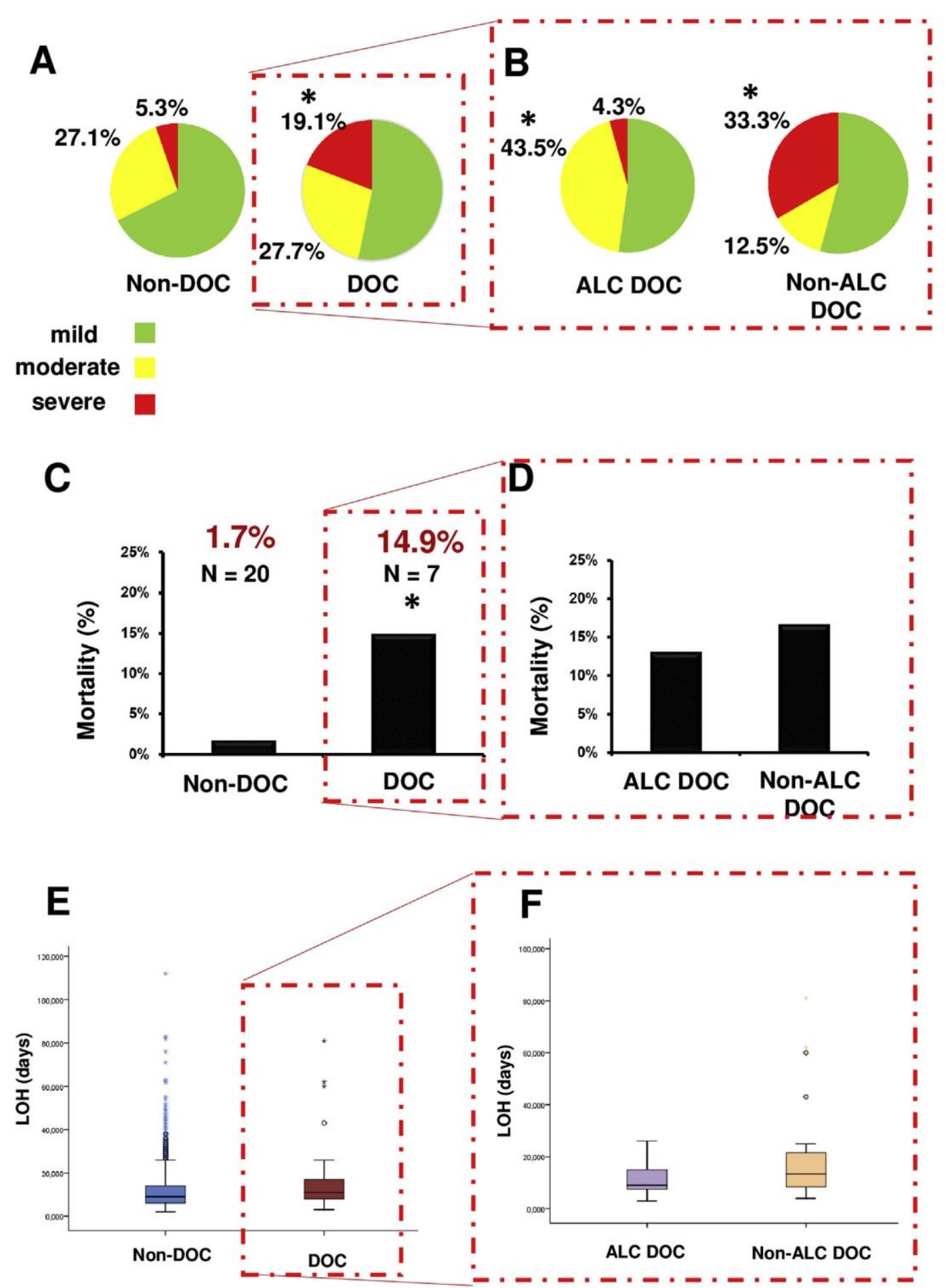

Fig. 14. A Distribution of severity of pancreatitis in disturbance of consciousness (DOC) and Non-DOC groups (Compared with Fisher test). 4.B Distribution of severity of acute pancreatitis of alcohol-related DOC (ALC DOC) and non-alcohol-related (Non-ALC DOC) groups (Compared with Fisher test). 4.C Distribution of mortality of DOC and Non-DOC groups (Compared with Fisher test). 4.D Mortality distribution of ALC DOC and Non-ALC DOC groups (Compared with Fisher test). 4.E Distribution of length of hospitalization ( $\mathrm{LOH}$ ) in DOC and Non-DOC groups (Compared with Mann-Whitney test). 4.F Distribution of LOH in ALC DOC and Non-ALC DOC groups (Compared with Mann-Whitney test). 


\section{III.5 Discussion}

The whole medical staff, especially nurses have an essential role in recognizing the early signs of changes in mental status and in preventing delirium [62]. However, the hospitalacquired delirium often remains unnoticed, because its symptoms resemble dementia and depression, further complicating the diagnosis [63]. Not surprising that no data is available concerning the relationship of DOC and the outcome of AP. Here we show for the first time that DOC is associated with more severe and higher mortality rates of AP. The question arises, which factor comes first, the severe AP, or the DOC. It is possible that due to AP released metabolic mediators, hypovolemia and systemic inflammatory response syndrome may lead to different organ failures, such as encephalopathy. On the other hand, in a patient with chronic alcohol consumption during hospitalization with mild AP (based on Atlanta classification), delirium tremens may occur, which is a severe illness in itself, which can lead to multi-organ failure, ICU admission, and mechanical ventilation. It is also important to mention that the development of delirium increases the mortality risk in the ICU, and it is also associated with longer ICU-stay [64]. A systematic review found that multi-component implementation programs with strategies, targeting ICU delirium assessment, prevention, and adequate treatment including pain, agitation and delirium management, and a strategy of early awakening, breathing, delirium screening, and early exercise have a clinical outcome improving potential [65]. Furthermore, we found that moderate pancreatitis is more common in the ALC DOC group, whereas in the Non-ALC DOC group, more severe cases were detected. There was no difference in the mortality rate in the ALC DOC and Non-ALC DOC groups. However, there was a lower rate of severe AP in the ALC group; it had the same mortality rate. This difference may be explained by the fact that, in the ALC DOC group, chronic alcohol consumption is higher. These individuals are of lower social standing, with lower income, often malnourished, have vitamin deficiencies, cachexia/ sarcopenia, and are at various stages of liver cirrhosis, all of which can lead to higher mortality in moderate AP. The other suggestion is that DOC influences mortality regardless of etiology. The findings of this study have some limitations. Based on the cohort analysis, there was a difference in the demographic parameters, which may influence our results. Also, between the DOC and NonDOC and between the ALC and Non-ALC DOC groups' differences in gender were seen; however, in the ALC DOC group, the gender distribution in alcoholic AP confirms these results. In the DOC and Non-ALC DOC groups, the average age is higher, which may have a causal role in the more severe course of the disease. Besides, based on the analysis method, no 
conclusion, according to the casualty of DOC and severity could be shown, only associations between the parameters can be provided.

A meta-analysis of randomized controlled studies suggests that dexmedetomidine could be a therapeutic option [66]. Benzodiazepines are currently in the first-line treatment for alcohol withdrawal syndrome. They significantly reduce the risk of recurrent seizures related to alcohol withdrawal compared to placebo [67]. In the case of older adults and liver disease, the half-life of diazepam increases with its accumulation and results in a higher rate of side effects. In the elderly and patients with cirrhosis or severe liver dysfunction, lorazepam or oxazepam are preferred [68]. It is pivotal to recognize the symptoms of benzodiazepine toxicity because it leads to respiratory depression, confusion, and delirium through excessive sedation, which may be challenging to differentiate from delirium tremens. In older critically ill patients, polypharmacy may also play an essential role in developing delirium [69]. In the United Kingdom, the Prevention of Delirium system was implemented and delivered in several wards with a staff training program, and they found it feasible [70]. Despite the high prevalence rate of delirium and the marked deteriorating effects on the outcome of the different illnesses, the management of delirium lacks unified professional guidelines. 


\section{Conclusions}

This Ph.D work deals with the outcomes of two major GI disease, with GI bleeding and acute pancreatitis. In these life-threatening diseases a proper risk assessment is needed to detect the potential instabile and vulnerable patients.

According GI bleeding, there are several risk assessment and outcome predictor scoring systems which calculates outcome based on comorbidities, however, e.g. in terms of renal failure, the stages are not properly defined. Our work is the first meta-analysis and systematic review in this topic, which quantifies CKD as a negative risk factor in GI bleeding. GI bleeding in patients with chronic renal failure significantly increases the mortality rate, rebleeding rate, $\mathrm{LOH}$, and they require more blood transfusion compared to patients with normal kidney functions. Kidney disease significantly worsens the outlook of patients presenting with GI bleeding. Patients with CKD will need to be treated with more caution due to the worse outcomes of GI bleeding. Although CKD, ESRD, and other comorbidities are major risk factors for unfavorable outcomes in GI bleeding, their roles are not well investigated nor understood and they need further scrutiny. We would better understand the role of CKD in ESRD in GI bleeding from analysis of extensive data from large multicenter and multinational observational studies and registries accurately recording the outcomes and the kidney functions.[71]

Acute pancreatitis is one of the most common gastrointestinal diseases requiring urgent hospitalization worldwide, characterized by significant morbidity and mortality. Several scoring systems are available, but they characterize patients on admission. Disorder of consciousness may develop in severe diseases, also in AP, but there is no literature about the influence of DOC on the outcome of AP. This is the first cohort analysis from the HPSG registry data, which showed that DOC is associated with a more severe course of AP, these patients requires longer $\mathrm{LOH}$. In these patients a higher mortality rate of the underlying disease. Alcohol consumption in medical history elevates the rate of moderate AP in the DOC group. As a clinical implication, according to our data, we can conclude that the onset of DOC is a negative prognostic factor in the outcome of AP. To answer this clinical question, it is necessary to organize an observational clinical trial to monitor all relevant parameters for DOC continuously. This observational clinical study could prove the real causal relationship between DOC and the outcomes of AP. Furthermore, if the observational study confirms our data, randomized clinical trials aiming to prevent DOC should be organized. Our data suggest that reducing the development of delirium should be part of the management of AP.[72] 


\section{Acknowledgment}

I am very thankful to Kálmán Tóth, the head of my institution who created the conditions for my $\mathrm{PhD}$ work and allowed my intensive research work in addition to daily work.

I would like to thank my supervisor Alexandra Mikó, for her support. She managed my scientific studies and assisted my work with her advice and experience. I would like to express my thanks to Péter Hegyi, who convinced me to join the HPSG and begin my scientific work, and then supported me as a supervisor.

I am also grateful to the interdisciplinary research unit led by Andrea Szentesi. My Ph.D. work would not have been possible without the work of administrators, patient coordinators and local clinical investigators of the HPSG and the Institute for Translational Medicine, University of Pécs. Furthermore, I would like to thank Nelli Farkas for her help in the statistical calculations. My deepest gratefulness goes to my parents and my family who supported me during my studies and research work. I would also like to thank those colleagues who always assured me that I would be able to manage and finish my Ph.D. work. 


\section{References}

1. Laura E. Targownik, A.N., Trends in Management and Outcomes of Acute Nonvariceal Upper Gastrointestinal Bleeding: 1993-2003. Clinical Gastroenterology and Hepatology, 2006: p. $1459-1466$.

2. Rockall, T.A., et al., Risk assessment after acute upper gastrointestinal haemorrhage. Gut, 1996. 38(3): p. 316-21.

3. Demcsák, A., et al., Acid suppression therapy, gastrointestinal bleeding and infection in acute pancreatitis - An international cohort study. Pancreatology, 2020.

4. Farkas, N., et al., A Multicenter, International Cohort Analysis of 1435 Cases to Support Clinical Trial Design in Acute Pancreatitis. Frontiers in Physiology, 2019. 10(1092).

5. Mosztbacher, D., et al., Hypertriglyceridemia-induced acute pancreatitis: A prospective, multicenter, international cohort analysis of 716 acute pancreatitis cases. Pancreatology, 2020. 20(4): p. 608-616.

6. Kiss, L., et al., The effect of serum triglyceride concentration on the outcome of acute pancreatitis: systematic review and meta-analysis. Scientific Reports, 2018. 8(1): p. 14096.

7. Whitcomb, D.C., Clinical practice. Acute pancreatitis. The New England Journal of Medicine, 2006. 354(20): p. 2142-50.

8. Párniczky, A., et al., Antibiotic therapy in acute pancreatitis: From global overuse to evidence based recommendations. Pancreatology, 2019. 19(4): p. 488-499.

9. Marshall, J.C., et al., Multiple organ dysfunction score: a reliable descriptor of a complex clinical outcome. Critical Care Medicine, 1995. 23(10): p. 1638-52.

10. Cutler, J.A. and A.I. Mendeloff, Upper gastrointestinal bleeding. Nature and magnitude of the problem in the U.S. Digestive Diseases and Sciences, 1981. 26(7 Suppl): p. 90s-96s.

11. Vreeburg, E.M., et al., Acute upper gastrointestinal bleeding in the Amsterdam area: incidence, diagnosis, and clinical outcome. The American Journal of Gastroenterology, 1997. 92(2): p. 236-43. 
12. Rob P. Adang, R.W.S., Appropriateness of indications for diagnostic upper gastrointestinal endoscopy: Association with relevant endoscopic disease. Gastrointestinal Endoscopy, 1995. 42(5): p. 390-397.

13. Hussain, H., S. Lapin, and M.S. Cappell, Clinical scoring systems for determining the prognosis of gastrointestinal bleeding. Gastroenterology Clinics of North America, 2000. 29(2): p. 445-464.

14. Zuccaro, G., Jr., Management of the adult patient with acute lower gastrointestinal bleeding. American College of Gastroenterology. Practice Parameters Committee. The American Journal of Gastroenterology, 1998. 93(8): p. 1202-8.

15. Lin, C.C., et al., The etiology and clinical characteristics of acute lower gastrointestinal bleeding in patients hospitalized for comorbid illnesses. Hepatogastroenterology, 2006. 53(69): p. 395-8.

16. Laeeq Syed, M., et al., Upper gastrointestinal bleeding in patients with end stage renal disease: causes, characteristics and factors associated with need for endoscopic therapeutic intervention. Journal of Translational Internal Medicine. 2017. p. 106.

17. Blatchford o, M.W.R., Blatchford M, A risk score to predict need for treatment for upper-gastrointestinal haemorrhage. Lancet, 2000: p. 1318-21.

18. Saltzman R., T.P.H.H., Johannes S., A simple risk score accurately predicts inhospital mortality, length of stay, and cost in acute upper GI bleeding. Gastrointestinal Endoscopy, 2011. 74(6): p. 1215-1224.

19. Mankongpaisarnrung, C., et al., Risk assessment in patients with gastrointestinal bleeding. The Southwest Respiratory and Critical Care Chronicles, 2013. 1: p. 15.

20. Stevens, L.A., et al., Assessing kidney function-measured and estimated glomerular filtration rate. The New England Journal of Medicine, 2006. 354(23): p. 2473-83.

21. Cheung, J., et al., Peptic ulcer bleeding outcomes adversely affected by end-stage renal disease. Gastrointestinal Endoscopy, 2010. 71(1): p. 44-9.

22. Kuo, C.C., et al., The risk of upper gastrointestinal bleeding in patients treated with hemodialysis: a population-based cohort study. BMC Nephrology, 2013. 14: p. 15.

23. Sood, P., et al., Chronic kidney disease and end-stage renal disease predict higher risk of mortality in patients with primary upper gastrointestinal bleeding. American Journal of Nephrolgy, 2012. 35(3): p. 216-24.

24. Gheissari, A., et al., Gastrointestinal hemorrhage in end stage renal disease patients. International Surgery, 1990. 75(2): p. 93-5. 
25. Docherty, E., et al., Use of small bowel capsule endoscopy in patients with chronic kidney disease: experience from a University Referral Center. Annals of Gastroenterology, 2015. 28(1): p. 99-104.

26. Karagiannis, S., et al., Wireless capsule endoscopy in the investigation of patients with chronic renal failure and obscure gastrointestinal bleeding (preliminary data). World Journal of Gastroenterology, 2006. 12(32): p. 5182-5185.

27. Ohmori, T., et al., Abnormalities of the small intestine detected by capsule endoscopy in hemodialysis patients. Internal Medicine, 2012. 51(12): p. 1455-60.

28. Matera James J., M.J., Diet Planning Guide: Nutritional Considerations in CKD and ESRD. Nutrition 411, 2019.

29. Moher, D., et al., Preferred reporting items for systematic reviews and meta-analyses: the PRISMA statement. PLoS Medicine, 2009. 6(7): p. e1000097.

30. Tsai, C.J. and J.C. Hwang, Investigation of upper gastrointestinal hemorrhage in chronic renal failure. Journal of Clinical Gastroenterology, 1996. 22(1): p. 2-5.

31. Boyle, J.M. and B. Johnston, Acute upper gastrointestinal hemorrhage in patients with chronic renal disease. The American Journal of Medicine, 1983. 75(3): p. 409-12.

32. Hozo, S.P., B. Djulbegovic, and I. Hozo, Estimating the mean and variance from the median, range, and the size of a sample. BMC Medical Research Methodology, 2005. 5: p. 13.

33. Higgins JPT, Green S (editors). Cochrane Handbook for Systematic Reviews of Interventions. Version 5.1.0 (updated March 2011). The Cochrane Collaboration; 2011.

34. Wells, G., et al., The Newcastle-Ottawa Scale (NOS) for Assessing the Quality of Non-Randomized Studies in Meta-Analysis, 2000.

35. Stevens, P.E. and A. Levin, Evaluation and management of chronic kidney disease: synopsis of the kidney disease: improving global outcomes 2012 clinical practice guideline. Annals of Internal Medicine, 2013. 158(11): p. 825-30.

36. Alvarez, L., J. Puleo, and J.A. Balint, Investigation of gastrointestinal bleeding in patients with end stage renal disease. The American Journal of Gastroenterology, 1993. 88(1): p. 30-3.

37. Hung, T.H., et al., Is end stage renal disease a risk factor for the mortality of cirrhotic patients with esophageal variceal bleeding? Hepatogastroenterology, 2014. 61(135): p. 1871-5. 
38. Zuckerman, G.R., et al., Upper gastrointestinal bleeding in patients with chronic renal failure. Annals of Internal Medicine, 1985. 102(5): p. 588-92.

39. Khedmat, H., et al., Gastro-duodenal lesions and Helicobacter pylori infection in uremic patients and renal transplant recipients. Transplantation Proceedings, 2007. 39(4): p. 1003-7.

40. Sugimoto, M., et al., Prevalence of Helicobacter pylori infection in long-term hemodialysis patients. Kidney International, 2009. 75(1): p. 96-103.

41. Luo, J.C., et al., Incidence of bleeding from gastroduodenal ulcers in patients with end-stage renal disease receiving hemodialysis. CMAJ, 2011. 183(18): p. E1345-51.

42. Kalman, R.S. and M.C. Pedrosa, Evidence-based review of gastrointestinal bleeding in the chronic kidney disease patient. Seminars is Dialysis, 2015. 28(1): p. 68-74.

43. Weng, S.C., et al., In-hospital mortality risk estimation in patients with acute nonvariceal upper gastrointestinal bleeding undergoing hemodialysis: a retrospective cohort study. Renal Failure, 2013. 35(2): p. 243-8.

44. Holden, R.M., et al., Major bleeding in hemodialysis patients. Clinical Journal of the American Society of Nephrology, 2008. 3(1): p. 105-10.

45. Wasse, H., et al., Risk factors for upper gastrointestinal bleeding among end-stage renal disease patients. Kidney International, 2003. 64(4): p. 1455-61.

46. Jalal, D.I., M. Chonchol, and G. Targher, Disorders of hemostasis associated with chronic kidney disease. Seminars in Thrombosis and Hemostasis, 2010. 36(1): p. 3440.

47. Szirmai, I., A tudat és a tudatzavarok, Medicina Könyvkiadó Zrt, XI. fejezet. . 2011. $158-75$.

48. Székely, M. 2013. Kórélettani alapok. Medicina Könyvkiadó Zrt. 7.5. fejezet: A pancreas müködési zavarai, 238-40.; A11.2.3. Tudatborult állapotok, 492-93. .

49. Perry, E.C., Inpatient management of acute alcohol withdrawal syndrome. CNS Drugs, 2014. 28(5): p. 401-10.

50. Carlson, R.W., et al., Alcohol withdrawal syndrome. Critical Care Clinics, 2012. 28(4): p. 549-85.

51. Sun, G.H., et al., Pancreatic encephalopathy and Wernicke encephalopathy in association with acute pancreatitis: a clinical study. World Journal of Gastroenterology, 2006. 12(26): p. 4224-7.

52. Yadav, D. and A.B. Lowenfels, The epidemiology of pancreatitis and pancreatic cancer. Gastroenterology, 2013. 144(6): p. 1252-1261. 
53. Szakacs, Z., et al., Aging and Comorbidities in Acute Pancreatitis II.: A CohortAnalysis of 1203 Prospectively Collected Cases. Frontiers in Physiology, 2018. 9: p. 1776.

54. Szentesi, A., et al., Multiple Hits in Acute Pancreatitis: Components of Metabolic Syndrome Synergize Each Other's Deteriorating Effects. Frontiers is Physiology, 2019. 10: p. 1202.

55. Parniczky, A., et al., Prospective, Multicentre, Nationwide Clinical Data from 600 Cases of Acute Pancreatitis. PLoS One, 2016. 11(10): p. e0165309.

56. Banks, P.A., et al., Classification of acute pancreatitis--2012: revision of the Atlanta classification and definitions by international consensus. Gut, 2013. 62(1): p. 102-11.

57. Buter, A., et al., Dynamic nature of early organ dysfunction determines outcome in acute pancreatitis. British Journal of Surgery, 2002. 89(3): p. 298-302.

58. Yang, C.J., et al., Predictors of severe and critical acute pancreatitis: a systematic review. Digestie and Liver Disease, 2014. 46(5): p. 446-51.

59. Lee, W.-S., J.-F. Huang, and W.-L. Chuang, Outcome assessment in acute pancreatitis patients. The Kaohsiung Journal of Medical Sciences, 2013. 29: p. 469-77.

60. Kantly, R. and A. Medikeri, Study on severity assessment of acute pancreatitis using BISAP score in rural area of south India. International Surgery Journal, 2018.

61. Miko, A., et al., Preexisting Diabetes Elevates Risk of Local and Systemic Complications in Acute Pancreatitis: Systematic Review and Meta-analysis. Pancreas, 2018. 47(8): p. 917-923.

62. Faught, D.D., Delirium: The Nurse's Role in Prevention, Diagnosis, and Treatment. Medsurg Nursing, 2014. 23(5): p. 301-5.

63. Volland, J., A. Fisher, and D. Drexler, Preventing and identifying hospital-acquired delirium. Nursing, 2020. 50(1): p. 32-37.

64. Lahariya, S., et al., Delirium in patients admitted to a cardiac intensive care unit with cardiac emergencies in a developing country: incidence, prevalence, risk factor and outcome. General Hospital Psychiatry, 2014. 36(2): p. 156-64.

65. Trogrlic, Z., et al., A systematic review of implementation strategies for assessment, prevention, and management of ICU delirium and their effect on clinical outcomes. Critical Care, 2015. 19: p. 157.

66. Pasin, L., et al., Dexmedetomidine reduces the risk of delirium, agitation and confusion in critically Ill patients: a meta-analysis of randomized controlled trials. Journal of Cardiothorac and Vascular Anesthesia, 2014. 28(6): p. 1459-66. 
67. D'Onofrio, G., et al., Lorazepam for the prevention of recurrent seizures related to alcohol. The New England Journal of Medicine, 1999. 340(12): p. 915-9.

68. Gershkovich, P., et al., Effect of variations in treatment regimen and liver cirrhosis on exposure to benzodiazepines during treatment of alcohol withdrawal syndrome. Drugs Context, 2015. 4: p. 212287.

69. Garpestad, E. and J.W. Devlin, Polypharmacy and Delirium in Critically Ill Older Adults: Recognition and Prevention. Clinincs in Geriatric Medicine, 2017. 33(2): p. 189-203.

70. Godfrey, M., et al., Process of implementing and delivering the Prevention of Delirium system of care: a mixed method preliminary study. BMC Geriatrics, 2019. 20(1): p. 1 .

71. Hágendorn, R., et al., Chronic kidney disease severely deteriorates the outcome of gastrointestinal bleeding: A meta-analysis. World Journal of Gastroenterology, 2017. 23(47): p. 8415-8425.

72. Hágendorn, R., et al., Development of disturbance of consciousness is associated with increased severity in acute pancreatitis. Pancreatology, 2020. 20(5): p. 806-812. 


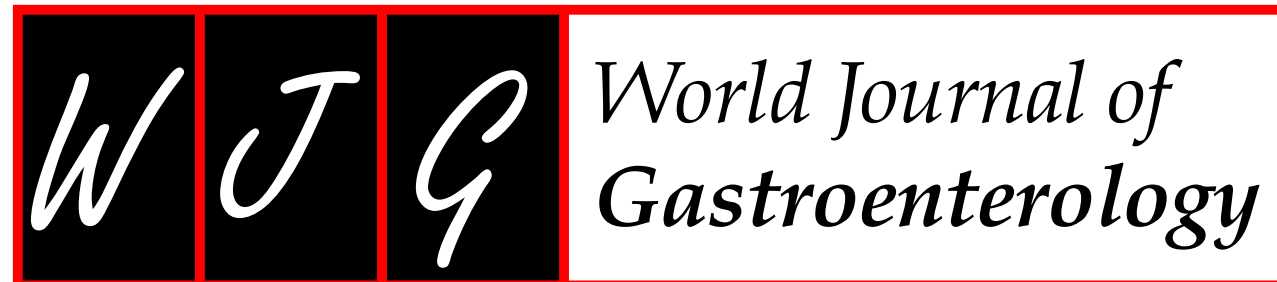

Submit a Manuscript: http://www.f6publishing.com

World J Gastroenterol 2017 December 21; 23(47): 8415-8425

DOI: 10.3748/wjg.v23.i47.8415

ISSN 1007-9327 (print) ISSN 2219-2840 (online)

META-ANALYSIS

\title{
Chronic kidney disease severely deteriorates the outcome of gastrointestinal bleeding: A meta-analysis
}

\author{
Roland Hágendorn, Nelli Farkas, Áron Vincze, Zoltán Gyöngyi, Dezső Csupor, Judit Bajor, Bálint Erőss, Péter \\ Csécsei, Andrea Vasas, Zsolt Szakács, László Szapáry, Péter Hegyi, Alexandra Mikó
}

Roland Hágendorn, Áron Vincze, Judit Bajor, Department of Gastroenterology, First Department of Medicine, University of Pécs, Pécs 7624, Hungary

Nelli Farkas, Institute of Bioanalysis, University of Pécs, Pécs 7624, Hungary

Bálint Erőss, Zsolt Szakács, László Szapáry, Péter Hegyi, Alexandra Mikó, Institute for Translational Medicine, University of Pécs, Pécs 7624, Hungary

Zoltán Gyöngyi, Department of Public Health Medicine, University of Pécs, Pécs 7624, Hungary

Dezső Csupor, Andrea Vasas, Department of Pharmacognosy, Faculty of Pharmacy, University of Szeged, Szeged 6720, Hungary

Péter Csécsei, Department of Neurology, University of Pécs, Pécs 7623, Hungary

ORCID number: Roland Hágendorn (0000-0002-9984-2309); Nelli Farkas (0000-0002-5349-6527); Áron Vincze (0000 -0003-2217-7686); Zoltán Gyöngyi (0000-0001-9330-9110); Dezső Csupor (0000-0002-4088-3333); Judit Bajor (0000-0002 -3941-4871); Bálint Erőss (0000-0003-3658-8427); Péter Csécsei (0000-0002-4982-2481); Andrea Vasas (0000-0002-1818-7702); Zsolt Szakács (0000-0002-7035-941X); László Szapáry (0000 -0003-2056-0825); Péter Hegyi (0000-0003-0399-7259); Alexandra Mikó(0000-0002-5322-4425).

Author contributions: Hegyi P and Mikó A contributed equally to this article; Hegyi P and Mikó A designed the research and the study concept; Hágendorn R and Mikó A performed the acquisition of data; Farkas $\mathrm{N}$ analysed and interpreted the data; Hágendorn R, Farkas N, Hegyi P and Mikó A wrote the paper; Vincze Á, Eröss B, Gyöngyi $Z$ and Bajor $J$ supervised the study; Csupor D, Csécsei P, Vasas A, Szakács Z and Szapáry $L$ conducted a critical revision of the manuscript for important intellectual content; all of the co-authors granted final approval of the version of the article to be published.

Supported by Project Grants No. K116634 and KH125678 (to Hegyi P); Economic Development and Innovation Operative Programme Grant, No. GINOP 2.3.2-15-2016-00048 (to Hegyi P); Human Resources Development Operational Programme Grant No. EFOP-3.6.2-16-2017-00006 (to Hegyi P) of the National Research, Development; and Innovation Office and by a Momentum Grant of the Hungarian Academy of Sciences No. LP2014-10/2014 to (Hegyi P).

Conflict-of-interest statement: The authors declare that there is no conflict of interest regarding the publication of this article.

Data sharing statement: No additional data are available.

Open-Access: This article is an open-access article which was selected by an in-house editor and fully peer-reviewed by external reviewers. It is distributed in accordance with the Creative Commons Attribution Non Commercial (CC BY-NC 4.0) license, which permits others to distribute, remix, adapt, build upon this work non-commercially, and license their derivative works on different terms, provided the original work is properly cited and the use is non-commercial. See: http://creativecommons.org/ licenses/by-nc/4.0/

Manuscript source: Invited manuscript

Correspondence to: Alexandra Mikó MD, PhD, Centre for Translational Medicine, University of Pécs, Szigeti Street 12., II. floor, Pécs 7624, Hungary, alexandra.miko@aok.pte.hu Telephone: $+36-72-536246$

Fax: $+36-72-536247$

Received: October 30, 2017

Peer-review started: October 31, 2017

First decision: November 14, 2017

Revised: November 23, 2017

Accepted: December 4, 2017

Article in press: December 4, 2017 


\begin{abstract}
AIM

To understand the influence of chronic kidney disease (CKD) on mortality, need for transfusion and rebleeding in gastrointestinal (GI) bleeding patients.
\end{abstract}

\section{METHODS}

A systematic search was conducted in three databases for studies on GI bleeding patients with CKD or endstage renal disease (ESRD) with data on outcomes of mortality, transfusion requirement, rebleeding rate and length of hospitalization ( $\mathrm{LOH}$ ). Calculations were performed with Comprehensive Meta-Analysis software using the random effects model. Heterogeneity was tested by using Cochrane's $Q$ and $I^{2}$ statistics. Mean difference (MD) and OR (odds ratio) were calculated.

\section{RESULTS}

1063 articles (EMBASE: 589; PubMed: 459; Cochrane: 15) were found in total. 5 retrospective articles and 1 prospective study were available for analysis. These 6 articles contained data on 406035 patients, of whom 51315 had impaired renal function. The analysis showed a higher mortality in the CKD group $(\mathrm{OR}=1.786$, 95\%CI: $1.689-1.888, P<0.001)$ and the ESRD group (OR $=2.530,95 \% \mathrm{CI}: 1.386-4.616, P=0.002)$, and a rebleeding rate $(\mathrm{OR}=2.510,95 \% \mathrm{CI}: 1.521-4.144, P$ $<0.001$ ) in patients with impaired renal function. CKD patients required more unit red blood cell transfusion $(\mathrm{MD}=1.863,95 \% \mathrm{CI}: 0.812-2.915, P<0.001)$ and spent more time in hospital (MD $=13.245,95 \% \mathrm{CI}$ : 6.886-19.623, $P<0.001$ ) than the controls.

\section{CONCLUSION}

ESRD increases mortality, need for transfusion, rebleeding rate and $\mathrm{LOH}$ among GI bleeding patients. Prospective patient registries and observational clinical trials are crucially needed.

Key words: Gastrointestinal bleeding; Chronic kidney disease; Mortality; Blood transfusion; Rebleeding

() The Author(s) 2017. Published by Baishideng Publishing Group Inc. All rights reserved.

Core tip: Acute gastrointestinal bleeding is a potentially life-threatening abdominal emergency that remains a common cause of hospitalization. Pre-existing chronic kidney disease (CKD) may worsen the prognosis. This is the first meta-analysis to compare CKD patients and normal renal function patients based on GI bleeding. We investigated these two groups in terms of mortality, transfusion amount, rebleeding rate and length of
Hágendorn R, Farkas N, Vincze Á, Gyöngyi Z, Csupor D, Bajor J, Erőss B, Csécsei P, Vasas A, Szakács Z, Szapáry L, Hegyi P, Mikó A. Chronic kidney disease severely deteriorates the outcome of gastrointestinal bleeding: A meta-analysis. World $J$ Gastroenterol 2017; 23(47): 8415-8425 Available from: URL: http://www.wjgnet.com/1007-9327/full/v23/i47/8415.htm DOI: http://dx.doi.org/10.3748/wjg.v23.i47.8415

\section{INTRODUCTION}

Acute gastrointestinal bleeding (GI) is an abdominal emergency which remains a common cause of hospitalization $^{[1]}$. An accurate diagnosis of GI bleeding relies on prompt resuscitation, initial risk evaluation, and provisional clinical diagnosis followed by an appropriate definitive investigation which enables specific therapeutic interventions. GI bleeding involves any bleeding in the GI tract from the esophagus, stomach, small intestines or large intestines to the anus.

Upper GI bleeding has an annual incidence that ranges from 40 to 150 episodes per 100000 persons and a morality rate of $6 \%-10 \%{ }^{[2]}$, whereas lower GI bleeding has an annual incidence ranging from 20 to 27 episodes per 100000 persons and a mortality rate of $4 \%-10 \%{ }^{[3,4]}$. Since GI bleeding is a potentially lifethreatening acute disorder, understanding the risk factors that worsen the disease is of great importance. Scoring systems have therefore been developed to predict the outcome of therapy. The Rockall score is one of these scoring systems. It includes preendoscopic (age, shock and comorbidity) and postendoscopic (diagnosis and presence or absence of endoscopic stigmata of recent haemorrhage) factors ${ }^{[5]}$. Several studies have demonstrated high mortality with higher Rockall scores ${ }^{[6]}$. However, Laeeq et $a^{[7]}$ have not found significantly higher mortality in patients with high pre-endoscopic Rockall score (> 5). The Rockall score only assesses the risk of mortality in patients with upper GI bleeding. The Glasgow Blatchford score is another scoring system which uses clinical and laboratory parameters. Neither scoring system makes distinction between pre-existing renal failure and acute renal failure due to haemorrhage. Both of these scoring systems have been designed for the risk assessment of upper GI bleeding. Previous studies have shown evidence of increased risk of GI bleeding in chronic kidney disease (CKD) patients and with end-stage renal disease (ESRD) requiring renal replacement therapy in comparison with the general population, but also an association with higher 
mortality ${ }^{[8-10]}$. Further studies have demonstrated that bleeding in CKD patients from the upper GI tract is more common than from the lower GI tract ${ }^{[11]}$. The increased prevalence of small bowel erosions, ulcers and angioectasias is also well known in CKD patients and it may be as high as 33\% and it often causes obscure gastrointestinal bleeding ${ }^{[12-14]}$. However, no meta-analyses or systematic reviews have been conducted to assess the difference between CKD/ESRD patients and the normal renal function population with regard to GI bleeding.

The aim of this study was therefore to examine outcomes of GI bleeding, such as mortality, blood transfusion requirement, rebleeding rate and length of hospitalization ( $\mathrm{LOH}$ ) in CKD/ESRD patients compared to patients with normal renal functions.

\section{MATERIALS AND METHODS}

\section{Search strategy}

This study was conducted using the preferred reporting items for systematic review and metaanalysis protocols (PRISMA-P ${ }^{[15]}$. It was registered in the international prospective register of systematic reviews, PROSPERO (under registration number CRD42017077987). The meta-analysis was based on the PICO (Patient, Intervention, Comparison, Outcome) format ( $P$ : patients with GI bleeding; I: chronic renal failure; $\mathrm{C}$ : normal renal function; $\mathrm{O}$ : mortality, blood transfusion, rebleeding). A systematic search was performed in 3 databases, Pubmed, EMBASE and the Cochrane Library, with the following terms: ("GI bleeding" OR "gastrointestinal bleeding" OR "gastrointestinal hemorrhage") AND ("chronic renal failure" OR "uremia" OR "chronic kidney failure"). The search was limited to human data and to fulltext English-language articles if appropriate. The exact search term in Pubmed was: ["GI bleeding" (All Fields) OR "gastrointestinal bleeding"(All Fields) OR "gastrointestinal hemorrhage"(All Fields)] AND ["chronic renal failure"(All Fields) OR "uraemia" (All Fields) OR "uremia"(MeSH Terms) OR "uremia" (All Fields) OR "chronic kidney failure"(All Fields)] AND ["humans"(MeSH Terms) AND English(lang)]. The database search was conducted up to 10 March 2017. Reference management software (EndNote X7) was used to remove duplicates by searching overlaps between titles, authors and publication years. The reference lists in the articles obtained were also checked, and one more eligible publication was found.

\section{Study selection}

The studies were selected separately by two investigators (RH and $\mathrm{AM}$ ). Disagreements were resolved by consulting a third reviewer $(\mathrm{PH})$. Clinical studies were eligible provided they reported data on adult patients hospitalized with upper or lower GI bleeding grouped into normal renal function and CKD or ESRD groups. Articles were eligible containing data of CKD/ ESRD patients and a control group in the same study. Information on mortality, transfusion, rebleeding and length of hospitalization ( $\mathrm{LOH}$ ) was manually searched. Case reports, conference abstracts, reviews and studies on paediatric patients up to age 18 alone were excluded. We found a high number of articles in which the risk of GI bleeding in CKD patients was studied, but they were not eligible for our meta-analysis, as there were no data available on outcomes of the GI bleeding in a control population without CKD/ESRD.

\section{Data extraction, synthesis and analysis}

Mortality data, number of transfused blood units, rebleeding and length of hospitalization data were extracted to analyse the influence of CKD and/or ESRD on the outcome of GI bleeding. In Sood et $a l^{[9]}$, Tsai et $a l^{[16]}$ and Boyle et $a l^{[17]}$, the number of patients was calculated from percentages of mortality. Boyle et $a{ }^{[17]}$ supplied information on transfusion in mean and standard error of mean, for which statistical calculation standard deviation (SD) was computed. Tsai et $a l^{[16]}$ reported data from transfusions in the median and interquartile range (IQR), from which mean and SD were calculated with Hozo's method ${ }^{[18]}$. All meta-analytic calculations were performed with Comprehensive Meta-Analysis software (Version 3.0, Biostat Inc.) using the random effects model (DerSimonian-Laird method $^{[19]}$ ). Odds ratios (OR) and $95 \%$ confidence intervals (CI) were calculated for binary outcomes. In the case of $\mathrm{LOH}$ and transfusion for comparing mean data, a mean difference (MD) with $95 \% \mathrm{CI}$ was calculated. All analyses were twotailed, with an $\alpha$ of 0.05 .

Heterogeneity was tested using Cochrane's $Q$ and the $I^{2}$ statistics. Based on the Cochrane Handbook, $I^{2}=100 \% \times(Q-\mathrm{df}) / \mathrm{Q}$, with $I^{2}$ representing the magnitude of the heterogeneity (moderate: 30\%-60\%; substantial: 50\%-90\%; considerable: $75 \%-100 \%)^{[20]}$. Only results that were available from at least 3 studies were displayed graphically with forest plots. We performed a sensitivity analysis to assess whether removing any study result in different interpretation and final conclusion ${ }^{[21]}$. To assess the effect of the year of publication on the outcome data we performed meta-regression analysis. We calculated the regression coefficient and interpreted the data with their 95\%CI and r-analog.

\section{Quality of studies and risk of bias}

Because of the low number of eligible articles, publication bias was obtained with a visual inspection of the funnel plots alone according to the Cochrane Handbook $^{[20]}$. The Newcastle-Ottawa Scale (NOS) adjusted to our study design was used ${ }^{[22]}$ to assess the quality of nonrandomized cohort studies. The 
Table 1 Modified Newcastle-Ottawa Scale criteria

\begin{tabular}{|c|c|c|}
\hline Adapted Newcastle-Ottawa Scale Items & $\begin{array}{l}\text { High-quality items carrying a low risk of bias } \\
\text { (green) }\end{array}$ & $\begin{array}{c}\text { Low-quality items carrying a high (red) or an } \\
\text { unknown (yellow) risk of bias }\end{array}$ \\
\hline $\begin{array}{l}\text { Item 1: Representativeness of the initial study } \\
\text { population - patients with GI bleeding and CKD/ } \\
\text { ESRD }\end{array}$ & $\begin{array}{l}\text { All patients with upper or lower GI bleeding and } \\
\qquad \text { CKD/ESRD were included. }\end{array}$ & $\begin{array}{l}\text { Low: any selection criteria were applied to the } \\
\text { study population (e.g., only transplanted patients). } \\
\text { Unknown: no data on selection process. }\end{array}$ \\
\hline $\begin{array}{l}\text { Item 2: Representativeness of the initial study } \\
\text { population - patients with GI bleeding without } \\
\text { CKD/ESRD }\end{array}$ & $\begin{array}{l}\text { All patients with upper or lower GI bleeding } \\
\text { without CKD/ESRD included. }\end{array}$ & $\begin{array}{l}\text { Low: any selection criteria were applied to the } \\
\text { study population. } \\
\text { Unknown: no data on selection process. }\end{array}$ \\
\hline Item 3: Ascertainment of exposure & $\begin{array}{l}\text { We defined chronic renal failure as present when } \\
\text { eGFR was }<60 \mathrm{~mL} / \mathrm{min} \text { at least } 3 \mathrm{mo} \text {. We defined } \\
\text { end-stage renal disease as a condition where } \\
\text { hemodialysis or chronic peritoneal dialysis is } \\
\text { performed at least for } 3 \text { mo. }\end{array}$ & $\begin{array}{l}\text { Low: CKD or ESRD is not present in all of the } \\
\text { patients. } \\
\text { Unknown: no definitions of the conditions } \\
\text { mentioned are provided. }\end{array}$ \\
\hline Item 4: Comparability of cohorts A & $\begin{array}{l}\text { Study controls for age: no significant difference } \\
\text { was detected. }\end{array}$ & $\begin{array}{l}\text { Low: significant difference was detected. } \\
\text { Unknown: no statement. }\end{array}$ \\
\hline Item 5: Comparability of cohorts B & $\begin{array}{l}\text { Study controls for taking ulcerogenic drugs: no } \\
\text { significant difference was detected }\end{array}$ & $\begin{array}{l}\text { Low: significant difference was detected between } \\
\text { taking ulcerogenic drugs. } \\
\text { Unknown: no comparison made by taking } \\
\text { ulcerogenic drugs. }\end{array}$ \\
\hline Item 6: Follow-up time for rebleeding & The follow-up time is clearly defined. & $\begin{array}{l}\text { Low: incomplete follow-up } \\
\text { Unknown: no follow-up time is mentioned. }\end{array}$ \\
\hline
\end{tabular}

CKD: Chronic kidney disease; ESRD: End-stage renal disease.

selection, comparability and outcome data were assessed based on 6 items (Table 1) with the "star system": high-quality items with a low risk of bias received one star, while low-quality items with a high or unknown risk of bias were assigned no stars. 3 items were included during the selection process. In the case of representativeness in the study population, we assigned a star if all of the GI bleeding patients with normal or impaired renal function were included. If any selection criteria applied, we assigned no points. We used the classical definition of $\mathrm{CKD}^{[23]}$, which characterizes the disease with a glomerular filtration rate $(G F R)<60 \mathrm{~m} / \mathrm{min}$ lasting longer than $3 \mathrm{mo}$. ESRD was defined as a condition where haemodialysis or chronic peritoneal dialysis is performed for at least 3 mo. With regard to outcome, only the follow-up time for rebleeding was rated in articles that provided this information. Assessment of outcome and length of follow-up were not rated because most of the articles were retrospective.

\section{RESULTS}

\section{Study selection}

1063 articles (EMBASE: 589; PubMed: 459; Cochrane: 15) were found altogether through database searches. The flowchart (Figure 1) shows the study selection strategy. Studies in our meta-analysis were dated from 1946 to 2017. After removing duplicates, 875 publications remained. Following initial screening based on titles and abstracts, 23 articles were retrieved and screened. A further 18 were excluded because of missing outcome data or a missing control group. Patients with acute renal failure were also included in the analysis reported in Alvarez et $\mathrm{al}^{[24]}$, so we did not use the data in that publication. The remaining $5^{[9,16,17,25,26]}$ and one other ${ }^{[10]}$ eligible record which was found in reference lists were included in the meta-analysis. The basic characteristics of the 6 eligible articles in the meta-analysis are shown in Table 2. These 6 publications contained data on 406,035 patients, of whom 51315 had impaired renal function parameters and 354720 had normal renal functions. 2 articles contained data on patients with CKD and 4 on ESRD patients. There were 2 studies involving CKD and ESRD patients, with their group identified as the CKD mixed group. The number of ESRD patients analysed was 15201, the CKD group had 36035 members, and 79 patients could be classified in the CKD mixed group.

\section{Mortality}

Data on mortality was available in all of the articles included, but Zuckerman et $a l^{[26]}$ reported no mortality data for the control group; we therefore removed it from the statistical analysis. Hung et $a l^{[25]}$ reported mortality data from a 6-wk follow-up period, while the other articles contained data on an unknown follow-up period. In the subgroup analysis for CKD and ESRD, a higher mortality rate was detected compared to the control population (CKD: OR $=1.786,95 \% \mathrm{CI}$ : $1.689-1.888, P<0.001$; ESRD: $\mathrm{OR}=2.530,95 \% \mathrm{CI}$ : $1.386-4.616, P=0.002$, Figure 2).

\section{Required units for transfusion}

4 studies reported data on the transfused units of red blood cells. The required transfusion was 1.8 times higher in the patients with abnormal renal function (MD 

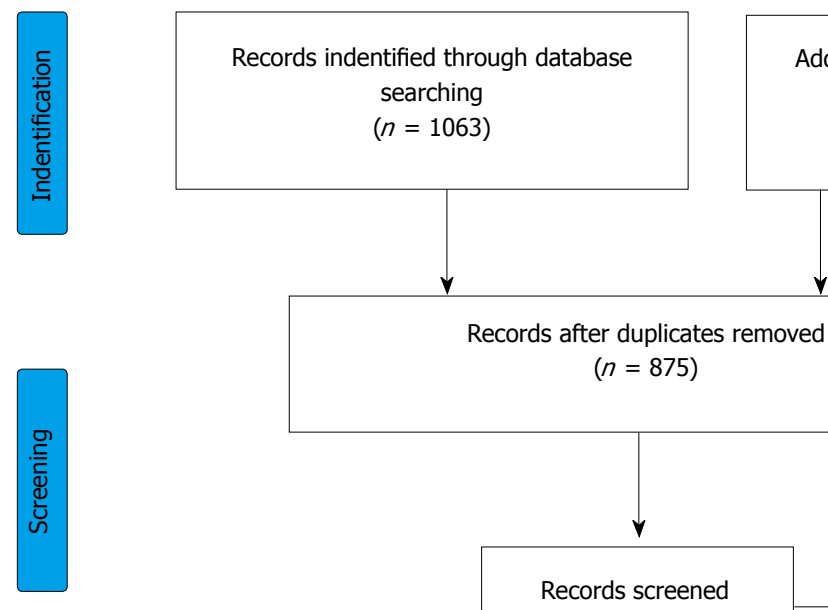

Additional records identified through other sources $(n=1)$
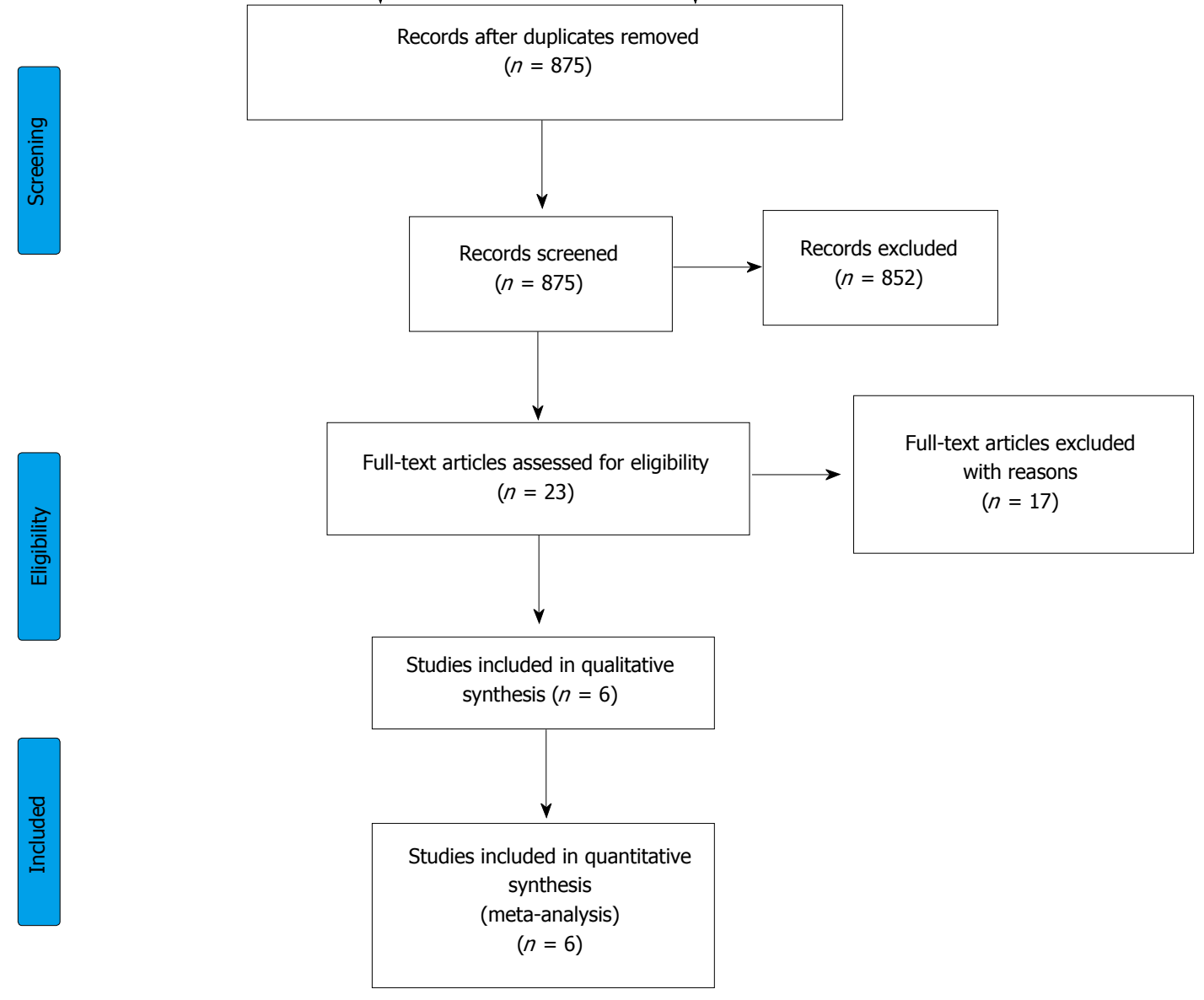

Figure 1 Flowchart of the study selection procedure.

$=1.863,95 \% \mathrm{CI}: 0.812-2.915, P<0.001$, Figure 3$).$

\section{Rebleeding rate}

It was possible to retrieve data on the rebleeding rate from 3 articles, but Cheung et al ${ }^{[10]}$ contained simultaneous data from the CKD and ESDR groups, which could be analysed. Boyle et $\mathrm{al}^{[17]}$. also presented data on rebleeding. However, this included cases of uncontrolled bleeding, so we excluded these data from our analysis. We found that patients with impaired renal function tend to bleed again 2.5 more times than patients with normal renal function $(\mathrm{OR}=2.510$, 95\%CI: $1.521-4.144, P<0.001$, Figure 4$)$.

\section{Length of hospitalization}

Two of the six articles included reported hospital stay outcomes. Patients with impaired renal function spent significantly more time in hospital after GI bleeding (MD
$=13.245,95 \% \mathrm{CI}: 6.886-19.623, P<0.001$, Figure 5).

\section{Heterogeneity and quality assessment of data}

High heterogeneity was detected for mortality in the ESRD group $\left(\mathrm{Q}=17.082 ; \mathrm{DF}=3 ; I^{2}=82.438 \% ; P\right.$ $<0.001$ ), while the heterogeneity for CKD was low $\left(\mathrm{Q}=1.767 ; \mathrm{DF}=2 ; I^{2}=0 \% ; P=0.413\right)$. However, a low heterogeneity was detected for the transfusion requirements $\left(\mathrm{Q}=3.448 ; \mathrm{DF}=3 ; I^{2}=13.003 \% ; P\right.$ $=0.328)$, the rebleeding rate $(\mathrm{Q}=3.328 ; \mathrm{DF}=3$; $\left.I^{2}=9.845 \% ; P=0.344\right)$ and $\mathrm{LOH}(\mathrm{Q}=1.100 ; \mathrm{DF}$ $\left.=2 ; I^{2}=0 \% ; P=0.577\right)$. To ascertain publication bias, we only made a visual assessment of the funnel plot (Figure 6) because we were only able to include 6 studies in our meta-analysis. Sensitivity analysis showed no significant difference in the OR of mortality, by removing any of the articles (Supplementary Figure 1). Meta-regression showed slight significance, in the 
Hágendorn R et al. GI bleeding and chronic kidney disease

Table 2 Basic characteristics of the studies included in the meta-analysis

\begin{tabular}{|c|c|c|c|c|c|c|c|c|c|c|}
\hline Ref. & Country & Study type & Years of study & Group & Sample size & Age & Mortality & Transfusion & Rebleeding & $\begin{array}{c}\text { Length of } \\
\text { hospitalization }\end{array}$ \\
\hline \multirow[t]{2}{*}{ Boyle et al ${ }^{[17]}, 1983$} & United & Retrospective & $1977-1981$ & Control & 40 & $54 \pm 2^{1}$ & $\sqrt{ }$ & $\sqrt{ }$ & - & $\sqrt{ }$ \\
\hline & States & & & CKD (mix) & 20 & $59 \pm 4^{1}$ & & & & \\
\hline \multirow[t]{3}{*}{ Cheung et al ${ }^{[10]}, 2010$} & Canada & Retrospective & $2000-2006$ & Control & 50 & $67 \pm 13$ & $\sqrt{ }$ & $\sqrt{ }$ & $\sqrt{ }$ & $\sqrt{ }$ \\
\hline & & & & CKD & 50 & $71 \pm 13$ & & & & \\
\hline & & & & ESRD & 50 & $68 \pm 12$ & & & & \\
\hline \multirow{2}{*}{ Hung et al ${ }^{[25]}, 2014$} & Taiwan & Retrospective & 2007 & Control & 6322 & $54.6 \pm 13.3$ & $\sqrt{ }$ & - & - & - \\
\hline & & & & ESRD & 110 & NR & & & & \\
\hline \multirow[t]{3}{*}{ Sood et al ${ }^{[9]}, 2012$} & United & Retrospective & 2007 & Control & 347245 & NR & $\sqrt{ }$ & - & - & - \\
\hline & States & & & CKD & 35985 & NR & & & & \\
\hline & & & & ESRD & 14983 & NR & & & & \\
\hline \multirow[t]{2}{*}{ Tsai et al ${ }^{[16]}, 1996$} & Taiwan & Prospective & 1991-1994 & Control & 640 & $55.7 \pm 16.2^{2}$ & $\sqrt{ }$ & $\sqrt{ }$ & $\sqrt{ }$ & - \\
\hline & & & & ESRD & 58 & $64.1 \pm 11.4^{2}$ & & & & \\
\hline \multirow[t]{2}{*}{ Zuckerman et al ${ }^{[26]}, 1985$} & United & Retrospective & $1980-1983$ & Control & 423 & $63(16-96)^{3}$ & - & - & $\sqrt{ }$ & - \\
\hline & States & & & CKD (mix) & 59 & $57(24-84)^{3}$ & & & & \\
\hline
\end{tabular}

${ }^{1}$ Data expressed as mean \pm SEM (standard error of mean); ${ }^{2}$ Data expressed as mean \pm SD (standard deviation); ${ }^{3}$ Data expressed as median (interquartile range). NR: Not reported; CKD: Chronic kidney disease; ESRD: End-stage renal disease.

Table 3 Stars based on the Modified Newcastle-Ottawa Scale

\begin{tabular}{|c|c|c|c|c|c|c|c|}
\hline Ref. & Item 1 & Item 2 & Item 3 & Item 4 & Item $\mathbf{5}$ & Item 6 & Total $\left({ }^{*}\right)$ \\
\hline Boyle et al ${ }^{[17]}, 1983$ & * & * & - & * & * & & 4 \\
\hline Cheung et al ${ }^{[10]}, 2010$ & * & * & * & * & * & * & 6 \\
\hline Hung et al ${ }^{[25]}, 2014$ & * & * & - & - & - & & 2 \\
\hline Sood et al ${ }^{[9]}, 2012$ & * & * & - & - & - & & 2 \\
\hline Tsai et $_{a l} l^{[16]}, 1996$ & * & * & * & - & * & - & 4 \\
\hline Zuckerman et al ${ }^{[26]}, 1985$ & * & * & - & - & - & * & 3 \\
\hline
\end{tabular}

\begin{tabular}{|c|c|c|c|c|c|c|c|c|c|}
\hline \multirow[t]{2}{*}{ Study name } & \multirow[t]{2}{*}{ Subgroup within study } & \multicolumn{4}{|c|}{ Statistics for each study } & \multicolumn{2}{|c|}{ Dead/Total } & \multirow{2}{*}{ Odds ratio and $95 \% \mathrm{CI}$} & \multirow[t]{2}{*}{ Risk of bias } \\
\hline & & $\begin{array}{c}\text { Odds } \\
\text { ratio }\end{array}$ & $\begin{array}{c}\text { Lower } \\
\text { limit }\end{array}$ & $\begin{array}{c}\text { Upper } \\
\text { limit }\end{array}$ & $P$ value & Renal failure & Control & & \\
\hline Sood et al 2012 & CKD & 1.782 & 1.685 & 1.885 & 0.000 & $1511 / 35985$ & $8334 / 347245$ & & $\oplus \oplus$ (?) ? ? \\
\hline Boyle et al 1983 & CKD (mix) & 3.083 & 0.618 & 15.390 & 0.170 & $4 / 20$ & $3 / 40$ & & $\oplus \oplus \oplus \oplus \oplus$ \\
\hline \multirow[t]{2}{*}{ Cheung et al 2010} & CKD & 4.571 & 0.919 & 22.730 & 0.063 & $8 / 50$ & $2 / 50$ & & $\oplus \oplus \oplus \oplus \oplus \oplus$ \\
\hline & CKD & 1.786 & 1.689 & 1.888 & 0.000 & $1523 / 36055$ & $8339 / 347335$ & 1 & \\
\hline Hung et al 2014 & ESRD & 1.190 & 0.793 & 1.786 & 0.401 & & & & $\oplus \oplus$ ?? ? ? \\
\hline Sood et a/ 2012 & ESRD & 2.276 & 2.112 & 2.452 & 0.000 & $794 / 14983$ & $8334 / 347245$ & $\mathbf{\square}$ & $\oplus \oplus$ (?) (?) ? \\
\hline Cheung et al 2010 & ESRD & 4.571 & 0.919 & 22.730 & 0.063 & $8 / 50$ & $2 / 50$ & & $\oplus \oplus \oplus \oplus \oplus \oplus$ \\
\hline \multirow[t]{2}{*}{ Tsai et al 1996} & ESRD & 7.717 & 3.055 & 19.493 & 0.000 & $8 / 58$ & $13 / 640$ & & $\oplus \oplus \oplus \odot \oplus$ \\
\hline & ESRD & 2.530 & 1.386 & 4.616 & 0.002 & $810 / 15091$ & $8349 / 347935$ & & 1 \\
\hline
\end{tabular}

Favours CKD/ESRD favours control

Figure 2 Forest plot representing the differences in mortality in gastrointestinal bleeding patients with normal and impaired renal function. Size of squares for risk ratio reflects weight of trial in pooled analysis. Horizontal bars represent $95 \% \mathrm{Cl}$. CKD: Chronic kidney disease; ESRD: End-stage renal disease.

most recent articles the OR is decreasing with the time (regression coefficient: $b=-0.0548$; 95\%CI: -0.0968 to $-0.0128 ; P=0.0105$; r-analog: 0.2 , Supplementary Figure $2 \mathrm{~A}$ ). The number of required units for transfusion has not changed since the 1980s ( $b=-0.0028$; 95\%CI: -0.0242 to $-0.0186 ; P=0.7972$; r-analog: 0.00, Supplementary Figure 2B). Based on data from 4 articles, no difference in rebleeding rate could be observed in the last 30 years $(b=0.0027$; 95\%CI: -0.0353 to $0.03 ; P=0.8726$; r-analog: 0.00 , Supplementary Figure 2C).
On the score based on the Newcastle-Ottawa Scale, articles were assigned between 2 and 6 stars out of a maximum of 6 stars (Table 3). There was a low risk of bias in representativeness in the study and the control population; it received $100 \%$ (Figure 7). With regard to ascertaining exposure, $33 \%$ of the articles represented a low risk of bias, while $66 \%$ had an unclear risk of bias. In these articles CKD and ESRD were not clearly defined, or patients were sorted based on a code system. With regard to a comparison of age, half of the articles contained no clear data on 
Hágendorn R et al. GI bleeding and chronic kidney disease

\begin{tabular}{lccccc} 
Study name & Subgroup within study & \multicolumn{2}{c}{ Statistics for each study } & Difference in means \\
and $95 \% C I$
\end{tabular}

Figure 3 Forest plot representing the required units of transfusion in gastrointestinal bleeding patients with normal and impaired renal function. Size of squares for the difference in standardized mean values reflects weight of trial in pooled analysis. Horizontal bars represent $95 \% \mathrm{Cl}$. $\mathrm{CKD}$ : Chronic kidney disease; ESRD: End-stage renal disease.

\begin{tabular}{|c|c|c|c|c|c|c|c|c|c|c|}
\hline Study name & Subgroup within study & Outcome & \multicolumn{4}{|c|}{ Statistics for each study } & \multicolumn{2}{|c|}{ Exposed/Total } & Odds ratio and $95 \% \mathrm{CI}$ & Risk of bias \\
\hline & & & $\begin{array}{l}\text { Odds } \\
\text { ratio }\end{array}$ & $\begin{array}{c}\text { Lower } \\
\text { limit }\end{array}$ & $\begin{array}{l}\text { Upper } \\
\text { limit }\end{array}$ & $P$ value & Cases & Controls & & \\
\hline Cheung et al 2010 & CKD & Rebleeding & 1.194 & 0.371 & 3.841 & 0.766 & $7 / 50$ & $6 / 50$ & $\rightarrow$ & $\oplus \oplus \oplus \oplus \oplus$ \\
\hline Tsai et al 1996 & ESRD & Rebleeding & 1.691 & 0.487 & 5.869 & 0.408 & $3 / 58$ & $20 / 640$ & - & $\oplus \oplus \odot \oplus ?$ \\
\hline Zuckerman et al 1985 & CKD (mix) & Rebleeding & 2.864 & 1.476 & 5.555 & 0.002 & $15 / 59$ & $45 / 423$ & $\oplus$ & $\oplus$ (?) (?) (?) $\oplus$ \\
\hline Cheung et al 2010 & ESRD & Rebleeding & 4.495 & 1.610 & 12.545 & 0.004 & $19 / 50$ & $6 / 50$ & $\oplus$ & $\oplus \oplus \oplus \oplus \oplus$ \\
\hline & & & 2.510 & 1.521 & 4.144 & 0.000 & $44 / 217$ & $77 / 1163$ & 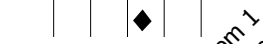 & \\
\hline
\end{tabular}

Figure 4 Forest plot representing the rebleeding rate in gastrointestinal bleeding patients with normal and impaired renal function. Size of squares for risk ratio reflects weight of trial in pooled analysis. Horizontal bars represent $95 \% \mathrm{Cl}$. CKD: Chronic kidney disease; ESRD: End-stage renal disease.

\begin{tabular}{|c|c|c|c|c|c|c|c|}
\hline \multirow[t]{2}{*}{ Study name } & \multirow[t]{2}{*}{ Subgroup within study } & \multicolumn{4}{|c|}{ Statistics for each study } & \multirow[t]{2}{*}{$\begin{array}{c}\text { Difference in means } \\
\text { and } 95 \% \mathrm{CI}\end{array}$} & Risk of bias \\
\hline & & Difference in means & Lower limit & Upper limit & $P$ value & & \\
\hline Cheung et al 2010 & CKD & -8.400 & -20.020 & 3.220 & 0.157 & & $\oplus \oplus \oplus \oplus \oplus \oplus$ \\
\hline Boyle et al 1983 & CKD (mix) & -14.300 & -23.636 & -4.964 & 0.003 & & $\oplus \oplus(?) \oplus$ \\
\hline Cheung et a/ 2010 & ESRD & -17.400 & -30.556 & -4.244 & 0.010 & & $\oplus \oplus \oplus \oplus \oplus \oplus$ \\
\hline & & -13.254 & -19.623 & -6.886 & 0.000 & & $123 \times 56$ \\
\hline
\end{tabular}

Favours CKD/ESRD favours control

Figure 5 Forest plot representing the differences in length of hospitalization in gastrointestinal bleeding patients with normal and impaired renal function. Size of squares for the difference in standardized mean values reflects weight of trial in pooled analysis. Horizontal bars represent $95 \% \mathrm{Cl}$. CKD: Chronic kidney disease; ESRD: End-stage renal disease.

the groups and there was a significant difference in the ages of the ESRD and control groups in Tsai et $a l^{[16]}$. $50 \%$ of the articles reported data on taking ulcerogenic drugs; the other half represented an unclear risk of bias. The follow-up time for rebleeding was analysed in 3 articles; only one did not report this clearly.

\section{DISCUSSION}

CKD is a term that covers all degrees of decreased renal function (mild, moderate, and severe chronic kidney disease), where the GFR is lower than $60 \mathrm{~mL} / \mathrm{min}$ for longer than $3 \mathrm{mo}^{[23]}$. CKD is a worldwide public health problem, with both incidence and prevalence rising and the main causes being diabetes mellitus and high blood pressure. ESRD patients requiring haemodialysis or peritoneal dialysis 3 times a week represent a high burden and cost for the health care system. As the prevalence of hypertension and diabetes mellitus, the most important etiological factors for CKD and ESRD is increasing worldwide, we predict that GI bleeding with CKD will be a growing problem. According to Ohmori et $a^{[13]}$ the number of patients on hemodyalisis has tripled between 1990 and 2010. This is the first metaanalysis to report on the severity of complications after GI bleeding in patients with CKD or ESRD and normal renal function groups. Based on a systematic search in 3 databases, we were able to include 6 articles, which contained data on 406035 patients, of whom 51315 had impaired renal function. A higher prevalence of peptic ulcers was reported among ESRD patients undergoing long-term dialysis ${ }^{[27,28]}$. The elevated risk 
A
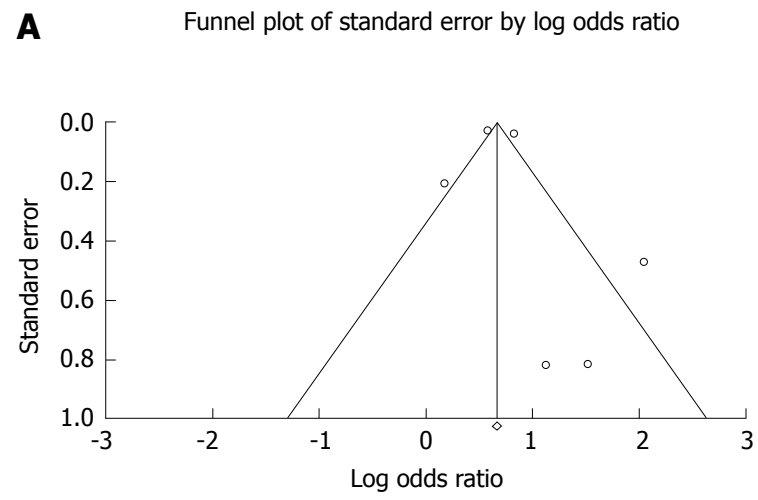

B

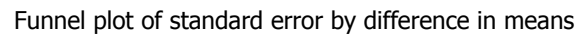

Funnel plot of standard error by difference in means

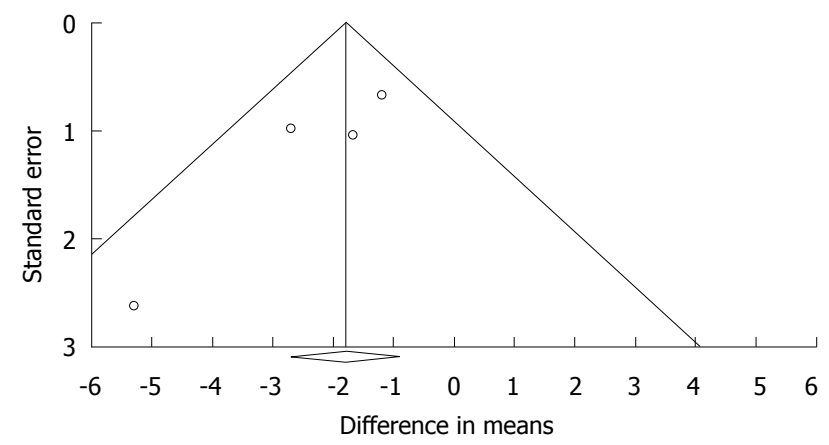

C

Funnel plot of standard error by log odds ratio

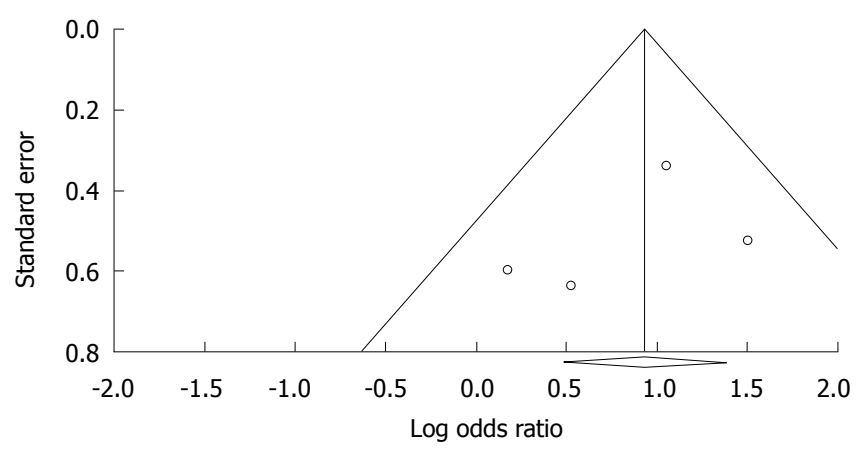

Figure 6 Funnel plot. A: Funnel plot of mortality; B: Funnel plot of required transfusion; and C: Funnel plot of rebleeding.

A

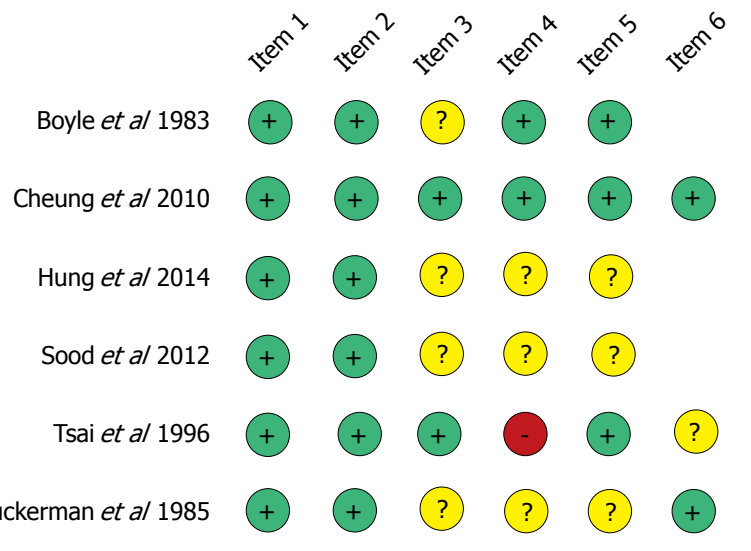

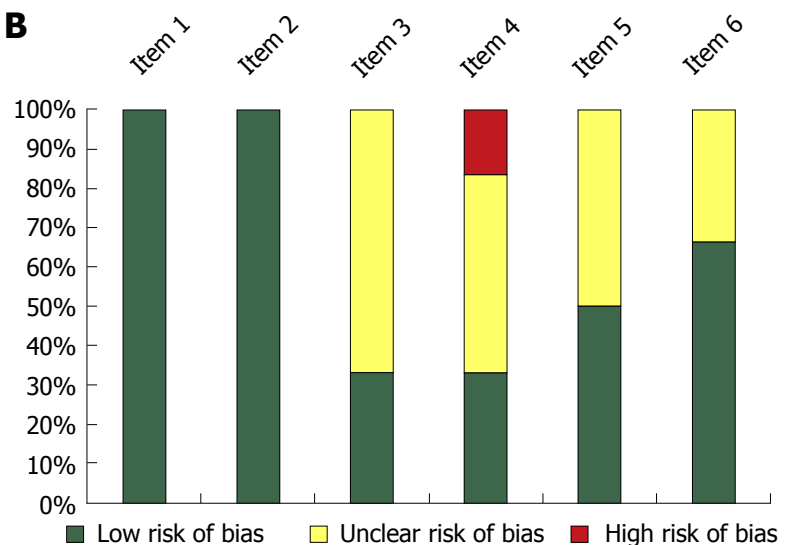

Figure 7 Risk assessment of articles included in the meta-analysis based on the modified Newcastle-Ottawa Scale (A); Risk of bias assessment graph (B).

for GI bleeding in CKD and ESRD patients is also well known ${ }^{[29]}$. The most frequent causes of lower GI bleeding in this population have been described; diverticulosis, haemorrhoids, and ischaemic colitis have been identified in addition to angioectasias ${ }^{[30]}$, but no cohort study has been conducted on this topic yet. Although we did not intend to narrow our search to upper GI bleeding, the articles eligible for our inclusion criteria contained data only on patients with upper GI bleeding, and no studies with lower GI bleeding met our inclusion criteria. Only a few of the studies detailed the endoscopic findings and cause of bleeding. Cheung et $a{ }^{[10]}$ included only peptic ulcer bleeding patients, while the study of Hung et $a^{[25]}$ examined only esophageal variceal bleeding. Tsai et $a{ }^{[16]}$ found that erosive gastritis was significantly higher in ESRD group, while Boyle et $a^{\left[{ }^{[17]}\right.}$ saw gastric ulcer as the most common cause of bleeding in the impaired renal function group, but it was not significant compared to controls. Zuckerman et $a^{[26]}$ found significantly more angiodysplasia and erosive esophagitis in the impaired renal function group.

Based on the pooled data, we found that ESRD increases mortality 2.5 times while CKD increases it 1.8 times in GI bleeding compared to the controls with normal renal function, but these ORs are not 
significantly different. Weng et $a^{[31]}$ reported that ESRD patients admitted with primary upper GI bleeding have a profoundly increased risk of in-hospital mortality. Using a large multi-centre database, Sood et $a l^{[9]}$ reported that the in-hospital mortality risk is 50\% higher in CKD patients and 3 times greater in ESRD patients. Holden et $a l^{[32]}$ reported that the incidence rate of major bleeding episodes in haemodialyzed patients was $2.5 \%$ per person-year and that use of aspirin and/or warfarin increased this risk. Based on the result of the meta-regression the mortality-rate of GI bleeding has improved since the 1980s. It is likely one of the reasons for the heterogeneity of the data. Inhomogen patient groups also result in a significant bias. However the sensitivity analysis showed that none of the articles influences significantly the pooled OR.

Cardiovascular disease, current smoking ${ }^{[33]}$ and even haemostasis disorders ${ }^{[34]}$ may play a role in the background of higher risk for GI bleeding in ESRD patients. Unfortunately only few of the analysed articles detailed the other comorbidities of the GI bleeding patients. In the article of Cheung et $a^{[10]}$. there was no significant difference in the comorbidities between ESRD, CKD and normal renal function group. More people in CKD and ESRD groups suffered from hypertension, diabetes mellitus and platelet abnormalities in the study of Sood et $a l^{[9]}$, while the cirrhosis was less common than in controls. Volume replacement and blood transfusion are important parts of the therapy of GI bleeding. This meta-analysis demonstrated that patients with chronic impaired renal function develop 2.5 times more rebleeding episodes and require almost 2 more red blood cell units for transfusion than the control group. Patients with impaired renal function spent more time in hospital than the control group.

There are several limitations to this study; therefore, the results of this meta-analysis should be regarded with caution. Unfortunately, only a low number of articles was found on this topic, with half of them written in the 1980s and 1990s. In the recent articles, CKD and ESRD groups were separated, but in the earlier publications these groups were mixed, leading to a bias in our analysis, and the definition of GFR was also not mentioned. The diagnosis was based on elevated creatinine level. Hung et $\mathrm{al}^{\left[{ }^{[25]}\right.}$ only involved patients with cirrhosis and the mortality rate was monitored up to $6 \mathrm{wk}$, while hospital mortalities were presumably included in the other articles. Publications with rebleeding data did not follow patients for the same time interval, and 1 paper did not report on the follow-up time. The strength of this meta-analysis is the high number of patients.

Our results have demonstrated that patients with ESRD show higher mortality during GI bleeding. CKD patients require more transfusion, and the rebleeding rate is also more elevated than that in patients with normal renal function. Because of these severe conditions, the $\mathrm{LOH}$ is also longer. Patients with ESRD or CKD should be observed more carefully due to the elevated complication rate. In this meta-analysis we wanted to highlight the importance of this clinical problem and we believe that it needs further scientific research. In order to understand the effect of CKD/ ESRD and other comorbidities on the outcomes of GI bleeding in more details, observational trials, and registries on GI bleeding should be developed.

\section{ARTICLE HIGHLIGHTS}

\section{Research background}

Chronic kidney disease is a significant comorbidity, which can worsen the outcomes of gastrointestinal (GI) bleeding.

\section{Research motivation}

We wanted to understand the role of chronic kidney disease (CKD) and endstage renal disease (ESRD) in the natural history of GI bleeding.

\section{Research objectives}

Our goal was to investigate the influence of CKD and ESRD on the outcomes of $\mathrm{GI}$ bleeding, based on all available data published in this topic.

\section{Research methods}

A comprehensive search was carried out in PubMed, Embase and Cochrane Library databases for studies detailing the outcomes of GI bleeding in the context of kidney functions. We used the PRISMA P protocol, registered our project through PROSPERO and assessed the quality of the included articles by using the Newcastle-Ottawa Scale, to ensure that this meta-analysis is done to the highest possible standards. The statistical calculations were performed with Comprehensive Meta-Analysis software, using the random effects model (DerSimonian-Laird method).

\section{Research results}

In this analysis 51315 patients with CKD and 354720 controls were included ( 6 articles). We found that the mortality of GI bleeding was significantly worse in CKD and ESRD with an OR of 1.79 and 2.53 respectively. Patients with kidney disease needed significantly more transfusion with a MD of 1.86 and the rebleeding rate was significantly worse in the group with impaired kidney function with an OR of 2.51. Patients with impaired kidney function needed significantly longer hospitalization with a MD of 13.25 .

\section{Research conclusions}

This is the first meta-analysis and systematic review in this topic, which quantifies kidney disease as a negative risk factor in GI bleeding. GI bleeding in patients with chronic renal failure significantly increases the mortality rate, rebleeding rate, length of hospitalization, and require more blood transfusion compared to patients with normal kidney functions. Kidney disease significantly worsens the outlook of patients presenting with GI bleeding. Patients with chronic kidney disease will need to be treated with more caution due to the worse outcomes of $\mathrm{GI}$ bleeding. Close monitoring of the fluid balance and kidney functions, careful fluid therapy and prevention of acute kidney injury in these patients may improve the outcomes of GI bleeding.

\section{Research perspectives}

Although CKD, ESRD, and other comorbidities are major risk factors for unfavorable outcomes in GI bleeding, their roles are not well investigated nor understood and they need further scrutiny. We would better understand the role of CKD in ESRD in GI bleeding from analysis of extensive data from large multicenter and multinational observational studies and registries accurately recording the outcomes and the kidney functions. 


\section{ACKNOWLEDGMENTS}

The present paper is dedicated to the $650^{\text {th }}$ anniversary of the founding of the University of Pécs, Hungary.

\section{REFERENCES}

1 Cutler JA, Mendeloff AI. Upper gastrointestinal bleeding. Nature and magnitude of the problem in the U.S. Dig Dis Sci 1981; 26: 90S-96S [PMID: 6985341]

2 Vreeburg EM, Snel P, de Bruijne JW, Bartelsman JF, Rauws EA, Tytgat GN. Acute upper gastrointestinal bleeding in the Amsterdam area: incidence, diagnosis, and clinical outcome. $\mathrm{Am} \mathrm{J}$ Gastroenterol 1997; 92: 236-243 [PMID: 9040198]

3 Hussain H, Lapin S, Cappell MS. Clinical scoring systems for determining the prognosis of gastrointestinal bleeding. Gastroenterol Clin North Am 2000; 29: 445-464 [PMID: 10836189 DOI: $10.1016 / \mathrm{S} 0889-8553(05) 70122-9$ ]

4 Zuccaro G Jr. Management of the adult patient with acute lower gastrointestinal bleeding. American College of Gastroenterology. Practice Parameters Committee. Am J Gastroenterol 1998; 93: 1202-1208 [PMID: 9707037 DOI: 10.1111/ j.1572-0241.1998.00395.x]

5 Rockall TA, Logan RF, Devlin HB, Northfield TC. Risk assessment after acute upper gastrointestinal haemorrhage. Gut 1996; 38: 316-321 [PMID: 8675081]

6 Lin CC, Wang HP, Wu MS, Ho WC, Lee H, Lin JT. The etiology and clinical characteristics of acute lower gastrointestinal bleeding in patients hospitalized for comorbid illnesses. Hepatogastroenterology 2006; 53: 395-398 [PMID: 16795980]

7 Laeeq SM, Tasneem AA, Hanif FM, Luck NH, Mandhwani R, Wadhva R. Upper Gastrointestinal Bleeding in Patients with End Stage Renal Disease: Causes, Characteristics and Factors Associated with Need for Endoscopic Therapeutic Intervention. $J$ Transl Int Med 2017; 5: 106-111 [PMID: 28721343 DOI: 10.1515/ jtim-2017-0019]

8 Kuo CC, Kuo HW, Lee IM, Lee CT, Yang CY. The risk of upper gastrointestinal bleeding in patients treated with hemodialysis: a population-based cohort study. BMC Nephrol 2013; 14: 15 [PMID: 23324652 DOI: 10.1186/1471-2369-14-15]

9 Sood P, Kumar G, Nanchal R, Sakhuja A, Ahmad S, Ali M, Kumar N, Ross EA. Chronic kidney disease and end-stage renal disease predict higher risk of mortality in patients with primary upper gastrointestinal bleeding. Am J Nephrol 2012; 35: 216-224 [PMID: 22310659 DOI: 10.1159/000336107]

10 Cheung J, Yu A, LaBossiere J, Zhu Q, Fedorak RN. Peptic ulcer bleeding outcomes adversely affected by end-stage renal disease. Gastrointest Endosc 2010; 71: 44-49 [PMID: 19595311 DOI: 10.1016/j.gie.2009.04.014]

11 Gheissari A, Rajyaguru V, Kumashiro R, Matsumoto T. Gastrointestinal hemorrhage in end stage renal disease patients. Int Surg 1990; 75: 93-95 [PMID: 2379997]

12 Docherty E, Koulaouzidis A, Douglas S, Plevris JN. Use of small bowel capsule endoscopy in patients with chronic kidney disease: experience from a University Referral Center. Ann Gastroenterol 2015; 28: 99-104 [PMID: 25608445]

13 Ohmori T, Konishi H, Nakamura S, Shiratori K. Abnormalities of the small intestine detected by capsule endoscopy in hemodialysis patients. Intern Med 2012; 51: 1455-1460 [PMID: 22728474]

14 Karagiannis S, Goulas S, Kosmadakis G, Galanis P, Arvanitis D, Boletis J, Georgiou E, Mavrogiannis C. Wireless capsule endoscopy in the investigation of patients with chronic renal failure and obscure gastrointestinal bleeding (preliminary data). World $J$ Gastroenterol 2006; 12: 5182-5185 [PMID: 16937529 DOI: 10.3748/wjg.v12.i32.5182]

15 Moher D, Liberati A, Tetzlaff J, Altman DG; PRISMA Group. Preferred reporting items for systematic reviews and metaanalyses: the PRISMA statement. PLoS Med 2009; 6: e1000097
[PMID: 19621072 DOI: 10.1371/journal.pmed.1000097]

16 Tsai CJ, Hwang JC. Investigation of upper gastrointestinal hemorrhage in chronic renal failure. J Clin Gastroenterol 1996; 22: 2-5 [PMID: 8776085]

17 Boyle JM, Johnston B. Acute upper gastrointestinal hemorrhage in patients with chronic renal disease. Am J Med 1983; 75: 409-412 [PMID: 6604455]

18 Hozo SP, Djulbegovic B, Hozo I. Estimating the mean and variance from the median, range, and the size of a sample. BMC Med Res Methodol 2005; 5: 13 [PMID: 15840177 DOI: 10.1186/1471-2288-5-13]

19 DerSimonian R, Laird N. Meta-analysis in clinical trials. Control Clin Trials 1986; 7: 177-188 [PMID: 3802833]

20 Higgins JP, Green S. Cochrane Handbook for Systematic Reviews of Interventions. Version 5.1.0 (updated March 2011). The Cochrane Collaboration, 2011

21 Viel JF, Pobel D, Carré A. Incidence of leukaemia in young people around the La Hague nuclear waste reprocessing plant: a sensitivity analysis. Stat Med 1995; 14: 2459-2472 [PMID: 8711281]

22 Wells G, Shea B, O'connell D, Peterson J, Welch V, Losos M, Tugwell P. The Newcastle-Ottawa Scale (NOS) for assessing the quality of nonrandomised studies in meta-analyses. 2010

23 Stevens PE, Levin A; Kidney Disease: Improving Global Outcomes Chronic Kidney Disease Guideline Development Work Group Members. Evaluation and management of chronic kidney disease: synopsis of the kidney disease: improving global outcomes 2012 clinical practice guideline. Ann Intern Med 2013; 158: 825-830 [PMID: 23732715 DOI: 10.7326/0003-4819-158-11201306040-00007]

24 Alvarez L, Puleo J, Balint JA. Investigation of gastrointestinal bleeding in patients with end stage renal disease. $A m J$ Gastroenterol 1993; 88: 30-33 [PMID: 8420270]

25 Hung TH, Tseng CW, Tseng KC, Hsieh YH, Tsai CC, Tsai $\mathrm{CC}$. Is end stage renal disease a risk factor for the mortality of cirrhotic patients with esophageal variceal bleeding? Hepatogastroenterology 2014; 61: 1871-1875 [PMID: 25713881]

26 Zuckerman GR, Cornette GL, Clouse RE, Harter HR. Upper gastrointestinal bleeding in patients with chronic renal failure. Ann Intern Med 1985; 102: 588-592 [PMID: 3872616]

27 Sugimoto M, Sakai K, Kita M, Imanishi J, Yamaoka Y. Prevalence of Helicobacter pylori infection in long-term hemodialysis patients. Kidney Int 2009; 75: 96-103 [PMID: 18843261 DOI: 10.1038/ ki.2008.508]

28 Khedmat $\mathbf{H}$, Ahmadzad-Asl M, Amini M, Lessan-Pezeshki M, Einollahi B, Pourfarziani V, Naseri MH, Davoudi F. Gastroduodenal lesions and Helicobacter pylori infection in uremic patients and renal transplant recipients. Transplant Proc 2007; 39: 1003-1007 [PMID: 17524875 DOI: 10.1016/j.transproceed.2007.0 $3.034]$

29 Luo JC, Leu HB, Huang KW, Huang CC, Hou MC, Lin HC, Lee FY, Lee SD. Incidence of bleeding from gastroduodenal ulcers in patients with end-stage renal disease receiving hemodialysis. CMAJ 2011; 183: E1345-E1351 [PMID: 22083684 DOI: 10.1503/ cmaj.110299]

30 Kalman RS, Pedrosa MC. Evidence-based review of gastrointestinal bleeding in the chronic kidney disease patient. Semin Dial 2015; 28: 68-74 [PMID: 25215610 DOI: 10.1111/ sdi.12301]

31 Weng SC, Shu KH, Tarng DC, Tang YJ, Cheng CH, Chen $\mathrm{CH}$, Yu TM, Chuang YW, Huang ST, Sheu WH, Wu MJ. In-hospital mortality risk estimation in patients with acute nonvariceal upper gastrointestinal bleeding undergoing hemodialysis: a retrospective cohort study. Ren Fail 2013; 35: 243-248 [PMID: 23336331 DOI: 10.3109/0886022X.2012.747140]

32 Holden RM, Harman GJ, Wang M, Holland D, Day AG. Major bleeding in hemodialysis patients. Clin J Am Soc Nephrol 2008; 3: 105-110 [PMID: 18003768 DOI: 10.2215/cjn.01810407]

33 Wasse H, Gillen DL, Ball AM, Kestenbaum BR, Seliger SL, Sherrard D, Stehman-Breen CO. Risk factors for upper 
Hágendorn R et al. GI bleeding and chronic kidney disease

gastrointestinal bleeding among end-stage renal disease patients. Kidney Int 2003; 64: 1455-1461 [PMID: 12969166 DOI: 10.1046/ j.1523-1755.2003.00225.x]
34 Jalal DI, Chonchol M, Targher G. Disorders of hemostasis associated with chronic kidney disease. Semin Thromb Hemost 2010; 36: 34-40 [PMID: 20391294 DOI: 10.1055/s-0030-1248722]

P- Reviewer: Kozarek RA, Perez-Cuadrado-Robles E, Triantafyllou K S- Editor: Gong ZM L- Editor: A E- Editor: Huang Y 


\section{DS \\ Baishideng ${ }^{\circledR}$}

Published by Baishideng Publishing Group Inc

7901 Stoneridge Drive, Suite 501, Pleasanton, CA 94588, USA

Telephone: +1-925-223-8242

Fax: +1-925-223-8243

E-mail: bpgoffice@wignet.com

Help Desk: http://www.f6publishing.com/helpdesk

http://www.wjgnet.com

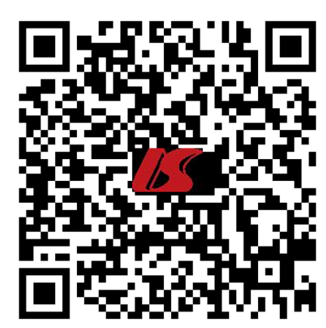

ISSN $1007-9327$

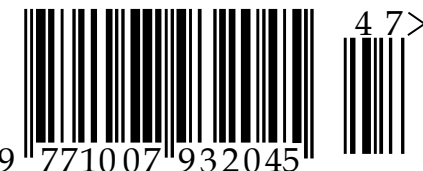




\title{
Development of disturbance of consciousness is associated with increased severity in acute pancreatitis
}

\author{
Roland Hágendorn a, b , Áron Vincze a , Ferenc Izbéki ${ }^{\mathrm{c}}$, László Gajdán ${ }^{\mathrm{c}}$, Szilárd Gódi a \\ Anita Illés a , Patrícia Sarlós ${ }^{a}$, Nelli Farkas ${ }^{d,}{ }^{e}$, Bálint Erőss ${ }^{\mathrm{d}}$, Veronika Lillik ${ }^{\mathrm{d}}$, Dóra Illés ${ }^{\mathrm{f}}$, \\ Péter Varjú ${ }^{\mathrm{d}}$, Katalin Márta ${ }^{\mathrm{d}}$, Imola Török ${ }^{\mathrm{g}}$, Mária Papp ${ }^{\mathrm{h}}$, Zsuzsanna Vitális ${ }^{\mathrm{h}}$, \\ Barnabás Bod ${ }^{\mathrm{i}}$, József Hamvas ${ }^{\mathrm{j}}$, Zoltán Szepes ${ }^{\mathrm{f}}$, Tamás Takács ${ }^{\mathrm{f}}$, László Czakó ${ }^{\mathrm{f}}$,

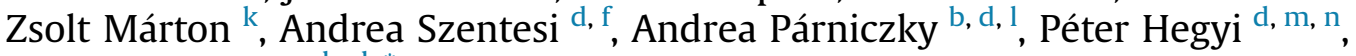 \\ Alexandra Mikó a, b, d, * \\ a Division of Gastroenterology, First Department of Medicine, Medical School, University of Pécs, Pécs, Hungary \\ b School of Clinical Medicine, University of Szeged, Szeged, Hungary \\ c Szent György University Teaching Hospital of Fejér County, Székesfehérvár, Hungary \\ d Institute for Translational Medicine, Szentágothai Research Centre, Medical School, University of Pécs, Hungary \\ e Institute of Bioanalysis, Medical School, University of Pécs, Pécs, Hungary \\ ${ }^{\mathrm{f}} 1$ st Department of Medicine, University of Szeged, Szeged, Hungary \\ ${ }^{g}$ County Emergency Clinical Hospital Târgu Mures, George Emil Palade University of Medicine, Pharmacy, Sciences and Technology of Târgu Mures, \\ Romania \\ ${ }^{\mathrm{h}}$ Department of Internal Medicine, Division of Gastroenterology, University of Debrecen, Debrecen, Hungary \\ ${ }^{\text {i }}$ Bugyi István Hospital, Szentes, Hungary \\ ${ }^{\mathrm{j}}$ Bajcsy-Zsilinszky Hospital, Budapest, Hungary \\ k Intensive Care Unit, First Department of Medicine, Medical School, University of Pécs, Pécs, Hungary \\ ${ }^{1}$ Heim Pál National Institute for Pediatrics, Budapest, Hungary \\ m Division of Translational Medicine, First Department of Medicine, Medical School, University of Pécs, Pécs, Hungary \\ ${ }^{\mathrm{n}}$ Hungarian Academy of Sciences, University of Szeged, Momentum Gastroenterology Multidisciplinary Research Group, Szeged, Hungary
}

\section{A R T I C L E I N F O}

\section{Article history:}

Received 27 February 2020

Received in revised form

6 May 2020

Accepted 8 May 2020

Available online 18 May 2020

\section{Keywords}

Disturbance of consciousness

Acute pancreatitis

Alcohol

Delirium

Mortality

\begin{abstract}
A B S T R A C T
Background: Disturbance of consciousness (DOC) may develop in acute pancreatitis (AP). In clinical practice, it is known that DOC may worsen the patient's condition, but we have no exact data on how DOC affects the outcome of AP.

Methods: From the Hungarian Pancreatic Study Groups' AP registry, 1220 prospectively collected cases were analyzed, which contained exact data on DOC, included patients with confusion, delirium, convulsion, and alcohol withdrawal, answering a post hoc defined research question. Patients were separated to Non-DOC and DOC, whereas DOC was further divided into non-alcohol related DOC (NonALC DOC) and ALC DOC groups. For statistical analysis, independent sample $t$-test, Mann-Whitney, Chisquared, or Fisher exact test were used.

Results: From the 1220 patients, 47 (3.9\%) developed DOC, 23 (48.9\%) cases were ALC DOC vs. 24 (51.1\%) Non-ALC DOC. Analysis between the DOC and Non-DOC groups showed a higher incidence of severe AP $(19.2 \%$ vs. $5.3 \%, \mathrm{p}<0.001)$, higher mortality $(14.9 \%$ vs. $1.7 \%, \mathrm{p}<0.001)$, and a longer length of hospitalization $(\mathrm{LOH})(\mathrm{Me}=11$; IQR: $8-17$ days vs. $\mathrm{Me}=9$; IQR: $6-13$ days, $\mathrm{p}=0.049)$ respectively. Patients with ALC DOC developed more frequently moderate AP vs. Non-ALC DOC (43.5\% vs. $12.5 \%$ ), while the incidence of severe AP was higher in Non-ALC vs. ALC DOC group (33.3\% vs. $4.4 \%$ ) (p < 0.001$)$. LOH showed a tendency to be longer in Non-ALC DOC compared to ALC DOC, respectively (Me:13; IQR:7-20 days vs. Me:9.5; IQR:8-15.5 days, $\mathrm{p}=0.119$ ).
\end{abstract}

* Corresponding author. Institute for Translational Medicine, Medical School, University of Pécs, Szigeti Street 12., II. floor, Pécs, 7624, Hungary.

E-mail addresses: miko.szandi@gmail.com, alexandra.miko@aok.pte.hu (A. Mikó). 
Conclusion: DOC during AP is associated with a higher rate of moderate and severe AP and increases the risk of mortality.

(C) 2020 IAP and EPC. Published by Elsevier B.V. This is an open access article under the CC BY license (http://creativecommons.org/licenses/by/4.0/).

\section{Introduction}

Acute pancreatitis (AP) is a sterile inflammation of the pancreas, leading to hospitalization, which is one of the most common among gastrointestinal diseases [1]. Based on the revised Atlanta classification, the severity of AP may be classified as mild, moderate, or severe [2], the presence of local complication, and organ failure differentiates between the grades of severity. The prognosis of the severe form is poor; it evolves in $8.8 \%$ in AP, and the mortality may reach $28 \%$ in the severe cases [3]. In case of moderate AP, organ failure develops and resolves within $48 \mathrm{~h}$, while in severe forms, it persists longer [2]. The modified Marshall scoring system reports that six dysfunctional organ systems strongly correlates with mortality and intensive care unit (ICU) admission [4]. From these, renal-cardiovascular and respiratory failures are mentioned and discussed the most frequently, while the neurologic complications and monitoring of the Glasgow Coma Scale (GCS) are not well studied in the relevance of AP.

There are several risk factors worsening severity and mortality, but there is little knowledge of the factors that have an effect on the outcome of the disease [5-9]. In clinical practice, patients with AP might present with several neurological symptoms, including 1) alcohol withdrawal syndrome, 2) confusion or delirium characterized by a disturbance of consciousness (DOC), 3) with reduced ability to focus, sustain, or shift attention with different etiological factors. In the pathophysiological background, during chronic alcohol exposure, N-methyl-D-aspartate (NMDA) receptors are upregulated, and gamma-aminobutyric acid type-A (GABAA) receptors are downregulated, leading to tolerance. Alcohol withdrawal causes the opposite effect as enhanced NMDA receptor function, reduced GABAergic transmission, and dysregulation of the dopaminergic system, leading to signs of withdrawal syndrome like tremors, diaphoresis, tachycardia, anxiety, and seizures [10]. Delirium tremens is the most severe form of alcohol withdrawal. It is characterized by sudden and severe mental or nervous system changes. Leading signs are altered mental status (global confusion) and sympathetic overdrive (autonomic hyperactivity), which can progress to cardiovascular collapse. It is a medical emergency with a high mortality rate, making early recognition and treatment essential. The prevalence of delirium in the elderly population is between 29 and 64\% [11], and its financial burden is extreme for the health care system [12] independently form the various etiological factors.

The few available reports about pancreatic encephalopathy reported different hypotheses about the underlying mechanisms; one even concluded that it is difficult to differentiate it from Wernicke encephalopathy [13]. Until now, no study focused on the influencing role of DOC on the outcome of AP. We aimed to determine its effect by a cohort analysis.

\section{Methods}

The Hungarian Pancreatic Study Group (HPSG) established a prospective international registry containing AP patients' data. All participants signed the written consent form. The study was approved by the Scientific and Research Ethics Committee of the Medical Research Council (22254-1/2012/EKU). For this HPSG cohort study data of 1220 patients were used, since they contained data about the level of consciousness during hospitalization. This cohort overlaps with the cohorts discussed in our previous articles $[3,8,9]$, but data and results of the analysis on DOC are only published in this report. Data were collected between January 2013 and January 2017. Based on the presence of DOC, patients were sorted into DOC and Non-DOC groups. The DOC group was further divided into alcohol-related DOC (ALC DOC) and non-alcohol related DOC (Non-ALC DOC).

\section{Definition and data collection}

DOC was diagnosed if the patient had confusion, disorientation, memory deficit, hyper- or hypoactivity, or symptoms of alcohol withdrawal such as anxiety, shaky hands, headache, insomnia or sweating, or epileptic seizure; or signs of delirium. The information of DOC was collected from the prospectively collected database of the HPSG registry and the patients' documentation, answering a post hoc defined research question. In severe cases, the documentation also included psychiatric consultation. Supplementary Table 2 contains the data of DOC of the 47 analyzed patients: time of onset, number of episodes, duration of DOC, description of symptoms, and applied therapy.

\section{Statistical analysis}

Descriptive statistical tools were used to characterize our cohort. To examine differences between the groups, in case of age, we used an independent sample $t$-test, whereas the length of hospitalization ( $\mathrm{LOH}$ ) with the Mann-Whitney test were analyzed. To analyze the connection between severity, mortality, and DOC, and between the time of onset of DOC and severity, the Chi-squared test or Fisher exact test was performed. All statistical analyses were done using SPSS Ver. 24 Software (IBM Corporation Armonk, New York). The significance level was set at 0.05.

\section{Results}

\section{General characteristics of the entire cohort}

A total of 1220 cases from 20 centers were analyzed. The list of centers is shown in Supplementary Table 1. Data were complete for age, gender, etiology of pancreatitis, $\mathrm{LOH}$, the severity of acute pancreatitis, and mortality. Our registry included data about alcohol consumption in 99.6\% (Table 1). The basic characteristics of the analyzed population are shown in Fig. 1. More than half of our patients were male $(n=683)$, and $46 \%$ were female $(n=537)$. The most common etiological factor was biliary pancreatitis $(38.4 \%$, $\mathrm{n}=469)$, followed by idiopathic (19.2\%, $\mathrm{n}=234)$, and alcoholinduced pancreatitis $(15.2 \%, \mathrm{n}=186)$. In the case of acute alcoholic pancreatitis, male dominance can be seen (male $87 \%, n=162$; female $13 \%, \mathrm{n}=24$ ). In some cases, we found combined etiology (11.9\%). In our study, $67.5 \%$ of the cases were mild. Moderate pancreatitis was observed in $26.7 \%$ of cases and severe inflammation in $5.8 \%$ of the cases. The LOH was almost three times more (23.5 days \pm 2.5 ) in case of severe acute pancreatitis than in mild ones (8.6 days \pm 0.17 ). In moderate cases, the average $\mathrm{LOH}$ was 
Table 1

Quality characteristics of the Hungarian Pancreatic Study Group registry for the 1220 patients with acute pancreatitis.

\begin{tabular}{llll}
\hline Epidemiology, etiology, outcome & OVERALL & UPLOADED DATA & $\%$ \\
\hline Age & 1220 & 1220 & 100 \\
Gender & 1220 & 1220 & 100 \\
Etiology & 1220 & 1220 & 100 \\
Alcohol consumption & 1220 & 1216 & 99.6 \\
Length of hospitalization & 1220 & 1220 & 100 \\
Severity of AP & 1220 & 1220 & 100 \\
Mortality & 1220 & 1220 & 100 \\
\hline Average uploaded data & & 99.9 \\
\hline
\end{tabular}

$18 \pm 0.7$ days. The total mortality rate was $2.4 \%$. In severe cases, the mortality reached $29.9 \%$, in mild cases, $0.2 \%$ only, and in moderate cases, 2.2\%. (Fig. 1A-F).

\section{Demographic characteristics in DOC vs. Non-DOC groups}

From the 1220 patients of the HPSG registry, 47 patients (3.9\%) developed DOC (Fig. 2A). Based on the type of DOC, delirium $(\mathrm{n}=18)$, confusion $(\mathrm{n}=16)$, alcohol withdrawal syndrome $(\mathrm{n}=9)$, and convulsion $(n=3)$ groups were identified. According to the etiology of DOC, in our cohort, alcohol $(n=23)$, older age $(n=9)$, and sepsis $(n=6)$ caused the most cases of DOC. However, ischemia $(\mathrm{n}=3)$ hypoglycemia $(\mathrm{n}=1)$ and electrolyte imbalance $(\mathrm{n}=1)$ also caused DOC. In addition, 4 cases were idiopathic (Fig. 2C). The male ratio was $55.4 \%(n=650)$ in the Non-DOC group, while $70.2 \%$ $(\mathrm{n}=33)$ in the DOC group. The presence of DOC showed higher incidence in men than in women ( $70.2 \%$ vs. $29.8 \%, n=33$ vs. $n=14$, $\mathrm{p}=0.045$ ) (Fig. 3A). The age differed significantly between the groups; in the DOC group, the subjects were older (62.2 \pm 18.7 vs. $56.5 \pm 17$ years, $\mathrm{p}=0.025$ ) (Fig. $3 \mathrm{C}$ ). Supplementary Table 2 shows the data of the 47 cases with DOC. From the nine severe AP, in 3 cases were two episodes seen, from the 13 moderate in 1 case could be two episodes detected, while in the 25 mild cases, no one had two episodes. Regarding the time of onset, an analysis with the Fisher test was performed, which showed no significant difference $(\mathrm{p}=0.321)$ as to whether DOC started on the first day or other days of hospital stay.

\section{Demographic characteristics in ALC DOC vs. Non-ALC DOC groups}

From the registered 47 patients with DOC, 23 (48.9\%) cases were ALC DOC, whereas 24 (51.1\%) cases were Non-ALC DOC (Fig. 2B). In the ALC DOC group, the delirium was present more often than in the Non-ALC DOC group ( $\mathrm{n}=12$ vs. $\mathrm{n}=7$ ), while in the Non-ALC

\section{A Gender distribution}

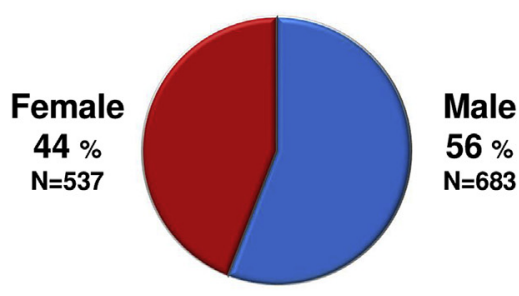

C LOH (days)

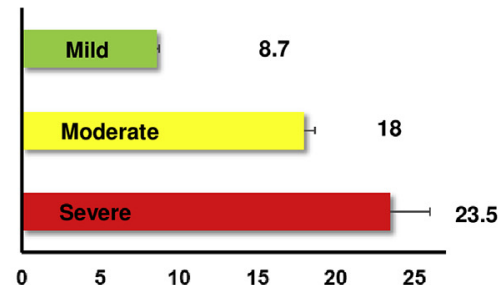

E

Etiology

\begin{tabular}{|c|c|}
\hline biliary & 469 \\
\hline alcoholic & 186 \\
\hline hyperlipidaemia & 44 \\
\hline drug induced & 4 \\
\hline anatomic malformation & 1 \\
\hline postERCP & 34 \\
\hline idiopathic & 234 \\
\hline infection & 2 \\
\hline combined & 145 \\
\hline others & 96 \\
\hline
\end{tabular}

B

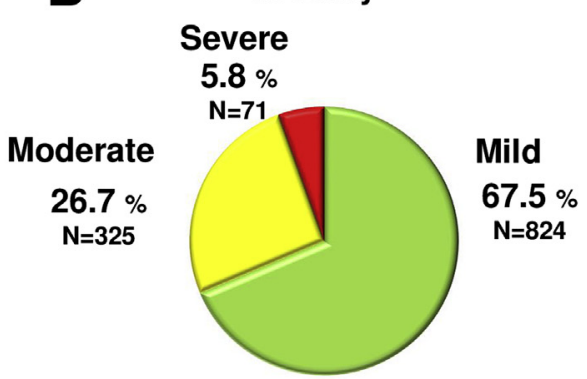

D

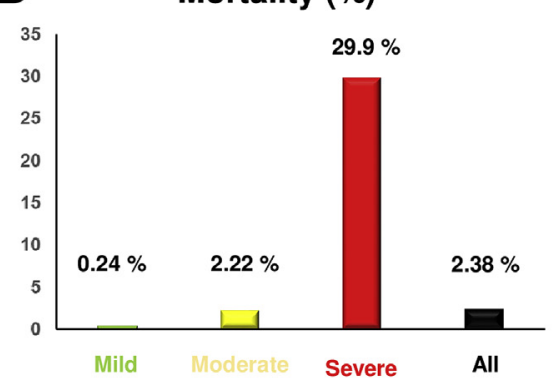

F Age distribution

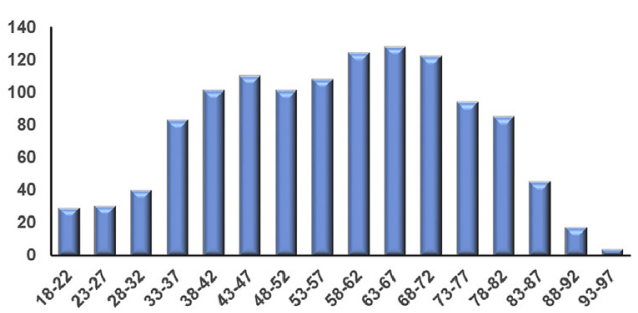

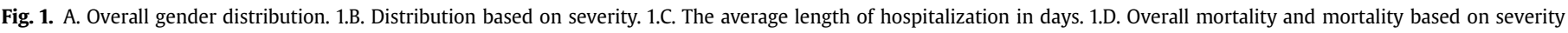
classes. 1.E. Distribution based on the etiology of acute pancreatitis. 1.F. Age distribution of the population. 


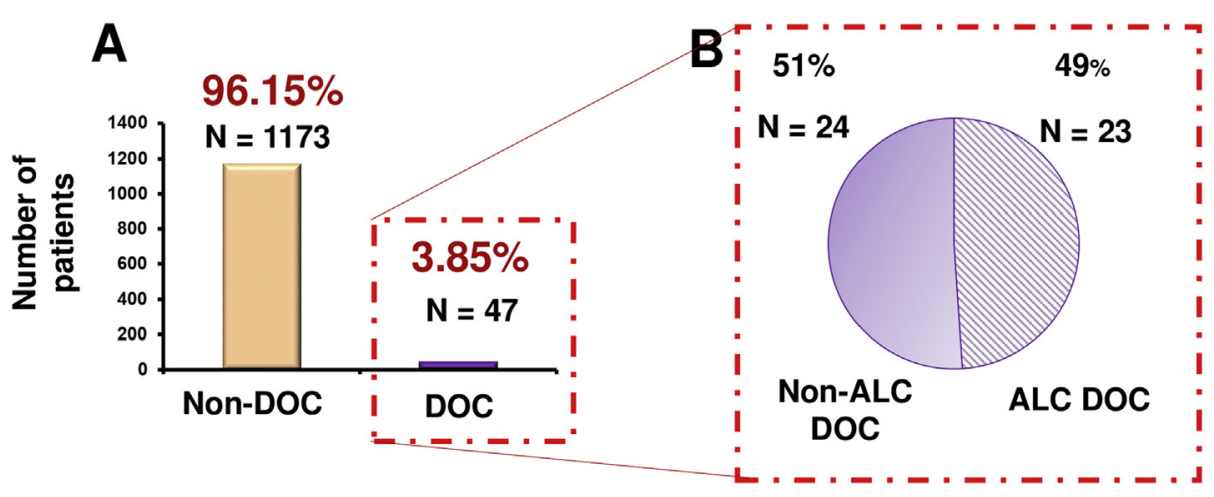

C

Type of DOC

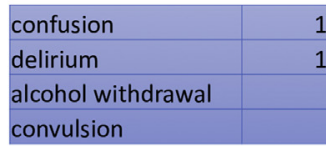

Etiology

\begin{tabular}{|l|r|}
\hline alcohol & 23 \\
\hline sepsis & 6 \\
\hline dementia & 9 \\
\hline ischemia & 3 \\
\hline idiopathic & 4 \\
\hline hypoglycaemia & 1 \\
\hline Impairment of salt and water balance & 1 \\
\hline
\end{tabular}

Alcohol-related: $\mathbf{2 3}$

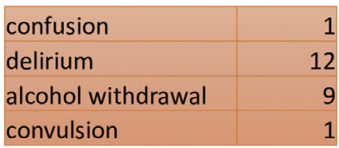

Non-alcohol related: 24

\begin{tabular}{|l|r|}
\hline confusion & 15 \\
\hline delirium & 7 \\
\hline alcohol withdrawal & 0 \\
\hline convulsion & 2 \\
\hline
\end{tabular}

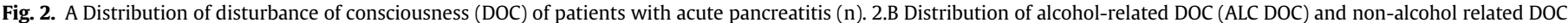
(Non-ALC DOC) (n). 2.C Distribution of DOC based on type and etiology (n).

group, the confusion with milder clinical features was more often present ( $\mathrm{n}=15$ ) (Fig. 2C). ALC DOC showed a significant correlation with gender. It developed more frequently in men than women ( $91.3 \%$ vs. $8.7 \% ; n=21$ vs. $n=2 ; p=0.002$ ), while in Non-ALC DOC, no difference was seen between the genders (Fig. 3B). Patients with Non-ALC DOC were older than patients with ALC DOC (70.5 \pm 18.4 vs. $53.5 \pm 15$ years, $\mathrm{p}=0.002$ ) (Fig. $3 \mathrm{D}$ ) .

\section{Severity and mortality of AP and $\mathrm{LOH}$ in DOC vs. Non-DOC groups}

Analysis between the DOC and Non-DOC groups showed higher incidence of severe AP (19.2\% vs. $5.3 \%, n=9 / 47$ vs. $n=62 / 1173$, $\mathrm{p}<0.001$ ) (Fig. 4A), 8.8 times higher mortality ( $14.9 \%$ vs. $1.7 \%, \mathrm{n}=7$ / 47 vs. $\mathrm{n}=20 / 1173, \mathrm{p}<0.001$ ) (Fig. $4 \mathrm{C}$ ), and a longer LOH in the DOC group (Me $=11$; IQR: 8-17 days vs. $\mathrm{Me}=9$; IQR: 6-13 days, $\mathrm{p}=0.049$ ) (Fig. 4E) respectively.

Severity and mortality of AP and $L O H$ in ALC DOC vs. Non-ALC DOC groups

Moderate AP developed more frequent in patients with ALC DOC vs. Non-ALC DOC group ( $43.5 \%$ vs. $12.5 \% \mathrm{n}=10$ vs. $\mathrm{n}=3$ ) while the incidence of severe AP was 7 times higher in Non-ALC vs. ALC DOC group ( $33.3 \%$ vs. $4.4 \%, \mathrm{n}=8$ vs. $\mathrm{n}=1$ ), $\mathrm{p}<0.001$ (Fig. $4 \mathrm{~B}$ ). Mortality showed no difference between the analyzed groups $(n=3$ vs. $n=4)$ (Fig. 4D). Concerning the LOH, patients with Non-ALC DOC showed a tendency for longer hospitalization (Me: 13; IQR: 7-20 days vs. Me: 9.5; IQR: 8-15.5 days, $\mathrm{p}=0.119$ ) (Fig. $4 \mathrm{~F}$ ).

\section{Discussion}

Nurses and the medical staff have an essential role in recognizing the early signs of changes in mental status and in preventing delirium [14]. However, the hospital-acquired delirium often remains unnoticed, because its symptoms resemble dementia and depression, further complicating the diagnosis [15]. Not surprising that no data is available concerning the relationship of DOC and the outcome of AP.

Here we show for the first time that DOC is associated with more severe and higher mortality rates of AP. The question arises, which factor comes first, the severe AP, or the DOC. It is possible that due to AP released metabolic mediators, hypovolemia and systemic inflammatory response syndrome may lead to different organ failures, such as encephalopathy. On the other hand, in a patient with chronic alcohol consumption during hospitalization with mild AP (based on Atlanta classification), delirium tremens may occur, which is a severe illness in itself, which can lead to multi-organ failure, ICU admission, and mechanical ventilation. It is also important to mention that the development of delirium increases the mortality risk in the intensive care unit (ICU), and it is also associated with longer ICU-stay [16]. A systematic review found that multi-component implementation programs with strategies, targeting ICU delirium assessment, prevention, and adequate treatment including pain, agitation and delirium management, and a strategy of early awakening, breathing, delirium screening, and early exercise have a clinical outcome improving potential [17].

Furthermore, we found that moderate pancreatitis is more common in the ALC DOC group, whereas in the Non-ALC DOC 

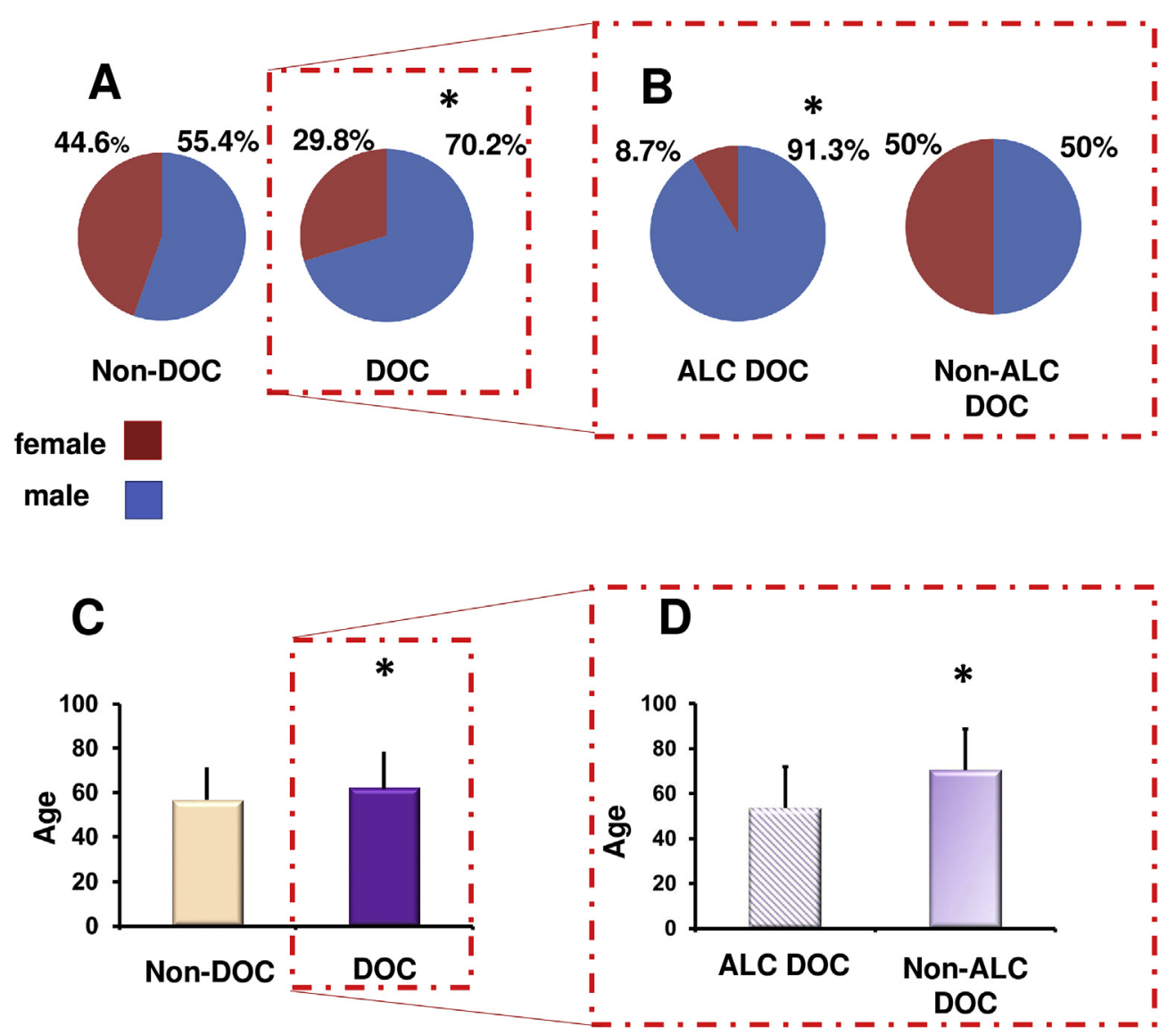

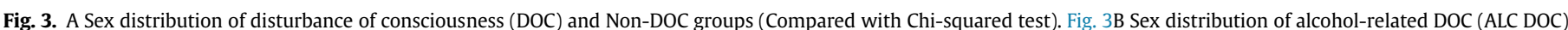

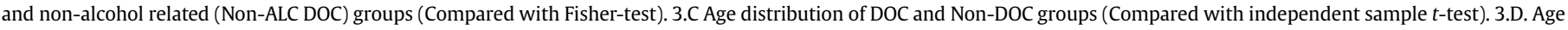
distribution of ALC DOC and Non-ALC DOC groups (Compared with independent sample $t$-test).

group, more severe cases were detected. There was no difference in the mortality rate in the ALC DOC and Non-ALC DOC groups. However, there was a lower rate of severe AP in the ALC group; it had the same mortality rate. This difference may be explained by the fact that, in the ALC DOC group, chronic alcohol consumption is higher. These individuals are of lower social standing, with lower income, often malnourished, have vitamin deficiencies, cachexia/ sarcopenia, and are at various stages of liver cirrhosis, all of which can lead to higher mortality in moderate AP. The other suggestion is that DOC influences mortality regardless of etiology.

The findings of this study have some limitations. Based on the cohort analysis, there was a difference in the demographic parameters, which may influence our results. Also, between the DOC and Non-DOC and between the ALC and Non-ALC DOC groups' differences in gender were seen; however, in the ALC DOC group, the gender distribution in alcoholic AP confirms these results. In the DOC and Non-ALC DOC groups, the average age is higher, which may have a causal role in the more severe course of the disease. Besides, based on the analysis method, no conclusion, according to the casualty of DOC and severity could be shown, only associations between the parameters can be provided.

As a clinical implication, according to our data, we can conclude that the onset of DOC is a negative prognostic factor in the outcome of AP. To answer this clinical question, it is necessary to organize an observational clinical trial to monitor all relevant parameters for DOC continuously. This observational clinical study could prove the real causal relationship between DOC and the outcomes of AP. Furthermore, if the observational study confirms our data, randomized clinical trials aiming to prevent DOC should be organized.

Our data suggest that reducing the development of delirium should be part of the management of AP. A meta-analysis of randomized controlled studies suggests that dexmedetomidine could be a therapeutic option [18]. Benzodiazepines are currently in the first-line treatment for alcohol withdrawal syndrome. They significantly reduce the risk of recurrent seizures related to alcohol withdrawal compared to placebo [19]. In the case of older adults and liver disease, the half-life of diazepam increases with its accumulation and results in a higher rate of side effects. In the elderly and patients with cirrhosis or severe liver dysfunction, lorazepam or oxazepam are preferred [20]. It is pivotal to recognize the symptoms of benzodiazepine toxicity because it leads to respiratory depression, confusion, and delirium through excessive sedation, which may be challenging to differentiate from delirium tremens. In older critically ill patients, polypharmacy may also play an essential role in developing delirium [21]. In the United Kingdom, the Prevention of Delirium system was implemented and delivered in several wards with a staff training program, and they found it feasible [22]. Despite the high prevalence rate of delirium and the marked deteriorating effects on the outcome of the different illnesses, the management of delirium lacks unified professional guidelines.

\section{Conclusions}

Disturbance of consciousness is associated with a more severe 

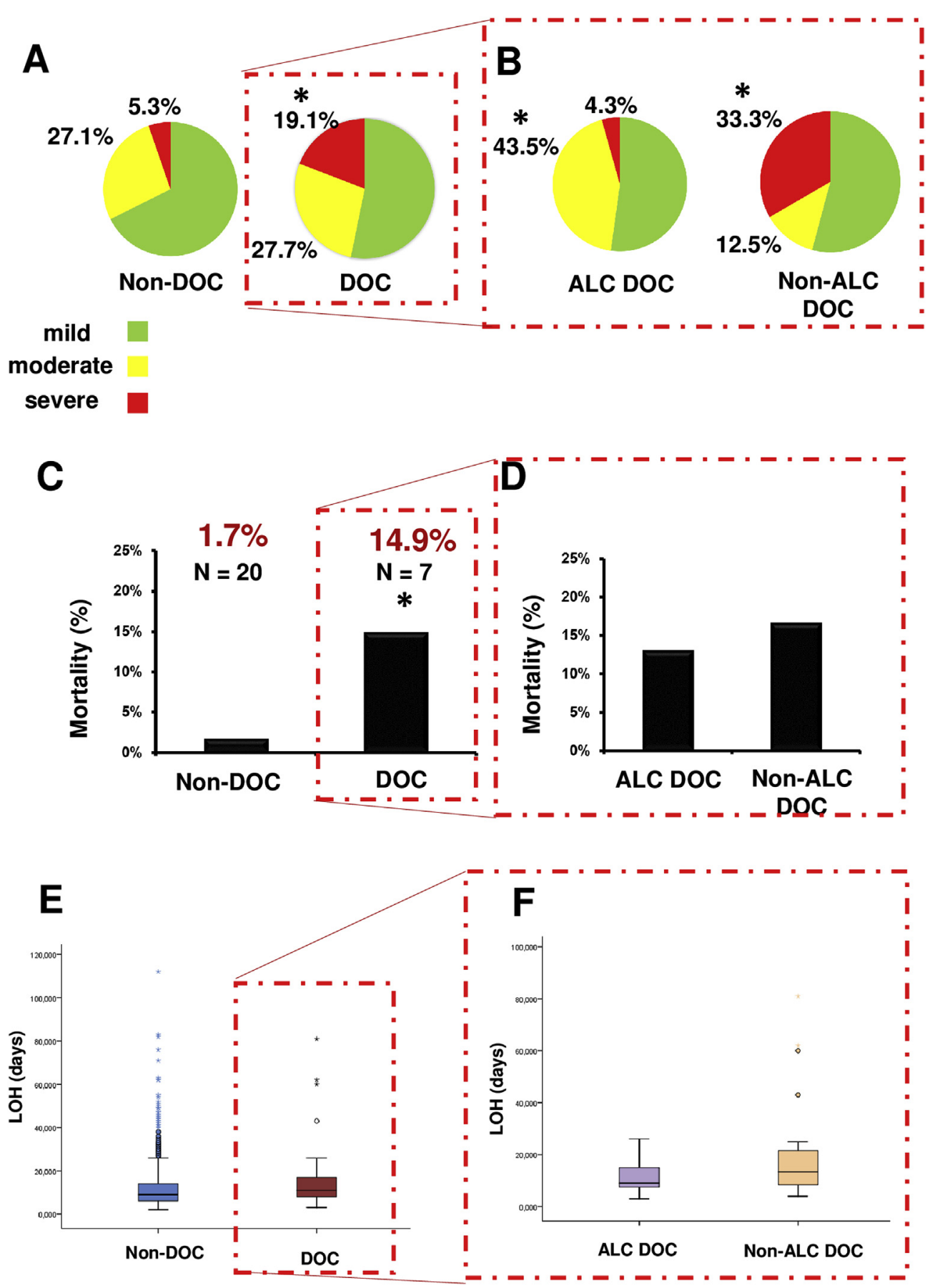

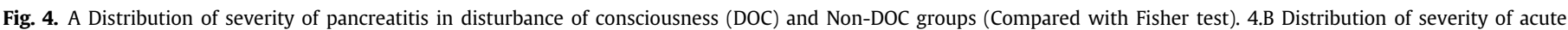

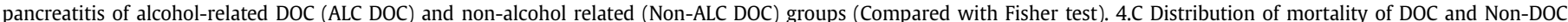

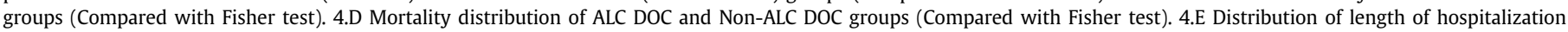
(LOH) in DOC and Non-DOC groups (Compared with Mann-Whitney test). 4.F Distribution of LOH in ALC DOC and Non-ALC DOC groups (Compared with Mann-Whitney test).

course of AP, longer LOH, and higher mortality rate of the underlying disease. Alcohol consumption in medical history elevates the rate of moderate AP in the DOC group.

\section{Author contributions}

Hegyi P., Párniczky A., Czakó L., Vincze Á., Szentesi A. and Mikó A. designed the research and the study concept; Izbéki F., Gajdán L., Gódi Sz., Illés A., Sarlós P. Illés D., Varjú P., Márta K., Török I., Papp M.,
Erőss B., Vincze Á., Vitális Zs., Bod B., Hamvas J., Lillik V., Márton Zs., Szepes Z. and Takács T., performed the acquisition of data; Farkas N. analyzed and interpreted the data; Hágendorn R, Farkas N, Hegyi P, and Mikó A wrote the paper; Izbéki F., Gajdán L., Gódi Sz., Illés A., Sarlós P supervised the study; all of the co-authors conducted a critical revision of the manuscript for important intellectual content; all of the co-authors granted final approval of the version of the article to be published. 


\section{Declaration of competing interest}

The authors declare that there is no conflict of interest in any consideration.

\section{Acknowledgments}

The research was supported by Project Grants (K131996 to PH and FK131864 to AM), an Economic Development and Innovation Operative Programme Grant (GINOP 2.3.2-15-2016-00048 to PH) and a Human Resources Development Operational Programme Grant (EFOP-3.6.2-16-2017-00006 to PH) of the National Research, Development and Innovation Office and by a Project Grant of the University of Pécs (KA-2019-14 to AM); and by the János Bolyai Research Scholarship of the Hungarian Academy of Sciences (to AP) and the ÚNKP-19-4 New National Excellence Program of the Ministry of Human Capacities (to AP).

\section{Appendix A. Supplementary data}

Supplementary data to this article can be found online at https://doi.org/10.1016/j.pan.2020.05.009.

\section{References}

[1] Lankisch PG, Apte M, Banks PA. Acute pancreatitis. Lancet 2015;386:85-96.

[2] Banks PA, Bollen TL, Dervenis C, Gooszen HG, Johnson CD, Sarr MG, et al. Classification of acute pancreatitis-2012: revision of the Atlanta classification and definitions by international consensus. Gut 2013;62:102-11.

[3] Parniczky A, Kui B, Szentesi A, Balazs A, Szucs A, Mosztbacher D, et al. Prospective, multicentre, nationwide clinical data from 600 cases of acute pancreatitis. PloS One 2016;11:e0165309.

[4] Marshall JC, Cook DJ, Christou NV, Bernard GR, Sprung CL, Sibbald WJ. Multiple organ dysfunction score: a reliable descriptor of a complex clinical outcome. Crit Care Med 1995:23:1638-52.

[5] Dobszai D, Matrai P, Gyongyi Z, Csupor D, Bajor J, Eross B, et al. Body-mass index correlates with severity and mortality in acute pancreatitis: a metaanalysis. World J Gastroenterol 2019;25:729-43.

[6] Marta K, Lazarescu AM, Farkas N, Matrai P, Cazacu I, Ottoffy M, et al. Aging and comorbidities in acute pancreatitis: a meta-analysis and systematic review based on 194,702 patients. Front Physiol 2019;10:328.
[7] Miko A, Farkas N, Garami A, Szabo I, Vincze A, Veres G, et al. Preexisting diabetes elevates risk of local and systemic complications in acute pancreatitis: systematic review and meta-analysis. Pancreas 2018;47:917-23.

[8] Szakacs Z, Gede N, Pecsi D, Izbeki F, Papp M, Kovacs G, et al. Aging and comorbidities in acute pancreatitis: a cohort-analysis of 1203 prospectively collected cases. Front Physiol 2018;9:1776.

[9] Szentesi A, Parniczky A, Vincze A, Bajor J, Godi S, Sarlos P, et al. Multiple hits in acute pancreatitis: components of metabolic syndrome synergize each other's deteriorating effects. Front Physiol 2019;10:1202.

[10] McKeon A, Frye MA, Delanty N. The alcohol withdrawal syndrome. J Neurol Neurosurg Psychiatr 2008;79:854-62.

[11] Inouye SK, Westendorp RG, Saczynski JS. Delirium in elderly people. Lancet 2014;383:911-22.

[12] Leslie DL, Marcantonio ER, Zhang Y, Leo-Summers L, Inouye SK. One-year health care costs associated with delirium in the elderly population. Arch Intern Med 2008;168:27-32.

[13] Sun GH, Yang YS, Liu QS, Cheng LF, Huang XS. Pancreatic encephalopathy and Wernicke encephalopathy in association with acute pancreatitis: a clinica study. World J Gastroenterol 2006;12:4224-7.

[14] Faught DD. Delirium: the nurse's role in prevention, diagnosis, and treatment Medsurg Nurs: Off J Acad Med Surg Nurs 2014;23:301-5.

[15] Volland J, Fisher A, Drexler D. Preventing and identifying hospital-acquired delirium. Nursing 2020;50:32-7.

[16] Lahariya S, Grover S, Bagga S, Sharma A. Delirium in patients admitted to a cardiac intensive care unit with cardiac emergencies in a developing country: incidence, prevalence, risk factor and outcome. Gen Hosp Psychiatr 2014;36: 156-64.

[17] Trogrlic Z, van der Jagt M, Bakker J, Balas MC, Ely EW, van der Voort PH, et al A systematic review of implementation strategies for assessment, prevention, and management of icu delirium and their effect on clinical outcomes. Crit Care 2015;19:157.

[18] Pasin L, Landoni G, Nardelli P, Belletti A, Di Prima AL, Taddeo D, et al. Dexmedetomidine reduces the risk of delirium, agitation and confusion in critically ill patients: a meta-analysis of randomized controlled trials. J Cardiothorac Vasc Anesth 2014;28:1459-66.

[19] D'Onofrio G, Rathlev NK, Ulrich AS, Fish SS, Freedland ES. Lorazepam for the prevention of recurrent seizures related to alcohol. N Engl J Med 1999;340: 915-9.

[20] Gershkovich P, Wasan KM, Ribeyre C, Ibrahim F, McNeill JH. Effect of variations in treatment regimen and liver cirrhosis on exposure to benzodiazepines during treatment of alcohol withdrawal syndrome. Drugs Context (US) 2015;4:212287.

[21] Garpestad E, Devlin JW. Polypharmacy and delirium in critically ill older adults: recognition and prevention. Clin Geriatr Med 2017:33:189-203.

[22] Godfrey M, Green J, Smith J, Cheater F, Inouye SK, Hurst K, et al. Process of implementing and delivering the prevention of delirium system of care: a mixed method preliminary study. BMC Geriatr 2019;20:1. 